\title{
A Compilation of Current Regulations, Standards, and Guidelines in Remote Afterloading Brachytherapy
}

Manuscript Completed: September 1994

Date Published: October 1994

Prepared by

J. P. Tortorelli, G. P. Simion, S. D. Kozlowski

Idaho National Engineering Laboratory

EO\&G Idaho, Inc.

Idabo Falls, ID 83415

Prepared for

Division of Industrial and Medical Nuclear Safety

Otice of Nuclear Material Safety and Safeguards

U.S. Nuelear Regulatory Commission

Washington, DC 20555-0001

NRC Jab Code L1939

Under DOE Contract No. DE-AC07-761D015\%0

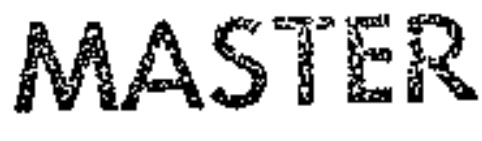





\section{DISCLAIMER}

This report was prepared as an account of work sponsored by an agency of the United States Government. Neither the United States Government nor any agency thereof, nor any of their employees, make any warranty, express or implied, or assumes any legal liability or responsibility for the accuracy, completeness, or usefulness of any information, apparatus, product, or process disctosed, or represents that its use would not infringe privately owned rights. Reference herein to any speciflc commercial product, process, or aervice by trade name, trademark, manufacturer, or otherwise does not necessarlly constitute or imply its endorsement, recommendation, or favoring by the United States Government or any agency thereof. The views and opinions of authors expressed herein do not necessarily state or reflect those of the United States Govarnment or any agency thereof. 


$$
\text { . }
$$




\section{DISCLAIMER}

Portions of this document may be illegible in electronic image products. Images are produced from the best available original document. 


\section{ABSTRACT}

Over a dozen government and professional organizations in the United States and Europe have issued regulations and guidance concerning quality management in the practice of remote afterloading brachytherapy. Information from the publications of these organdzations was collected and collated for this report. This report provides the brachytherapy licensee access to a broad field of quality management information in a single, topically organized document. 



\section{CONTENTS}

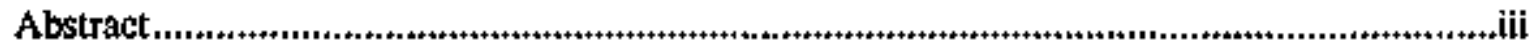

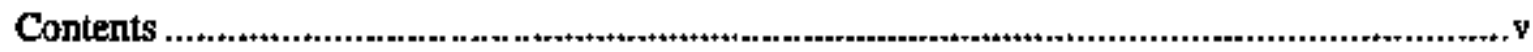

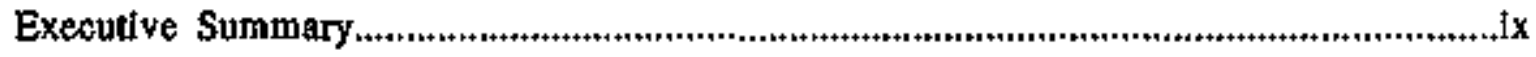

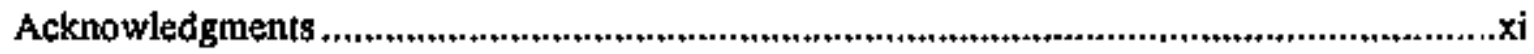

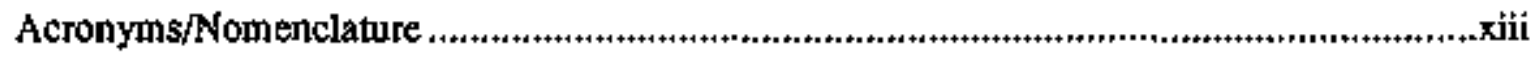

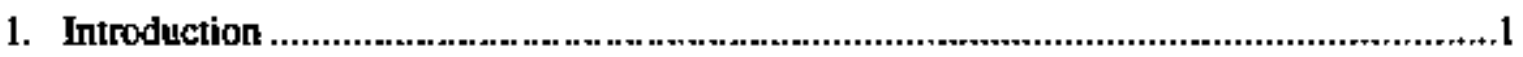

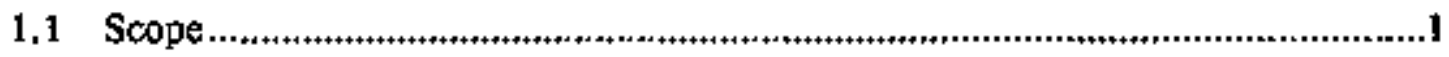

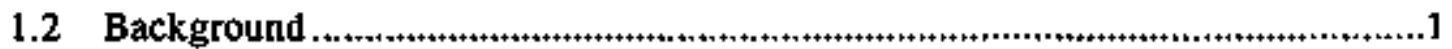

1.2.1. Role of NRC and Need for QM Program .........................................

1,2.2. Remote Afterioading Brachytherapy............................................2

1.2.3. High Dose Rate verses Low Dose Rate Remote Afterloading ..............3

1.2.4. Pulse Dose Rate ................................................................................3

1.2.5. Device Description......................................................................... 3

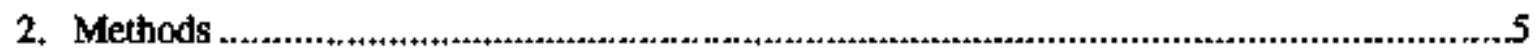

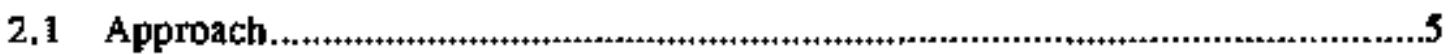

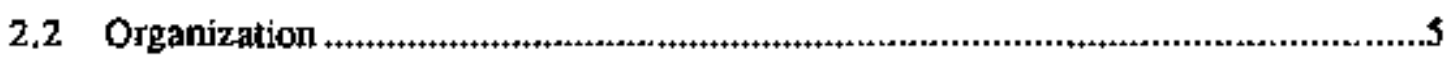

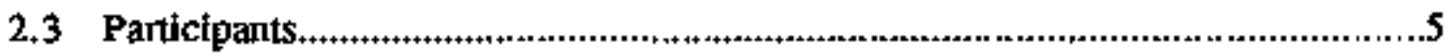

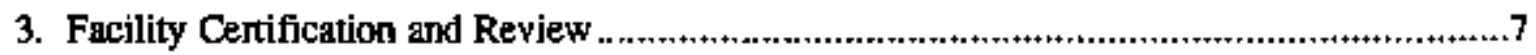

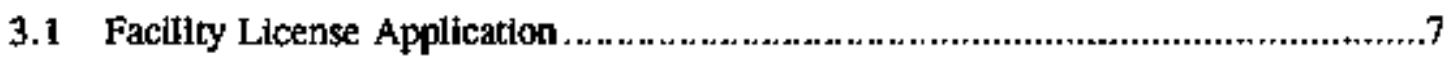

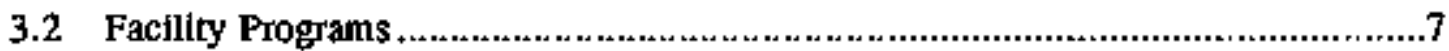

3.2.1. Facility Quality Management Programs .......................................7

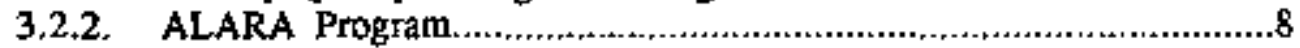

3.2.3. Radiation Safety Committee........................+.+.............................12

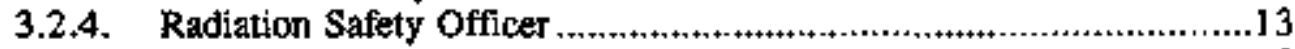

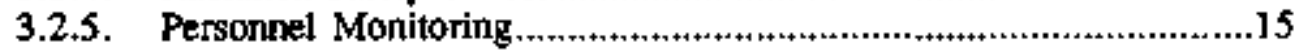

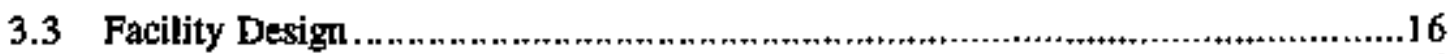

3.3.1. Facility Design.......................................................................16

3.3.2. Facility Shtelding .............................................................17

3.3.3. Facility Interlocks and Safety Devices..........................................19

3.3.4. Permanent Radjation Monftors......................................................21

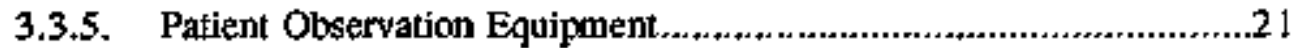

3.3.6. Strvey Instruments - Facility $\ldots+\ldots+\ldots+\ldots+\ldots+\ldots+\ldots \ldots \ldots \ldots+\ldots+\ldots+\ldots \ldots \ldots+\ldots \ldots \ldots \ldots . . .22$

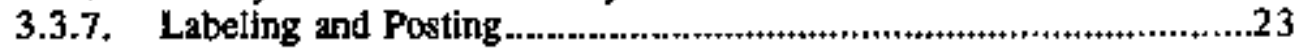

4. Maintenance Reqquirements ....................................................................+.+.+..........27 


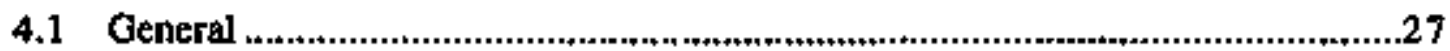

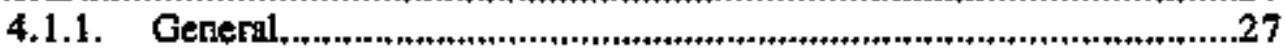

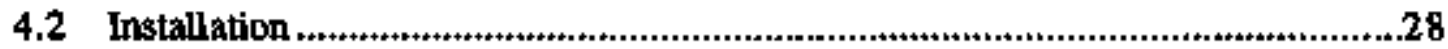

4.2.1. Acceptance Testing................................................................28

4.2.2. Survey Instrument Calibration and Response Check..........................31

4.2.3. Brachytherapy Source Installation and Calibration.............................31

4.2.4. Brachytherapy Source Leakage Check and Surveys...........................34

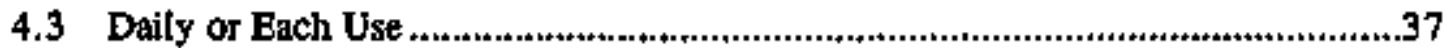

4.3.1. Source Activity Verification...........................................................37

4.3.2. Remote Afterloader and Facility Functional Checks.........................38

4.3.3. Survey Instrument Response Check ...............................................39

4.4 30-Day, Monthly or Quarterly...................................................................39

4.4.1. Source Inventory and QM Checks .............................................39

4.5 Semi-annually or Annually .....................................................................41

4.5.1. Leak Testing............................................................................41

4.5.2. Survey Instrument Calibration ......................................................41

4.5.3. Inspection.....................................................................................4 41

4.5.4. Quality Management Audit...........................................................41

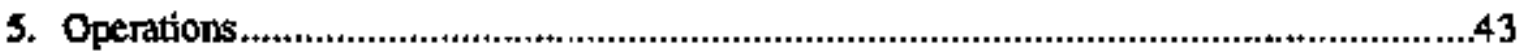

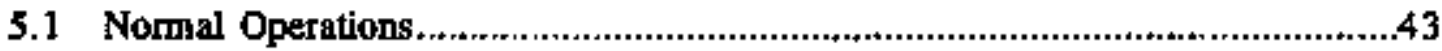

5.1.1. Definitions...............................................................................43

5.1.2. Procedures..........................................................................43

5.1.3. Written Directive........................................................................45

5.1.4. Patient Identiflcation.....................................................................45

5.1.5. Calculation Verification.............................................................46

5.1.6. Treatment Accuracy Verification......................................................47

5.1.7. Safe-Handling Precautions................................................................48

5.1.8. Record of Treatment.....................................................................48

5.1.9. Surveys - Patient and Surroundings................................................48

5.1.10. Brachytherapy Source Control \& Inventory....................................50

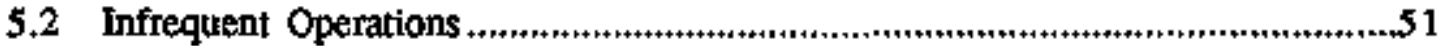

5.2.1. Misadministrations and Recordable Events.....................................51

5.2,2. Emergency Procedure Guidelines................................................52

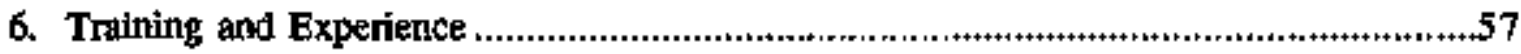

6.1 Training Administration.........................................................................57

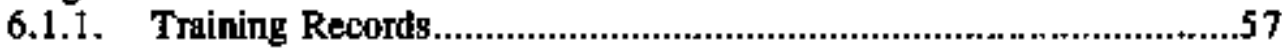

6.1.2. Training Programs.................................................................57

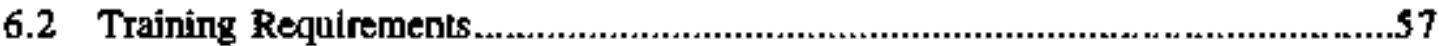

6.2.1. Safety Instuction ...............................................................57

6.2.2. Facility Maintenance Personnel...................................................58

6.2.3. Facility Staff/Anthorized Users....................................................59

6.2.4. Radiation Safety Officer ….........................................................6 1

Appendix A - Bibliography …................................................................................. A-1 
Appendix B - Cross Reference Guide................................................................ 



\section{EXECUTIVE SUMMARY \\ Background}

The use of remote afterloading brachytherapy has increased due to many factors, including improved technology, advantages in radiation protection for staff, and their ability to control the placement and durstion of exposure of the radioactive sources.

Researchers at the Idaho National Engineering Laboratory gathered over one hutidred publications from the US NRC, standards institutes, and professional societies. These publications were reviewed and sections that pertained to quality management for remote afterloading brachytherapy were collected and sorted by topic.

The report begins with a brief explanation of remote afterloading brachytherapy and additional details on the making of this report. This is followed by the collected quality management infornation.

The collected works are organized by licensee activittes: programs, facility design, maintenance \& audits, operations, and training.

Appendix A provides a bibliography of the source publications used for this report and describes how individuals may obtain their own copies. Appendix $B$ is a cross reference table that summarizes the body of the report.

\section{How to use this document}

This report is organized in anticipation that the seader will tom to this docement with specific questions in one area rather than as a repport to be read cover to cover. Therefore, the collected references are arranged by functional area so that the reader may go to a single applicable chapter. Chapter 3 deals with the establishment of a new brachytherapy program. Chapter 4 deals with ongoing maintenance and record keeping. Chapter $\$$ deals with operations. Chapter 6 deals with training.

The information collected in this report can provide a basis for a quality management progran and can save the Jicensee many hours searching the literature for information on a particular topic: however, this is not a controlled document, and the source publications may be updated at any time without revision to this report, so the prudent user will verify the information reproduced within is current. 
- 


\section{ACKNOWLEDGMENTS}

The authors acknowledge the contributions of the medical and regulatory professionals who provided significant input for this report.

Patricla Rathbun, Ph.D., served as the NRC's Project Manager for this work. Other NRC staff members who participated in the work include Card Paperiello, Ph.D., the Director of the Division of Industrial and Medical Nuclear Safety; John Glenn, Ph.D., Chtef of the Meojcal, Academic and Commercial Use Safety Branch; Patricia K. Holahan, Ph.D. Linda Kasner, and Robert Ayres, Ph.D., members of the NRC technical staff; and Ms. Donna Umbel the Technical Assistance Project Manager.

Many radiation oncologists and medical physicists also provided comments and guidance based on their many years of expertence in the field. Principal medical contributors and reviewers were Glenn P. Glasgow, Ph.D., Professor and Head Division of Medical Physics, Loyola University Medical Center; Maywood, IL; Perry W. Grigsby, M.D., Washington University School of Medicine, Mallinckrodt Institute of Radiology, Radjation Oncology Center, St. Louis, MO; Douglas W. Johnson, M.D., F.A.C.R., Williams Cancer Center, Jacksonville, FL; Herbert W, Mower, Sc.D., Radiation Physics Department at Lahey Clinic, Burlington, MA; Keith A. Weaver, Ph.D., Department of Radiation Oncology, Medical Center at the Universty of Califomia, San Francisco, CA; and Jeffrey F. Williamson, Ph.D., Washington University School of Medicine, Mallinckrodt Institute of Radiology, Radiation Oncology Center, St. Louis, MO. 



\section{ACRONYMS/NOMENCLATURE}

AAPM American Association of Physicists in Medicine

ACMP American College of Medical Physics

ACNP American College of Nuclear Physiclans

ACR American College of Radiology

AEC Atomic Energy Commission

ALARA as low as reasonably achievable

ALI annual limit on intake

ANSI Amcrican National Standards Institute

ARRT American Registry of Radiologic Technology Certification

ASTRO American Soclety of Therapeutic Radiology \& Oncology

Bq becquerel, $1 \mathrm{~Bq}=1$ disintegration per second

BSI British Standards Institute

CAP College of American Pathologists

CCTV closed circuit television

CFR Code of Federal Regulations

c curie, $1 \mathrm{Ci}=3.7 \times 10^{10}$ disintegrations per second

$\begin{array}{ll}\text { CREF } & \text { cross reference } \\ \text { CTPS } & \text { Computerized Trearment Planning } \\ & \text { System }\end{array}$

DAC derived air concentration

dpm disintigrations per minute

FDA Food \& Dng Administration

GMP good manufacturing practices

Gray SI unit of absorbed dose. One gray is equal to an absorbed dose of 1 Joule/kilogram (100 rads).

HDR high dose rate

HPA Hospital Physicists' Association

IAEA Intemational Atomic Energy Agency

ICRP International Commission of Radiological Protection

IEC Intermational Electrotechnical Commission

INEL Idaho National Engineering Laboratory
IPSM Institute of Physical Sciences in Medlcine

Ir iridium

JCAHO Joint Commission on Accreditation of Healthcare Organization

$\mathrm{keV}$ thousand election volts

LDR low dose rate

LLNL Lawtence Livemore National Laboratory

MDR medium dose rate

$\mathrm{MeV}$ million electron voits

NBS National Bureau of Standards

NCI National Cancer Institute

NCRP National Council on Radiation Protection \& Measurements

NIST National Ingtitute of Standards \& Technology

NRC Nuclear Regulatory Commission

NRCB NRC Bulletín

NVLAP National Voluntary Laboratory Accreditation Program

PDR pulse dose rate

QA Quality Assurance

QM Quality Management

Rad Special unit of absotbed dose. One rad is equal to an absorbed dose of 100 ergs/gram or 0.01 joule/kilogram $(0.01$ gray).

Rem Special unit of any of the quantities expressed as dose equivalent. The dose equiyalent in rems is equal to the absorbed dose in rads multiplied by the quality factor (1 rem=0,01 sievert).

RSC Radiation Safety Committee

RSO Radiation Safety Officer

Sievert St unit of any of the quantities expressed as dose equivalent. The dose equivalent in sieverts is equal to the absorbed dose in grays multiplied by the quality factor (1 $S v=100$ rems).

SNM Society of Nuclear Medicine

Sv seiverts 


\section{A Compilation of Current Regulations, Standards, and Guldellnes in Remote Afterloading Brachytherapy}

\section{INTRODUCTION}

\subsection{Scope}

This study is sponsored by the Division of Industrial and Medical Nuclear Safety of the U.S. Nuclear Regulatory Commission (NRC). It examines the regulations, recommendations, and practices that make up the quality management program associated with the safe use of radioactive isotopes by authorized tusers in the medical community.

This report addresses the regulations, standards, and recommendations that apply specifically to the safe use of radioactive byproduct material. It does not address trade, medical, or other requirements.

The objective of this study is to identify the current regulations, standards and gujdelines for quality management in remote afterloading brachytherapy required or recommended by the U.S. Nuclear Regulatory Commission, selected standard-setting bodies. medical organizations, and other regulatory agencies.

\subsection{Background}

\subsubsection{Fole of NRC and Need tor ON Program \\ The Policy Statement of 1979}

The NRC and its predecessor the Atomle Energy Cornmlssion have regulated the medlcal use of radloisotopes since 1946. AEC recognized that physi. cians have the primary responsiblity for the prolection of their patlents and designed is regulations accordingly.

Based on past expertence and the comments and advice of the pubitic and other Federal Agencies, the States, and the NRC's Advisory Commiltee on the Medical Uses of Isotopes, the Commission has developed the following statement of general policy to gutide its regulation of the medicat uses of radloisotopes:

1. The NRC will continute to regulate Ine medical uses of radioisotopes as necessary to provide for the radiation salety of workers and the general public.
2. The NRC wili regulate the radiation sately of patients where justlfied by the risk to patients and where voluntary standards, or complience with these standards, are inadequate.

3. The NRC will minimize intusion into medical judgments affecting patients and Into other areas traditionally considered to be a part of the practice of medicine. ${ }^{1}$

The NRC regulates the use of byproduct material in medicine by regulating and licensing hospitals and medical centers that use byproduct materiai in diagnostic or therapeutic applications. The NRC uses several formats to issue regulatory requitements and to provide guidance regarding these recuirements to its licensees. These include issuance of the Code of Federal Regulations (CFR), Regulatory Gujdes, Policy and Guidance Directives (FC), and the licenses that specify commitments made by licensees during the licensing process. The intent of this system of rules, policy statements, and guidance documents is to address radiation safety and to ensure risk to members of the general public is maintained at a minimum. The NRC does not regulate the credentialing process for professionals who practice medicine.

The CFR contains the nules established by the executive branch or the federal govemment and has the force of law. The NRC's regulations are found in Titie 10 .- Energy. Part 35 of the 10 CFR deals specifically with the medical use of byproduct material, but other parts apply, too, particularly parts 19 and 20.

Regulatory Guides are issued through a formal review and comment process. They are Issued to assist licensees by providing techrical information and details of how to establish a program that meets the requirements of the

144 FR 29, Human Uses of Byproduct Material, Nuclear Regulatory Commisslon, B242, Fobruary 9. 1979 . 
regulations. Compliance with the Regulatory Guides is not required.

The Policy and Gujdance Directives disseminate NRC poticy to the NRC staff. Fantiliarity with these directives will belp the licensee meet the intent of NRC regulations.

Finally, licenses and the attendant conditions specify controls for the use of byproduct materiai and define the licensee's authority to use byproduct material. The standard license condlttons for brachytherapy are included in this report where appropriate.

The FDA is a federal agency that also issues regulations; however, concerning remote afterloading brachytherapy, the FDA nules address the design and safety features of such devices while the NRC rules, as stated above, address the individuals" use of the device.

Other private organizations also enter into the regulatory picture. Their standards do not have the force of law, but they clearly describe a level or performance considered the minimam acceptable by experts in the tield. These organizations include national standards bodies and professional societies such as the American National Standards Inslitute (ANSI). the American Association of Physicists in Medicine (AAPM) and the National Council on Radiation Protection (NCRP). A list of organizations contacted is in section 2.2. Many documents from these organizations were reviewed for this report, and are listed in Appendix A. These bodies provide a uniform sel of voluntary standaros that, if adopted and followed by the licensees, will improve the overall stale of safety in the medical use of isotopes and reduce the degree to which the NRC must issue regulations.

The administration of byproduct mate. rial can be a complex process for many types of diagrnostic and therapeutic procedures in nuckear medicine or oncology departments. A number of individuals may be lnwolved in the delivery process. For example, in an oncology department when the authorized user prescribes a teletherapy treatment, the delivery process may involve a team of medlcal professionals such as a radiation therepy physicist, dosimetrist, and radiation therapy technologist. Conducting the plan of treatment may involve a number of mea- surements, calculations, competer-generaled treatment plans, patient simulations, portal film verificalions, and beam modifying devices to deliver the prescribed dose. Therefore, instructions must be clearly communicated to the professional team members with constant attention devoted to delail during the treatment process. Complicated processes of this nature require good planning and clear, understandable procedures. ${ }^{2}$

\subsubsection{Remote Afterloading Brachytherepy}

Brachytherapy is any of several procedures for the radiation treatiment of cancer, with small. sealed radioactive sources, near or in contact with the target tissue. The sources are applied with intraluminal, interstitial, intracavitary, or intraoperative techniques.

Afterloading techniques are those in which non-radioactive applicators or guide tubes are initially placed in the patient and the radioactive sources are later loaded into these applicators.

Remote afterloaders ane radiation therapy devices that remotely inser and withdraw the radioactive sources from guide tubes and applicators. Depending on the manufacturer and model, remote afterloaders typically employ iridium-192, cobalt-60, or cesium-137 sources.

For licensing purposes, this guidance defines the following lents as:

- "high dose rate (HDR) to mean a dose rate of $\mathbf{2 0}$ or more centlgray (rads) per minute;

- "medium dose rate" (MDR) to mean a dose rate between 200 centigray (rads) per hour and 20 centigray (rads) per mirute; and

- "low dose raten (LDF) to mean a dose rate of 4-200 centigray (rads) per hour.

- "putsed dose rate atterloader" (PDR) refers to a spectal type of remole afterloading device that uses a single source capable of delivering cose rates in the "high dose rate" range, but is used to simulate the radiobiology of a low dose rate irealment by inserting the source for a

2 NRC Regulatory Guide 8.35, B 
given fraction of tach hour. Based solely on their Instantaneous exposure rate, these devices are treated the sarne as high dose rate devices in this document. ${ }^{3}$

Thus, for the purposes of [NRCB 93-01], all remote afterioading brachytherapy units capable of producing exposure rates in excess of 500 rads (centigray) per hour at one centimeter will be referred to as High-Dose-Rate (HDR) afterloaders. ${ }^{4}$

\subsubsection{High Dose Rate verses Low Dose Rate Remote Afterloading}

HDR afterloaders typically have a single source of five to 20 curies. LDR afterioaders may have single or multiple sources with activities of 10 to 50 millicuries. Typically, the HDR machine will step its single source through a series of dwell positions, while a LDR machine will not reposition its multiple source string. The HDR irradiations usually last several minutes while the LDR imadiations last up to I40 hours. HDR brachytherapy is normalty fone on an out-patient basis. LDR brachytherapy requires hospitalization. HDR treatment employs shorter irradiations at higher dose rates than LDR treatment. Because of the higher source levels involved, shielding requirements for HDR devices are greater than for LDR devices.

\subsubsection{Pulse Dose Rate}

A Pulse Dose Rate (PDR) machine is a new development which is being used at a few sites. It has a single source with a typical strength of about one curte. A device similar to a HDR machine controls the source for a treatment that typically lasts two to three days, thos requiring admission to the hospital. Daring the treatment the machine will step the source through the programmed treatment positions for five to chirty minutes, then retract the source and store it for the remainder of the cycie. Cycles are typically an hour long. This cycle is repeated dozens of times. The radia-

3 NRC Policy and Guldanco Directive, FC g6-4; Povisan 1

$4 \quad$ MFG Bulletin $\$ 3-01$
Table 1. Comparison of brachytherapy methods.

\begin{tabular}{lll} 
HDR & LDR & PDR \\
$2-12$ curie & $\begin{array}{l}10-50 \\
\text { milicurio }\end{array}$ & $\sim 1$ curis \\
$1-12$ & $1-3$ & $40-70$ \\
$1-25$ min. & $\begin{array}{l}12-140 \\
\text { hours. } \\
\text { ln patient }\end{array}$ & $5-30 \mathrm{~min}$. \\
Out patient & In pationt \\
\hline
\end{tabular}

tion is therefore applied at an instantaneous rate that is higher than LDR, but lower than HDR. The discontinuous application is divided over a time length similar to an LDR application. There are specific requtrements for PDR machines in the NRC's Policy and Guidance Directive FC 86-4, Revision 1, and NRCB 93-01.

\subsubsection{Device Description}

A resnote afterloader system consists of sev. eral inajor components:

- Treatment Unit -- Consists of a radiation safe that bouses the radioactive sources, a storage container for non-radioactive "dumny" sotrces, and electrical and mechanical hardwane such as drive cables and stepping motors required to deploy the sources from their storage positions into applicators in the patient. This unit resides in the treatment roorn.

- Control Unit -- Consists of the microcomputer that controts the ireatment unit and its display, keyboard, and system printer. Programming, treatment control, and treatment monitoring are performed from this unit. HDR devices normally place all these functions outside the treatment room. LDR devices normally include many of the programming functions within the same assembly as the treatment units and place only required treatment controls and status indicaions outside the treatment room.

- Source Transfer Tubes -- Tubes between the treatment unit and the patient applicators.

- Patient Applicators - Treatment tubes inserted into the pattent that the radioactive sources will enter during treatment. There are many designs of applicators for specific purposes. 
- Nomal and Emergency Power Supplies and Accessories -- Electrical and mechanical power supplies, such as the main $A C$ power, backup DC battery power, and a compressed air supply; and the equipment needed to control and conduct the power to the remote afterloading device, such as emergency stop switches, function boxes, and compressed ait lines.

- Computerized Treatment Planning System (CTPS) - A dedicated software system used in dose computations. Some CTPSs have a dose optimization feature that optimally plans the HDR or LDR brachytherapy treatments. 


\section{METHODS}

\subsection{Approach}

The data collected for the brachytherapy study was organized by the INEL and reviewed for technical accuracy by physicians and physticists working independently and by the U. S. NRC.

\subsection{Organization}

For each of the technical headings, a synopsis of the current NRC requirements and recommendations is provlded. Items from the Code of Federal Regulations are requilrements. Items from Policy and Guldance Directives (FC) and Regulatory Gudes are recommendations; unless included in the facility's license, in which case they are requirements.

This is followed by applicable material from other govemment agencies, national standards bodies and professtonal organizations. Summarized information from mantefacturers and users is also presented under the appropriate headings. User comments and recommendations were included only when they provided an additional contribution beyond the mere affirmation of compliance. Tectuical Opinion is provided in several areas to clarlfy or add to recommendations and requirements.

Appendix A lists all documents reviewed and provides information for ordering additional copies.

Appendix $\mathbf{B}$ summarizes the main body of this report in tabular form.

\subsection{Participants}

Information regarding regulations, standards and guidelines was obtained through interviews with representatives of the medical organdzations and agencies. Interviewers used a comprehensive interview checklist developed by INEL, LLNL, brachytherapy physicians, and medical physicists. The organizations contacted were:

by INEL:
- American National Standards Institute (ANSI);

- Hospital Physicists' Association (HPA):

- National Council on Radiation Protection and Measurements (NCRP):

- Intemational Atomic Energy Agency (IAEA):

- International Electrotechnicad Commission (IEC);

- British Standards Institute (B\$I).

by LLNL:

- Food and Drug Administration (FDA):

- American College of Radiology (ACR);

- American Association of Physicists in Medicine (AAPM);

- Institute of Physical Sciences in Medicine (IPSM);

- American Socfety for Therapeutic Radiology and Oncology (ASTRO);

- National Institute of Standaris and Technology (NIST).

The INEI also obtained information from three manufacturers of remote afterloaders that are distributed in the United States, and from five medical instibutions where remote afterloading brachytherapy is performed. The manufachurers or their U.S. distributors represented in this document are:

- Nucletron;

- Omnitson; and

- RTS Technology.

of the five medical institutions interviewed. three are medical centers associated with large teaching universitites, one is a large private clinic, and one is a mid-sized radiation oncology center at a private hospital. The instiłu. tions referenced in this report are described in Table 2. Practices of the instibutions were only noted when they exceeded the requirements already presented or provided a particularly useful insight into the application of require. ments. 
Methods

Table 2. Description of facilities

\begin{tabular}{|c|c|c|c|c|c|}
\hline Reference & Size & Type & Location & Licensing & Machine \\
\hline Faciliny 1 & Large & $\begin{array}{l}\text { University Medical } \\
\text { Center }\end{array}$ & West & $\begin{array}{l}\text { Agreement } \\
\text { State }\end{array}$ & $\begin{array}{l}\text { Nucietron Solectron LDR } \\
\text { Nucletron microSelectron PDR }\end{array}$ \\
\hline Facilty 2 & Mid & Hosplital & West & $\begin{array}{l}\text { Agreenrent } \\
\text { State }\end{array}$ & Nucletron microSelectron HDF \\
\hline Factiny 3 & Large & $\begin{array}{l}\text { Universily Medical } \\
\text { Center }\end{array}$ & Midwest & $\begin{array}{l}\text { NRC Li- } \\
\text { censeg }\end{array}$ & $\begin{array}{l}\text { Nucietron micraselectron LDA } \\
\text { Nucletion Selectron LDR } \\
\text { Nucletron microSelectron PDR } \\
\text { Nucletron microSelectron HDR }\end{array}$ \\
\hline Facillity 4 & Large & $\begin{array}{l}\text { Un'versity Medical } \\
\text { Center }\end{array}$ & East & $\begin{array}{l}\text { Agreement } \\
\text { State }\end{array}$ & Omnitron HDR \\
\hline Facilty 5 & Large & Clinic & East & $\begin{array}{l}\text { NRC li- } \\
\text { censee }\end{array}$ & Garrtnaked 12! HDR \\
\hline
\end{tabular}




\section{FACILITY CERTIFICATION AND REVIEW}

The training and experience of the staff are major factors in all phases of a successful temote-afterloading brachytherapy program. Training requirements should be reviewed and a training program established before the device is received and treatments are begun. Training and experience are discussed in section 6 of this report.

\subsection{Facility License Application}

\section{NRC Requirements \& \\ Recommendations}

\section{\$35.JI License required.}

(a) A person shall not manufacture, produce, acquire, receive, possess, use, or transfer byproduct material for medical use except in accordance with a specific license issued by the Commission or an Agreement State, or as allowed in paragraph (b) of this section.

(b) An individual may receive, possess, use, or transfer byproduct material in accordance with the regulations in this chapter under the supervision of an authorized user as provided in $\$ 35.25$ unless prohjbited by llcense condition.

[Note: Application procedures for a license for the medical use of byproduct material are described in detail in the following NRC documents: Policy and Guidance Directive FC 86-4 Revision 1: Information Required for Licensing Remote Afterloading Devices; 10 CFR 35: Medical Use of Byproduct Material: Regulatory Guide 10.8, Revision 2; Guide for the Preparation of Applications for Medical use Programs.?

\subsection{Facillty Programs}

\subsubsection{Facllity Quallty Management Programs}

\section{NRC Requirements \& AecommendatJons}

\section{$\$ 35.32$ Quality management program.}

(a) Each applicant or licensee under this part, as applicable, shall establish and maintain a written quality management program to provide kigh confidence that byproduct matejal or radiation from byproduct material will be administered as directed by the authorized user. The quality management program must include written policies and procedures 10 meet the following specific objectives:

(1) That, prior to administration, a written directive ${ }^{5}$ is prepared for:

(i) Any teletherapy radiation dose:

(ii) Any gamma stereotastic radiosurgery radiation dose;

(iii) Any brachytherapy radiation dose;

(iv) Any administration of quantities greater than 30 miticroctrries of either sodium iodide I-125 or 1-131; or

(v) Any therapeutic administration of a radiopharmaceutical, other than sodium iodide I-125 or I-131;

(2) That, prior to each administration, the patient's identity is verified by more than one method as the individual named in the written directive;

6 If, because of the patient's condition, a delay in order to provide a written revision to an existing written directive would jecpardze the patient's health, an oral revision 10 an existing written drective will be acceptable, grovided that the oral revision is documented immediately in the oationt's record and a revised writen directive is aigned by the authorized user wihin 46 hours of the oral revision.

Also, a written revision to an existing written directhe may be made for any diagnostic or therapeutic procedure provided that the reviston [s daled and slgned by an authorized user prior to tre acmhistration of the radiopharmacoulical dosege, the brachytherapy dose, the gamma storeptactlo radiosiugery dose, the toletherasy dose, or the next teletheraphy fractional dose.

If, because of the emergent nature of the patient's condition, a delay in order to provide a written directive would jeopardize the patient's heath, an oral directive will bo acceptable, provided that the information contained in the oral directho is doctumented immodielely in the patient's record and a writien directive is prepered within 24 hours of the oral directive. 
(3) That, final plans of treatment and related calculations for brachytherapy, teletherapy, and gamma stereotactic radiosurgery are in accordance with the respective written dinectives;

(4) That, each adninistration is in accordance with the written directive; and

(5) That any unintended deviation from the written Girective is identified and evaluated, and appropriate action is taken.

(b) The licensee shall:

(I) Develop procedures for and conduct a review of the quality management program including, since the last review, an evaluation of:

(i) A representative sample of patient administrations.

(ji) All recordable events, and

(ji) Alj misadministrations

to verify compliance with all aspects of the quality management program: these reviews shalf be conducted at intervals no greater than 12 months.

(2) Evaluate each of these reviews to de termine the effectiveness of the quality management program and. if required, make modifications to meet the objectives of paragraph (a) of this sectton; and

(3) Retain records of each review, including the evaluations and findings of the teview, in an auditable form for three years.

(c) The licensee shafl evaluate and respond, within 30 days after discovery of the recordable event, to each recordable event by:

(1) Assembling the relevant facts including the cause;

(2) Identify'ng what, if any, corrective action is required to prevent recurrence; and

(3) Retaining a record, th an auditable form, for three years, of the relevant facts and what corrective action, if any, was taken.

(d) The Iicensee shall retain:

(1) Each written directive; and

(2) A record of each administered radiation dose or radiopharmaceutical dosage where a written directive is required in paragraph (a)(1) above, in an auditable form, for three years after the date of administration.

(e) The licensee may make modifications to the quality management program to increase the progran's efficiency provided the program's effectiveness is not decreased. The ifcensee shall furmish the modification to the appropriate NRC Regional Office within $\mathbf{3 0}$ days after the modification has been made.

(f)(1) Each applicant for a new license. as applicable, shall submit to the appropriate NRC Regional Office in accordance with $\$ 30.6$ a quality management program as part of the application for a license and implement the program upon issuance of the license by the NRC.

(2) Each existing licensee, as applicable. shall stubnit to the approprate NRC Regional Offtce in accordance with $\$ 30.6$ by January 27,1992 a written certification that the quality management program has been implemented along with a copy of the program.

\section{\$35.25 Supervision. (CREF)}

[See \$35.25 in section 6.2.3.]

\section{Other Government, Standards, and Protessional Organizations} AAPM 4l, VII. (partial)

Quality assturance procedures must be established for the equipment, e.g.. the remote afterloader unit and its ancillary accessories, and for the process of using the equipment, e.g., proper execution of a pianned treatment.

\subsubsection{ALARA Program}

\section{NAC Requirements \& Recommendations}

\section{\$20.100I Purpose.}

(a) The regulations in this part establish standards for protection against ionizing radiation resulting from activities conducted under lifenses issued by the Nuclear Regulatory Commission. These regulations are issued under the Atomic Energy Act of 1954, as amended, and the Energy Reorganization Act of 1974 , as amended.

(b) It is the purpose of the regulations in this part to control the receipt, possession, use, 
transfer. and disposal of licensed material by any licensee in such a manner that the total dose to an individual (inciuding doses restit. ing from licensed and unlicensed radjoactive material and from radiation sources other than background radiation) does not exceed the standards for protection against radiation prescribed in the regulations in this part. However. nothing in this part shall be constnued as limiting actions that may be necessary to protect health and safety.

\section{$\$ 20.1002$ Scope.}

The regulations in this part apply to persons Iicensed by the Comtission to receive, possess, use, transfer, or dispose of byproduct, source. or special nuclear material or to operate a production or uttlization factlity under parts 30 through $36,39,40,50,60,61,70$, or 72 of this chapter. The limits in this part do not apply to doses due to background radiation, to exposure of patients to radiation for the purpose of medical diagnosis or therapy, ot to voluntary participation in medical research programs.

\section{$\$ 20.1003$ Definitions. (partial)}

ALARA (acronym for "as low as is reasonably achievable") means making every reasonable effort to maintain exposures to radiation as far below the dose limits in this part as is practical consistent with the purpose for which the licensed activity is undertaken, taking into account the state of technology, the economics of improvements in relation to state of technology, the economics of improvements in relation to benefits to the public health and safety, and other socjetal and socioeconomic considerations, and in relation to utiltzation of nuclear energy and Iicensed materials in the public interest.

\section{\$20.1101 Radiation protection programs.}

(a) Each licensee shall develop, document, and implement a radiation protection program commensurate with the scope and extent of licensed activities and sufficient to ensure compliance with the provisions of this part. (See s 20.2102 for recordkeeping requirements relating to these prograns.)

(b) The licensee shail use, to the extent practicable, procedures and engineering controls based upon sound ractiatton protection principles to achieve occupational doses and doses to members of the public that are as low as is reasonably achievable (ALARA).

(c) The licensee shall periodically (at least annually) review the radiation protection program content and implementation.

\$ 20.130I Dase limis for individual members of the public.

(a) Each licensee shall conduct operations so that--

(1) The total effective dose equivalent to individual members of the public from the 11 censed operation does not exceed 0.1 rem (1 $\mathrm{mSv}$ ) in a year, exclusive of the dose contribution from the licensee's disposal of radioactive material into sanitary sewerage in accordance with Sec. 20.2003, and

(2) The dose in any unrestricted area from external sources does not exceed 0.002 rem ( $0.02 \mathrm{mSv}$ ) in any one hour.

(b) If the licensee permits members of the public to have access to controlled areas, the finits for members of the public continue to apply to those individuals.

(c) A licensee or license applicant may apply for prior NRC authorization to operate up to an annual dose limit for an individual member of the public of $0.5 \mathrm{rem}(5 \mathrm{mSv})$. The licensee or license applicant shall include the following information in this application:

(1) Demonstration of the need for and the expected duration of operations in excess of the limit in paragraph (a) of this section;

(2) The licenseets program to assess and control dose within the $0.5 \mathrm{rem}(5 \mathrm{mSv}$ ) annual limit; and

(3) The procedures to be followed to maintain the dose as low as is reasonably achievable.

(d) In addition to the requjrements of this part, a licenses subject to the provisions of EPA's generally applicable environmental radiation standards in 40 CFR Part 190 shall comply with those standards.

(e) The Commission may impose additional restrictions on radiation levels in unrestricted areas and on the total quantity of radionu- 
clides that a licensee may release in effluents in order to restrict the collective dose.

\section{$\$ 20.1302$ Compllance with dose limirs for in- dividual members of the public.}

(a) The licensee shall make or cause to be made, as appropriate. surveys of radiation levels in unrestricted and controlled areas and radioactive materials in effluents released to unrestricted and controlled areas to demonstrate compliance with the dose limits for individual members of the public in $\$ 20.1301$.

(b) A jicensee shall show compliance with the annual dose Iimit in Sec. 20.1301 by--

(1) Demonstrating by measurement or calculation that the total effective dose equivalent to the individual likely to receive the highest dose from the jicensed operation does not exceed the annual dose limit; or

(2) Demonstrating that--

(i) The annual average concentrations of radioactive material released in gaseous and liquid effluents at the boundary of the unrestricted area do not exceed the values specified in table 2 of appendix $B$ to Secs. 20.1001. 20.2401; and

(ii) If an individual were continuously present in an unrestricted area, the dose from external sources would not exceed 0.002 rem $(0.02 \mathrm{mSv})$ in an hour and 0.05 rem $(0.5$ InSv) in a year.

(c) Upon approval from the Commission, the licensee may adjust the effuent concentration values in appendix B to Secs. 20.100120.2401 , table 2, for members of the pubtic, to take into account the actual physical and chemical characteristics of the effluents (e.g., aerosol size distribution. solubility, density, radioactive decay equilibrium, chemical form).

\section{$\$ 20.2101$ General provisions.}

(a) Each licensee shall use the units: curie, rad, rem, including multiples and subdjvisions, and shall clearly indicate the units of all quantities on records required by this part.

(b) The license shall make a clear distinction among the quantities entered on the records required by this part (e.g., total effective dose equivalent, shallow-dose equivalent, cye dose equivalent, deep-dose equivatent, committed effective dose equivalent).

\section{$\$ 20.2102$ Records of radiation protection programs.}

(a) Each licensee shall maintain records of the radiation protection progran, including:

(1) The provisions of the program; and

(2) Audits and other reviews of progran content and implementation.

(b) The licensee shall retain the records required by paragraph (a)(1) of this section until the Conmission terminates each pertinent license requiring the record. The licensee shall retain the records required by paragraph (a)(2) of this section for 3 years after the records is made.

\section{$\$ 35.20$ ALARA program.}

(a) Each licensee shall develop and implement a written radiation protection program that inciudes provisions for keeping doses as low as reasonably achievable (ALARA).

(b) To satisfy the requirement of paragraph (a) of this section:

(1) At a medical institution, management, the Radiation Safety Officer, and all authorized users must participate in the program as requested by the Radiation \$afety Committee.

(2) For licensees that are not medical institutions, management and all authorized users must participate in the program as requested by the Radiation Safety Officer.

(c) The program must include notice to workers of the program's existence and workers' responsibility to help keep dose equivalents ALARA, a review of summartes of the types and amounts of byproduct material used. occupational doses, changes in radiation safely proceduses and safety measures, and continuing education and training for all personnel who work with or in the vicinity of byproduct material. The purpose of the review is to ensure that licensees make a reasonable effort to maintain individual and collective occupational doses ALARA.

Regulatory Guide 10.8, Revision 2, \$1.

1. RADIATION PROTECTION PROGRAMS

(cf. Appendix $G$ to Regulatory Guide 10.8) 
In the revised Part 20, t0 CFR 20.1101 reguires each licensee to develop, document, and implement a radiation protection program ap. propriate to the scope and extent of the activities conducted and to review at ieast annually the program content and its implementation. Funther, 10 CFR 20.1101 requires that each licensee use engineering controls and procedures to ensure that occupational doses and doses to members of the public are as low as is reasonably achievabie (ALARA). In addition, 10 CFR 20.2102 provides the recordkeeping requirements for radiation protection pro. grams.

The requirements in $10 \mathrm{CFR} 20.1101$ are consistent with the requirements for control of accupational exposures in 10 CFR Parts 33 and 35. Radiation protection programs that have been established under the requirements of 10 CFR Parts 33 and 35 will be corsidered to be acceptable to meet the occupational ALARA requirements of the revised 10 CFR Part 20 when the program activities are limited to extemal occupational exposures. However, licensees who handle unsealed radioactive materials that may cause internal exposure to members of the public will need to supplement their ALARA programs to address potential intemal as well as extemal doses to menbers of the general public from effluents to unrestricted areas. Additional guidance is being developed on this, and it will be addressed in a separate regulatory guide. Licensees should establish ALARA goals or objectives for effluents.

In developing an ALARA radiation protection program, Jicensees should design the program based on the size of the licensed facility. the potential hazards associated with radiation exposure, the potential intake of radioactive material, and the physical characteristics of the radionuclides (i.e., solid, liquid, or gas). For example, the magnitude of an ALARA program for a large research hospttal would be expected to be considerably more comprehensive in scope than a radiation protection program for a private practice phystctan. The program should include the mechanisms for periodic (at least annually) review of performance, as well as actions to be taken when ALARA goals or objectives are not met.
The revised 10 CFR Part 20 does not requite that a numerical cost-benefit analysis (quantitative approach) be used to demonstrate ALARA. However, NRC encourages medical licensees to use quantitative analyses in developing ALARA programs and procedtres. If it can be gerfomed readily, licensees should demonstrate through quantitative analysis that the cost and benefits associated with design. engineering controls, and operating procedures have been optimized in accordance with the ALARA principle. If a quantitative analysis cannot be readily performed, licensees should thoroughly evaluate any design or engineering controls that may need to be changed to keep operating procedures ALARA.

Examples of the type of ALARA optimization considerations appropriate to the conduct of medical use programs are presented in the National Council on Radiation Protection and Measurement (NCRP) Report No. 107, "lmplementation of the Principle of As Low As Is Reasonably Achievable (ALARA) for Medical and Dental Personnel,"* December 31, 1990. This NCRP report provides speciffc hypothetlcal examples of optimization decisions in inplementing ALARA in nuclear medicine and radiation oncology.

*NCRP reports can be purchased by writing to NCRP Publications, 7910 Woodmont Avenue, Suite 800, Bethesda. MD 20814.

\section{Other Government, Standards, and Professional Organizations}

NCRP 105, 4.4. (partial)

The general philosophy followed by most institutions in minimizing radiation dose is that all exposures must be justified and, further, that they must be kept as jow as reasonably achievable (ALARA), economic and social factors being taken into account. The ALARA concept applies to radiation workers as well as to the general public. The ALARA statement represents a commtiment on the part of the institution to provide the resourices and the environment in which ALARA can be implemented. The NCRP recommends continuing efforts to maintain personnel exposures below allowable limits and to keep exposures as low as reasonably achievable. 
NST 92, 15.

Exposure to radioactive materials above the maximum permissible levels can be avoided by proven protective measures ln the handling of radionuclfdes.

The fundamental objectives of such protective measures are:

1. To maintain exposure to extemal radiation as low as feasible.

2. To minimize entry of radionuclides into the human body by ingestion, inhalation, absorption, or through open wounds when unconfined radioactive material is handled.

To accomplish these objectives requires positive planuing and diligent execution of procedures, beyond the usual care taken in work with other materials. It is necessary to analyze in advance the hazards of each job; to provide safeguards against foreseeable accidents; and to use protective devices and planned emergency procedures in accidents that do happen.

\section{NIST 92, 3.2. (partial)}

Wherever radioactive materials are ușed, there shall be a competent person responsible for the radiation protection program. His duties will vary depending upon the type of organization in which the work is being carried out, but he assists the supervisor in carrying out his program of radiation safety by advising on all phases of the work in matters of radiation protection. This person should preferably be in a position in the organization where he can effectively consult with those establishing the policy for the laboratory group or the procedure for carrying out work. His duties shall include instructing and training the workers and visitors in the use of protective equipment and procedures; arranging for proper waste disposal; keeping suitable records on personnel exposures; investigating accidents and unusual occurrerices; seeing that properly calibrated instruments are avajlable for workers or persons doing montoring and carrying out monitoring in cases where unusual contamination is suspected.

\section{Technical Note}

NCRP Report 107, Implementation of the Principle of As Low As Reasonably Achievabie
(ALARA) for Medlcal and Dental Personnel, provides additional details on this topic.

NRC Regulatory Guide 8.18, Information Relevant to Ensturing that Occupational Radiation Expostres at Medical Institutions will be As Low As Reasonably Achievable, should be reviewed when developing ALARA programs at Medical instinutions.

NRC Regulatory Guide 10.8, Guide for the Preparation of Applications for Medical Use Programs, Revision 2, Appendix G contains a model ALARA program.

\subsubsection{Radlation Safoty Committee}

\section{NRC Requitements \& Becommendations}

$\$ 35.22$ Radiation Safery Commitree.

Each medical institution licensee shall establish a Radiation Safety Committee to over* see the use of byproduct material.

(a) Each Committee must meet the follow* fng administrative requirements:

(1) Membership mist consist of at least three individuals and must include an authorized user of each type of use permitted by the license, the Radiation Safety Officer, a representative of the nursing service, and a representative of management who is neither an authorized user nor a Radiatton Safety Officer. Other members may be included as the licensee deems appropitate.

(2) The Committee must meet at least quarterly.

(3) To establish a quorum and to conduct business, at least one-half of the Committee's membership must be present including the Radiation Safety Officer and the management's representative.

(4) The minutes of each Radiation Safely Committee meeting must include:

(j) The date of the meeting;

(ii) Members present;

(iii) Members absent:

(iv) Summary of the deliberations and discrsssions;

(v) Recommended actions and the numerical results of all ballots; and 
(vi) ALARA program reviews described in 83.20 .

(5) The Committee must promptly provide each member with a copy of the meeting minutes, and retain one copy for the duration of the license.

(b) To oversee the use of licensed material, the Commituee must:

(1) Review recommendations on ways to matntain individual and collective doses ALARA;

(2) Review, on the basis of safety and with regard to the training and experience standards in subpart $J$ of this part, and approve or disapprove any individual who is to be listed as an authorized user, the Ractiation Safety Off. cer, or a Teletherapy Physicist before subnitting a license application or request for amendment or renewal;

(3) Review on the basis of safety, and approve with the advice and consent of the Radiation Safety Officer and the management representative, or disapprove minor changes in radiation safety procedures that are not potentially important to safety and are permitted under $\$ 35.31$ of this part;

(4) Review quarterly, with the assistance of the Radiation Safety Officer, a summary of the oceupational radiation dose records of all per. sonnel working with byproduct material;

(5) Review quanterly, with the assistance of the Radiation Safety Officer, all incidents in. volving byproduct matertal with respect to cause and subsequent actions taken; and

(6) Review annually, with the assistance of the Radiation Safety Officer, the radiation stafety program.

\section{$\$ 35.23$ Statements of authorty and respon- sibllites.}

(a) A licensee shall provide the Radiation Safety Officer, and at a medical institution the Radiation Safety Committee, sufficient authority, organizational freedom, and management premogative, to:

(1) Identify radiation safety problems;

(2) Initiate, recommend, or provide corrective actions; and
(3) Verify implementation of corrective actions.

(b) A licensee shall establish and state in wtiting the authorities, duties, responsibilities, and radiation safety activities of the Radiation Safety Officer, and at a medical institution the Radiation Safety Committee, and retain the current edition of these statements as a record until the Cormmission terminates the license.

Other Government, Standards, and Professtonal Orgamizations NCRP 105, 5.3. (partial)

The size of the program and federal or state licensing requirements will detemine the size of and the need for a radiation safety committee. The RSC's primary responsibility is to develop and maintain an effective radiation safety program for the medical facility. To do this, its members must possess adequate knowledge of the princliples of radiation physics and radiation protection. The membershlip of the Committee should include such individuals as a nuclear medicine physician, a radiologist, a radiation oncologist, a senior hospital administrator, a health or medical physicist, a senior nurse, an intemist, and an investigator who uses radiation in mesearch activities.

\section{Technicel Note}

NRC Regulatory Guide 10.8, Guide for the Preparation of Applications for Medical Use Programs, Revision 2, Appendix F contains a model program.

\subsubsection{Radlation Safety Offlcer \\ NAC Requirements \& Aecommendations}

\section{\$35.2I Radiation Safety Officer.}

(a) A licensee shall appoint a Radiation Safety Officer respansible for implementing the radiation safety program. The licensee, through the Radiation Safety Officer, shall ensure that radiation safety activities are being performed in accordance with approved procedures and regulatory requirements in the daily operation of the licensee's byproduct material program.

(b) The Radiation Safety Oficcer shall: 
(1) Investigate overexposures, accidents, spills, losses, thefts, onauthorized receipts, uses, transfers, disposals, misadministrations, and other deviations from approved radiation safety practice and implement corrective actions as necessary;

(2) Establish, collect in one binder or file, and implement written policy and procedures for:

(i) Authorizing the purchase of byproduct material;

(ii) Receiving and opening packages of byproduct material;

(iii) Storing byproduct material;

(jv) Keeping an inventory record of byproduct materlal;

(v) Using byproduct material safely;

(vi) Taking emergency action if control of byproduct material is lost; veys;

(vij) Performing periodic radiation sur-

(viii) Performing checks of survey instruments and other safety equipment;

\section{(ix) Disposing of byproduct material;}

(x) Training personnel who work in or frequent areas where byproduct material is used or stored;

(xi) Keeping a copy of all records and reports required by the Commission regulations, a copy of the regulations, a copy of each licensing request and jicense and amendments. and the written policy and procedures required by the regulations.

(3) Britef management once each year on the byproduct matetial program;

(4) Establish persontel exposure investigational levels that, when exceeded, will initiate an investigation by the Radiation Safety Officer of the cause of the exposure;

(5) Establish personnel exposure investigational levels that, when exceeded, will initiate a prompt investigation by the Radiation Safety Officer of the cause of the exposure and a consideration of actions that might be taken to reduce the probability of recurence;
(6) For medical use not at a medical institution, approve or disapprove minor changes in radiation safety procedures that are not potentially important to safety with the advice and consent of management; and

(7) For medical use at a medical institution, assist the Radiation Safety Committee in the performance of its duties.

\section{$\$ 35.19$ (c) License amendments.}

A licensee shall apply for and must recelve a license amendment:

... (c) before it changes Radiation Safety Officers or Teletherapy Physicists.

\section{\$ 35.14 Notifications.}

A licensee shall notify the Commission by letter within thirty days when an authorized user, Radiation Safety Offlcer, or Teletherapy Physicist permanently disconttnues perforntance of duties under the license or has a name change, or when the licensee's mailing address changes. The licensee sball mail the report to the appropriate address identified in $\$ 30.6$ of this chapter.

\section{$\$ 30.6$ Communicattons. (partial)}

(a) Unless otherwise specified or covered under the regional licensing program as provided in paragraph (b) of this section, any communication or report concening the regufations in parts 30 through 35 and 39 of this chapter and any application filed under these regulations may be submitted to the Commission as follows:

(1) By mail addressed to: Director, Offjce of Nuclear Material Safety and Safeguards, U.S. Nuclear Regulatory Commission, Washington, DC 20555

(2) By delivery in person to the Commlssion's offices to the Director, Office of $\mathrm{Nu}$ clear Material Safety and Safeguards at:

(i) 2120 L Street, NW., Washington, DC; or

(ii) 11555 Rockville Pike, One White Flint North, Rockville, Maryland.

\section{$\$ 35.23$ statements of authority and respon-} sibilities. (CREF).

[See \$ 35.23 in section 3.2.3.] 
Other Government, Standerds, and Professtonal Orgenizations NCRP 105, S.3. (partial)

The RSO should be an individual with extensive training and education in areas such as radiation protection, radiation physics, radiation biology, instrumentation, dosimetry, and shielding design. The designated RSO should be a health or medical physicist, but may be a physician or other individual qualified by virtue of experience or training. The primary function of the RSO is the supervision of the daily operation of a radiation safety program to ensure that individuals are protected from radiation. To do this the RSO should report directly to top management and have ready access to all levels of the orgentzation. NCRP Report No. 59 (NCRP, 1978a) describes these administrative artangements in detail.

\subsubsection{Personnel Monitorling \\ NRC Aequirements \& Recommendations}

$\$ 20.1502$ Conditions requiring indivldual monitoring of external and internal occupational dose.

Each licensee shall monitor exposures to radiation and radioactive material at levels sufficient to demonstrate compliance with the occupational dose limits of this part. As a minimum-

(a) Each licensee shall monltor occupational expostre to radiation and shall supply and require the use of individual monitoring devices by*

(1) Adults likely to receive, in 1 year from sources external to the body, a dose in excess of 10 percent of the limits in $\$ 20.1201$ (a).

(2) Minors and declared pregnant women likely to receive, in 1 year from sources external to the body, a dose in excess of 10 percent of any of the applicable lisnits in $\$ 20.1207$ or \$ 20.1208 , and

(3) Individuals entering a high or very high radiation area.

(b) Each licensee shall monitor (see $\$$ 20.1204) the occupational intake of radioactive material by and assess the committed effective dose equivalent to-
(1) Adults likely to receive, in 1 year, an intake in excess of 10 percent of the applicable ALJ(s) in table 1, Columns 1 and 2 of appendix $B$ to $\$ \$ 20.1001-20.2401$; and

(2) Minors and declared pregnant women iikely to teceive, in I year, a committed effective dose equivalent in excess of $0.05 \mathrm{rem}(0.5$ $\mathrm{mSv})$.

\section{$\$ 20.1501$ (c) General.}

(c) All persornel dosimeters (except for direct and indirect reading pocket ionization chambers and those dosimeters used to measure the dose to the extremities) that require processing to deternine the radiation dose and that are used by licensees to comply with $\mathrm{Sec}$. 20.1201, with other applicable provisions of this chapter, or with conditions specified in a license must be processed and evaluated by a dosimetry processor-

(1) Holding current personnel dosimetry accreditation from the National Voluntary Laboratory Accreditation Program (NVLAP) of the National Institute of Standards and Technology; and

(2) Approved in this accreditation process for the type of radiation or radiations included in the NVLAP program that most closely approximates the type of radiation or radiations for which the indjvidual wearing the dosimeter is monitored.

\section{Policy and Guidance Directive FC $86-4$.} Revision I, VI.

The licensee must confirm that pursuant to 10 CFR 20.1502, personnel involved with treating patients using a remote afterloading device will be monitored as appropriate, including whole body badges to be wom by persons entering the restricted area.

Other Government, Standards, and Professional Organizatlons

\section{AAPM 4I, V.C. (partial)}

Finger radjation monitors for personnel operating units are a good practice. While unusual events, such as source jammed in the applicator, are infrequent, if personnel are invoived in an emergency, their finger rings, in conjunction with theis whole body personnel 
monitors, will help provide estimates of dose equivalents received during emergencies.

ANSI NI3.2, 4.5.

A radiation monitoring progran must give due regard to the evaluation of exposures during equipment traintenance procedures. In some instances intervals between servicing of equipment might be so long as to preclude the assignnent of this work to a routine category. Furthemore, the perfomance of work which requires special and unusual strveillance to assure adequate radiation protection, for example, nonroutine operations involving significant risk of unexpected changes in radiation levels, will in many instances also require special monitoring procedures and equipment.

\section{ANSI N13.2, 5.2.I.3.}

Personnel monitoring for external exposure should be requited for teletherapy personnel, workers involved in the use of seated sources in "Open and Enclosed Protective Installatoons," and other personnel having access to the area such that they may be exposed to ra. diation in excess of applicable limits.

\section{IPSM 46, s.2. (portial)}

The Regulations specify the dose linits for the whole body, the lens of the eye, the abdomen of female employees, and for other individual organs and tissues. The monitoring programme should allow the doses to these various parts of the body to be established for classified and other wotkers likely to receive doses in excess of one-tenth of the quoted limits. Non-classiffed workers must not receive doses exceeding three-tenths of these limits.

\section{NCRP 105, 5.6. (partial)}

Personnel monitoring is recommended for individuals for whom there is a reasonable probability of exceeding 25 percent of the occupational dose equivalent limit of 5 rem per year in the course of their work (NCRP 1978 a).

\section{Users' Recommendations and Practices}

Personnel radiological monitoring programs at facilities interviewed require all per. sonnel involved in treatment administration to wear personal dosimeters. At one facility, persontel involved with source loading or prepsration activities for the microselectron LDR wear finger radiation monitors.

\section{Technical Note}

NRC Regulatory Guide 10.8, Guide for the Preparation of Appilcastons for Medical Use Programs, Revision 2, Appendix D contains a model program.

\subsection{Faciltty Design and Equipage}

\section{3.t. Facillty Dealgn \\ NRC Requlrements \& Recommendations}

$\$ 35.13$ (e) License amendments.

A licensee shall apply for and must receive a license amendment:

...(e) Before it adds to or changes the areas of use or address or addresses of use identifled in the application or on the license.

Policy and Guidance Directive FC 86-4. Revision I, VA.

A. The licensee must submit annotated drawings (not blueprints) of each dedicated treatrinent roon indicating:

1. Scale, plan and elevation.

2. Identiflcation of the room(s), including roam number(s).

3. Type, density and thickness of all shielding materials, including walls, floor and ceiling.

4. Location of doors, windows, conduits, etc.

5. Distance to and the nature of use for adjacent areas with indication of whether the areas are restricted or unrestritcted, as defined in $10 \mathrm{CFR} 20.1003$.

NOTE: Treatments using pulsed, medium, and high dose rate afterloading devices must be performed in rooms specially constructed or modified for radiation therapy. The use of pulsed, medium, and high dose rate afterloading devices must be restricted to the specific room described in the licensee's application. Relocation of a pulsed, mediun or high dose 
rate afterloading device to another area of use requires prior NRC approval through a license amendment.

Other Government, Standards, and Professlonal Organizations

AAPM 41, II,B. (partial)

LDR remate afterloading units usually can be located in rooms used for manual afterloading.

AAPM 41, HIC. (partial)

Instantaneous dose rates around HDR units with $370 \mathrm{GBq}$ (10 curles) sources preclude their use in conventional rooms unless patients are placed in specially designed local shielding areas or devices within the room. The size of a dedicated HDR vault will be detertined by the amount of equipment installed.

\section{Manufacturers}

For the high dose remote afterloaders, all three device manufacturers provide planning and other technical assistance to their customers on the facility and treatment room conflguration (e.g., layout of equipment, electrlcal and mechanical requirements, viewing systems, security, shielding recommendations). This service is typically included as part of the installation activity.

\subsubsection{Facllity Shleiding \\ NAC Requirements \& Recommendatrons}

\section{$\$ 20.1201$ Occupational dose timts for odults.}

(a) The licensec shall control the occupational dose to individual adults, except for planned special exposures under $\$$ ex, 20.1206, to the following dose limits.

(1) An annual limit, which is the more limiting of--

(i) The total effective dose equivalent being equal to $5 \mathrm{rems}$ (0.0S Sv); or

(ii) The sum of the deep-dose equivalent and the committed dose equivalent to any individual organ or tissue other than the lens of the eye being equal to 50 rems (0.5 Sv).

(2) The annual limits to the lens of the eye, to the skin, and to the extrernities, which are: (j) An eye dose equivalent of 15 rems (0.15 Sv), and

(ii) A shallow-dose equivalent of 50 rems $(0.50 \mathrm{~Sv})$ to the skin or to any extremity.

(b) Doses received in excess of the annual limits, including doses received during accjdents, emergencies, and planned special exposures, must be subtracted from the limits for planned spectial exposures that the individual may receive during the current year (see Sec. 20.1206 (e)(1)) and during the individual's lifetime (see Sec. 20.1206(e)(2)).

(c) The assigned deep-dose equivalent and shallow-dose equivalent must be for the part of the body receiving the highest exposure. The deep-dose equivalent, eye dose equivalent and shallow-dose equivalent may be assessed from surveys or other radiation measurements for the purpose of demonstrating compliance with the occupational dose limits, if the individual montoring device was not in the region of highest potential exposture, or the results of individual monitoring are unavatlable.

(d) Derived air concentration (DAC) and annual limit on intake (ALI) values are presented in table 1 of appendix B to Secs. 20.1001-20.2401 and may be used to determine the individual's dose (see Sec. 20.2106) and to demonstrate compliance with the occupational dose limits.

(e) In addition to the annual dose limits, the licensee shall limit the soluble uranium intake by an individual to 10 milligrams in a week in consideration of chemical toxicity (see footnote 3 of appendix B to Secs. 20.100120.2401).

(f) The licensee shall reduce the dose that an indivioual may be allowed to receive in the current year by the amount of occupational dose received while employed by any other person (see Sec. 20.2104(e)).

Policy and Guidance Directive FC 86-4, Revision 1, V.F.

F. The licensee must submit detailed calculations of maximum radiation levels (and dose rates) that will exist in each area, restricted and unrestricted, adjacent to the room(s) where treatment is performed using an afterloading device to demonstrate compli. ance with $10 \mathrm{CFR} 20.1301$. (This includes as- 
eas above and below the treatment room.) For programs authorizing the use of a low dose rate afterloading device in multiple tooms, the licensee must perform the calculations using one or more room configurations which are representative of those in which patient therapies will be perfomed. The calculations must include the following:

1. Expected radiation levels for each area adjacent to the room housing the aftetioader device considering the most adverse source orientations and maximum source activity to be used in the device. For low dose rate afterloading devices which may be used in multiple roomls and with varied treatment times and source combinations, the calculation(s) should consider the most adverse conditions to be encountered (i.e., maximum source strength or combination of sources used for treatment. source ortentation, and room size and layout). The licensee may need to perform several calculations for low dose rate afterlosding devices if the device will be iseed in rooms which are not similar in layout or if the ficensee anticipates using varied combinations of sources and/or source strengths.

These calculations must be sufficient to demonstrate that the expected dose rates in restricted and unrestricted areas adjacent to the treatment room(s), meet the requirement of 10 CFR Parts 20.1201 and 20.1301. [Paragraphs V.F.2-6 of FC 86-4 provide additional details.]

2. All parameters used to perform the calculations described above must be specjfied. These parameters should include such factors as distance to each area of concern, the type and thickness of material(s) used in barriers and shields, and the transmission factor of the bartiers or shields, and the maximum sousce strength. For low dose remote afterloading devices, the licensee should specify the configuration of portable shtelds, if applicable. used for each set of calculations and the source or source combination.

3. The maximum anticipated workload data, such as maximum "on time" per hour and per week for remote afterloading units which wtil be used in a dedicated room and occupancy faciors used for all adjacent areas. For low dose rate units which may be used in multiple roons, under varied treatment programs, a profile of the licensee's anticipated workload should be provided with representative exarlples of treatment times, source combinations and occtipancy factors for adjacent areas.

4. Calculations to determine the dose received by individuals present in unrestricled areas should consider continuous accupancy (i.e., occuparicy factor of one) unless the licensee can make a compelling argument for using a lower value. Calculations to determine the dose received by ancillary staff providing patient care during treatment with low dose rate afterfoading devices must include full details of the occupancy factors used.

5. Results of the calculations are to be expressed in units of rem (or millisieverts) in any one hour or year, as appropriate.

6. The licensee must demonstrate that the Itmits specified in 10 CFR 20.1301 (a) will not be exceeded. If the licensee's calculations demonstrate that these limits carnot be met, the licensee must be requested to outline further steps which will be taken to limit exposure to individual members of the public. Options which may be considered by the licensee include:

(a) Adding shielding to the barrier in question, with corresponding modification of the facility description if necessary.

(b) Request an exemption and demonstrate that the requirements of 10 CFR 20.1301 (c) will be met. The licensee musl demonstrate the need for and the expected duration of operations which will result in an individual dose in excess of the limits specified in 10 CFR 20.1301(a). A program to assess and control dose within the $0.5 \mathrm{rem}$ ( $5 \mathrm{mSv}$ ) annual limit and procedures to be followed to maintain the dose as low as is reasonably achievable must be developed and submitted for review.

Other Government, Standards, and Professlonal Organizations AAPM 41, IJ.B. (partial)

[For LDR treatment] the best entry way to the room features a "small maze."

AAPM 41, M.C. (partial)

A small [HDR] vault, 5.5 meters (18 ft) by 5.5 meters $(18 \mathrm{ft})$, will generally require $60 \mathrm{~cm}$ 
(2 ft) thick concrete walls (specific density 2.2 $\mathrm{g} / \mathrm{cm}^{3}$ ) for a $370 \mathrm{GBq}$ (10 curie) ${ }^{192} \mathrm{lr}$ source.

NIST 92, 4.1. (partial)

In the design of shields, the shielding matetial should, if possible, be placed near the source. If adjacent rooms or spaces are occupied, care should be taken to protect all such areas.

\section{Users' Recommendations and Practices}

HDR facilities installed thetr HDR remote afterloaders in treatment rooms previously used for external beam therapy or in specially constructed HDR vaults. Facilities use a combination of permanent and portable radiation shields in rooms used for LDR remote afterloading brachytherapy.

\section{Technical Note}

Each installation must be individually piansed, reviewed, and tested to verify the requirements of 10 CFR 20 are met. Variations in room size, structural materials, device used, stay times, proximity to occupied rooms, etc., all enter into the shielding problem; therefore, no general solutions of shielding thickness of material can be made.

Actual testing is needed when a new device is installed, even if the vault previously provided protection from a device that produced stronger radiation flelds. This is because the new fteld origin and direction might not be adequately shielded by a facility designed for a different radiation field geometry.

\subsubsection{Facility Interlocks and Safety Devices}

\section{NRC Requirements \&} fecommendatlons

Pollcy and Guidance Directive FC 83-20. Revision 2, 125.

(High, Medium, and Pulsed Dose Rate)

125. A. Access to the rooms housing the afterloading brachytherapy device shall be controlled by a door at each entrance.

B. The entrance to the irradiation roorm shat be equipped with an electrical interlock system that will cause the source to retum to the shielded position immediately upon opening of the entrance door. The interlock system shall be connected in such a manner that the source cannot be placed in the irradiation position until the entrance door is closed and the source "on-off" control is reset at the control panel.

C. Electrical interlocks on the entrance doot to the iradiator room shall be tested for proper operation at least once each day of use.

D. In the event of malfunction of the door interlock, the irradiation device shall be locked in the "off" position and not used, except as may be necessary for repair or replacement of the interlock system, until the interlock system is shown to be functioning properly.

Policy and Gridance Directive FC 86-4, Reviston 1, V.D.

D. The licensee must provide a description of the security to be provided for each noom where a remote afterloading device is to be used or stored. Areas or rooms used to store remote afterloading devices or source containers housing a source (sources) must be secured in accordance with 10 CFR 20.1801 .

1. For mediun and high dose rate devices which will be used in a dedicated treatment room, a description of the following is reguired:

(a) The physical/admintstrative control of arcess.

(b) The electrical interlock system installed at each entry, including the result of interrupting the interlock when the source is exposed (i.e.. whether the source is automatically retracted).

(c) The actions required following interruption of the interlack prior to resuming treatment, including confimmation that the interlock must be reset before the afterloading device can be activated.

(d) The actions required in the event of malfunction of the interlock system. The licensee must confirm that if the system malfunctions, the afterlosding device will be locked in the "off" position and not used, except as may be necessary for repair or replacement of the interlock system, until the 
interlock system is shown to be functioning properly.

(c) Restricted area controls (e.g., signs, locks, visible/audible alarms, etc.), including descriptions of signs with their location, sizes and wording (also see V.H.).

(f) The licensee must confirm that no other radiation- producing devices are located in the treatment room, or provide a description of the mechanisms installed to ensure that only one device can be placed in operation at a time.

(g) Method to ensure that whenever the afterloader device is not in use or is unattended, the console keys will be inaccessible to unauthorized persons.

2. For low dose rate afterloader devices which will be used in multiple rooms within a single building, a description of the following is required:

(a) Methods for providing security and surveillance of the patient room.

(b) Restricted area controls (e.g., signs and entrance controls) for both the treatment and storage roons, including the sign location, sizes and wording (also see V.H.).

(c) The proposed storage area for the device when not in use.

(d) Method to ensure that whenever the afterloader device is not in use or is tnattendect, the console keys will be inaccessible to unauthorized persons.

Other Government, Standards, and Professional Organizations

AAPM 4I, MLC. (partial)

Radiological safety requirements for a dedicated HDR yault...include positive action door interlocks that retract the source when the door is opened, and an emergency button that, when pushed, and will retract the source. Other features include warning lights, visible and audible alanms, remote closed circuit video camera (CCTV) and intercommunication devices for monjtoring patients, radiation detector independent of the HDR, visible access alams above the maze door, and a cable pass for dosimetry cables.
AAPM 41, HI.C. (partial)

Special care is required to ensure that the teletherapy unit or the linac (co-located with an HDR unit) cannot be turned on while a HDR procedure is underway; usually this can be achieved by using interfocks. One simple procedure keeps operating keys for both units on a single key ting with no duplicate keys available at the units.

\section{IPSM 46, 3.5.2.t. (partial)}

The room entrance must be interlocked so that if any person should enter, sources retum to the safe and remain there until deliberately exposed again. A reliable, independently powered radiation detector inside the room should operate waming signals (preferably including an audible one) both inside the roorn and at the entrance, where a warning notice and symbol should be displayed.

NCRP 57, 2.2.J.

Physical safeguards: Physical safeguards include all physical equipment used to restrict access of persons to radiation sources or to reduce the level of exposure in occupied areas. To minimize irradiation from external sources. protective devices include, but are not limited to, shields, barriers. locks, alarm signals, and source shutdown mechanisms. To minimize the irradiation from intemally deposited radionuclides, eypical protective devices are containers, hoods and glove boxes, ventilation, filtration and exhaust systems, protective clothing, and respiratory protective devices.

Planning and evaluation of physical safeguards should begin in the early phases of design and construction of an installation. Detailed inspection and evaluation of the radiation safety of equipment are mandatory at the time of the initial use of the installation. Additional investigations are necessary periodically to assure that the effectiveness of the safeguards has not decreased with time or as a result of equipment changes.

\section{Manufacturers}

Nucletron and Omnitron require users to install the remote afterloader units in rooms with intertocks and shielding that meet the applicable NRC or Agreement State regula. tions. 
RTS Technology, in the Operator's Manual, requires that the treatment vault/room be equipped with an interlock switch.

Key locks on the control panel. located on the remote afterloader console outside the treatment vault for HDR devices and on the unit and treatment room outside wall for LDR devices, prevent the units from being used by unauthorized individuals.

\section{Users' Recommendatlons and Practlces}

All HDR facilities interviewed have installed facility components and systems identified by AAPM for cobalt therapy. These include: Positive action door interlocks, emergency stop button, waning lights, visible and audible alarms, remote CCTV and communication systems for monitoring the patients, and radiation detectors independent of the HDR device. They consider those items to be criticat to the safe operation of the remote afterloader.

\subsubsection{Permanent Radiation Monitors \\ NRC Requirements \& \\ fiecommendatlons}

Policy and Guidance Directive FC 86-4, Revision 1, V.E. (partial)

E. The licensee must confirm that a permanent radiation moritor capable of continuously monitoring the source status will be installed in each dedicated treatment room for high, pulsed and medium dose rate devices. The licensec must confirm that the proposed monitoring system includes the features described below....

1. The radiation monitor will provide visible notice of an afterloader device malfunction that results in an exposed or partially exposed source, and must be observable by an indfvidual entering the roor.

2. The radiation monitor will be equipped with a backup power supply separate from the power supply to the afterloader device (may be a battery system).

Other Government, Standards, and Professlonal Organizations

AAPM 41, II.B. (partial)

An independent radiation monitor in the [LDR] room is generally required. As it will be 'on' when the patient is treated, some forethought should be given to its features and location. An audible alarm is undestrable; a continuously flashing light that indicates the source(s) is out of the unit should be located such that it is viewed by those entering the room, but visually shielded so that it does not disturb the patient.

AAPM 4I, IIIC. (CREF).

[See AAPM 41, III.C in section 3.3.3.]

\section{Manufacturers}

All manufacturers require their users to install an independent radiation detector in the treatment room. The detector is equipped with a light or an illuminated sign. indicating the presence of radiation.

\section{Technlcal Opinion}

A slave indicator driven from the independent radiation detector should be mounted outside the treatment room door and at the nurse station for LDR and PDR rooms.

\subsubsection{Patient Observation Equipment}

\section{NAC Requirements \& Recommendations}

Pollcy and Guidance Directive $F C$ 86-4, Revision 1, V.C.

C. The licensee must equip each dedicated treatment room for high and medium dose rate devices with continuous viewing and intercom systems to allow for patient observaton during treatment. A description of the systems must be provided with the application and must include:

1. The primary intercom and viewing systern.

2. Backup systems to be used if the primary systems fail or, alternatively, the licensee should commit to suspend further treatments until the primary system is repaired.

For patient roorns where treatment using a low dose rate afterloading device is planned. the licensee must describe how the patient and device will be monitored during treatment to ensure that the sources and catheter guide tube are not disturbed during treatment and to provide for pronipt detection of any opera. 
tonal problems with the afterloading device during treatment.

Other Government, Standards, and Professlonal Organizations

AAPM 4I, II.B. (partial)

Viewing of the [LDR] patient is generaily through a window in the maze wall or by remote video camera with monitor located at the murseses station.

AAPM 41, HI.C. (CREF).

[See AAPM 41, III.C in section 3.3.3.]

\section{Manufacturers}

All three manufacturers require their HDR afterloader users to have a CCTV system with a monitor at the operator's console.

\section{Users' Racommendations and Practices}

All users contacted recommend an audio monitoring capability in addition to the required video monitoring capability.

\section{Technical Opinion}

CCTV has the advantage over leaded windows of magnification. This allows easier performance of source position verification maintenance since the camera can read source positions against a millimeter rule.

\subsubsection{Survey Instruments - Facillty}

[See section 4.2 .2 below for addftional information on survey instruments.]

\section{NAC Requirements \&}

\section{Recommendations}

$\$ 35.420$ Possession of survey instrument.

A licensee authorized to use byproduct material for implant therapy shatl have in its possession a portable radiation detection survey instriment capable of detecting dose rates over the range 0.1 millirem per hour to 100 millisem per hour, and a postable radiation measurement survey instninent capable of measuring dose rates over the range 1 millirem per hour to 1000 millirem per hour.

Pollcy and Guidance Directive FC 86-4, Revision I, VIl. (partial)

The ficensee must confirm the possession and avallability of a portable radiatton detec- tion survey instrument and a portable radiation measurement survey instrument in accordance with 10 CFR 35.420. The instnuments must be available to device operators and ancillary personnel at all times when an afterloading device is in use. To satisfy the requirement to main. tain operable survey instruments, the licensee must confirm that the requisements specifted in 10 CFR 35.51 will be met.

\section{Other Government, Standards, and} Protesslonal Organizations

AAPM 4I, V.C. (partial)

Routine radiation control procedures include, but are not limited to, having available in the treatment facility...a radiation survey meter.

\section{IPSM 46, S.I.I. (partial)}

Suitable monitoring equipment must be provided and used appropriately. The equipment must have had its perfomance established by an approved test bouse or, where that is not appropiatie, by means of in-house tests. The equipment must be properly maintained and tested at suitable intervals. Records of the results from monitoring of areas and from the tests of the equipment must be kept for at least two years from the dates on which they were made.

NCRP 105, 7.3. (partial)

Correct use of properly calibrated and maintained survey instruments is essential for detection and measurement of radiation in the workplace (NCRP 1978b) Commercially avaitable, sensitive, portable radiation detectors can provide rapid indication of the presence of radiation or radioactive materials or the adequacy of shielding. Individuals who are involved in the handling of radioactive materials shall be competent in the use of survey meters.

\section{Users' Recommendations and Practices}

Staffs recommend that survey instruments be avaftable that are accurate in radiation fields as high as those which may occur in an emergency while attempting to contain an open source. Levels may reach $5 \mathrm{R} / \mathrm{hr}$ at 1 meter from an unshielded source. 


\subsubsection{Labeling and Posting}

\section{NRC Aequirements \&}

Recommendations

\$19.11 Posting of notices to workers.

(a) Each licensee shall post current copies of the following documents:

(1) The regulations in this part and in part 20 of this chapter;

(2) The license, ficense conditions, or documents incorporated into a license by reference, and amendments thereto;

(3) The operating procedures applicable to licensed activities;

(4) Any notice of violation involving radiological working condittons, proposed imposition of civil penalty, or order issued pursuant to subpart B of part 2 of this chapter. and any response from the licensee.

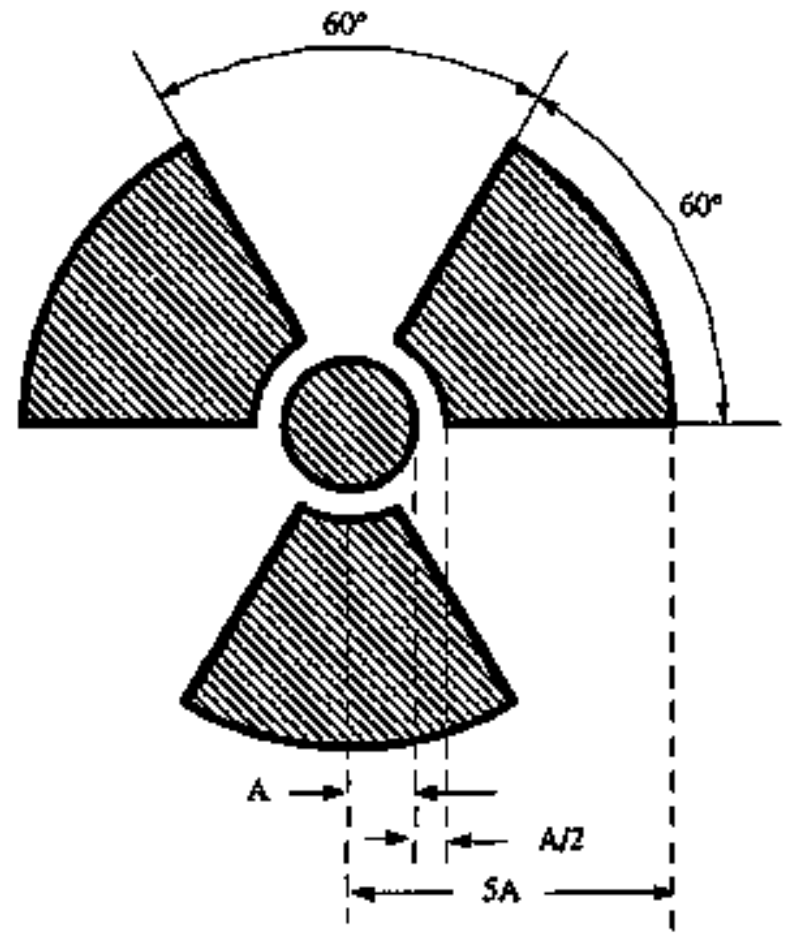

\section{RADIATION SYMBOL}

(1) Cross-hatched area is to be magenta, or purple, or black, and

(2) The background is to be yellow. (b) If posting of a document specified in paragraph (a)(1), (2), and (3) of this section is not practicable, the licensee may post a notice which describes the document and states where it may be examined.

(c) Each licensee and applicant shall post Forn NRC-3 (Revision 6-82 or later) "Notice 10 Employees," as required by parts 30,40 , $50,60,70,72$, and 150 of this chapter.

\section{\& 20.J901 Caution signs.}

(a) Standard radjation symbol. Unless otherwise authorized by the Commission, the symbol prescribed by this part shall use the colors magenta, or purple. or black on yellow background. The symbol prescribed by this part is the three-bladed design:

(b) Exception to color requirements for standand radiation symbol. Notwithstanding the requtsements of paragraph (a) of this section, licensees are authorized to label sources, source holders, or device components contalning sources of licensed materials that are subjected to high temperatures, with conspicurously etched or stamped radiation caution symbols and without a color requirement.

(c) Additional information on signs and labeis. In addition to the contents of signs and labels prescribed in this part, the licensee may provide. on or near the required signs and iabels, additional information, as appropriate, to make individuals aware of potential radiation exposures and to minimize the exposures.

\section{$\$ 20.1902$ Posting requirements.}

(a) Posting of radiation areas. The licensee shall post each radiation area with a consplcuous sign or signs bearing the radiation symbol and the words "CAUTION. RADIATION AREA,"

(b) Posting a high radiation areas. The licensee shatl post each figh radiation area with a conspicuous sign or signs bearing the radiation symbol and the works "CAUTION, HIGH RADIATION AREA" or "DANGER, HIGH RADIATION AREA."

(c) Posting of very high radiation areas. The licensee shall post each very high radittion area with a conspicuous sign or signs bearing the radiation symbol and words 
"GRAVE DANGER, VERY HIGH RADIATION AREA."

(e) Posting of areas or rooms in which licensed material is used or stored. The licensee shall post each area or room in which there is used or stored an amount of licensed material exceeding 10 times the quantity of such materal speciffed in appendlx to 20.240 I with a conspicuous sign or signs bearling the radiation symbol and the words "CAUTION RADIOACTIVE MATERIAL(S)" or "DANGER, RADIOACTIVE MATERIAL(S)."

\section{$\$ 20.3903$ Exceptions to posting requirements.}

(a) A licensee is not required to post caution signs in areas or rooms containing radioactive materials for periods of less than 8 bours, if each of the following condltions is inet:

(1) The materials are constantly attended during these periods by an individual who takes the precautions necessary to prevent the exposure of individuals to radiation of radioactive materials in excess of the limits established in this part; and

(2) The area or room is subject to the 1icensee's control.

(b) Rooms or other areas In hospitats that are occupied by patients are not required to be posted with caution signs pursuant to 8 20.1902 provided that the patient could be released from confinement pursuant to $\$ 35.75$ of this chapter.

(c) A room or area is not required to be posted with a caution sign because of the presence of a sealed source provided the radiation level at 30 centimeters from the surface of the source container or housing does not exceed 0.005 rem ( $0.05 \mathrm{mSv}$ ) per hour.

\section{$\$ 21.6$ Posting Requirements . (partial)}

(a) Each individual, partnership, corporation or other entity subject to the regulations of this part, shall post current copies of the following dacuments in a conspicuous posjtion on any premises, within the United States where the activities subject to this part are conGucted (1) the regulations in this part, (2) section 206 of the Energy Reorganization Act of
1974, and (3) procedures adopted pursuant to the regulations in this part.

(b) If posting of the regulations in this part or the procedures adopted pursuant to the regulations in this part is not practicable, the licensee or firm subject to the regutations in this part may, in addition to posting section 206. post a notice which describes the regulations/procedures, including the name of the individual to whom reports may be made, and states where they may be examined.

\section{$\$ 20.1904$ Labeling contalners.}

(a) The licensee shall ensure that each container of licensed material bears a durable, clearly visible label bearing the radiation symbol and the words "CAUTION, RADIOAC. TIVE MATERIAL" or "DANGER, RA. DIOACTIVE MATERIAL." The label must also provide sufficient information (such as the radionvclide(s) present, an estimate of the quantity of radioactivity, the date for which the activity is estimated, radjation levels, kinds of materials, and mass enrichunent) to permit individuals handling or using the containers, of working in the vicinity of the containers, to take precautions to avoid or minimize exposures.

(b) Each licensee shall, prior to removal or disposal of empty uncontaminated containers to unrestricted areas, remove or deface the radioactive material label or otherwise clearly fndlcate that the container no longer contains radioactive materials.

Pollcy and Guldance Directive FC 86-4, Revision $I, V . H$.

H. The licensee must confirm that conspicuous, durable labels stating "CAUTION RADIOACTYVE MATERIAL," or the equivalent, will be affixed to at least one ovter suiv face of the device as specified in 10 CFR 20.1904 .

Other Government, Standards, and Professional Organizations

IAEA 9, V.SII.

Controlled areas, where the access of the workers is controlled and subject to operating restriction, shall be established in places where workers could recejve exposures in excess of three-tenths of the dose equivalent limit. Controlled areas shall be marked and waming 
slgns shall be appropriately posted at the entrances and within the areas.

NCRP 49, 8.1. (partial)

"Radiation Area" warning signs should be posted in all areas wherein a person, if he were continuously present, could receive an exposure in excess of $5 \mathrm{mR}$ in any one hour or 100 $\mathrm{mR}$ in any 5 consecutive days, but less than $100 \mathrm{mR}$ in any one hour. Appropriate "High Radiation Area" waming signs shall be posted at the entrance to any area wherein a person could receive an exposure of $100 \mathrm{mR}$ or more in any one hour. Exceptions to the posting requirement for "High Radiation Area" signs may be permitted in locations visible to patients when such signs may be a source of ap- prehension, provided personnel occupying the areas are otherwise informed of the radiation levels to which they may be exposed and en. trance to the area is strictly controlled.

\section{Manufacturers}

Nucletron identifies in its microSelectron HDR "Pre-Installation Manual" specific information that is required by the regutatory bodies. Included is the requitrement that treatment area doors be posted with signs reading "CAUTION - RADIATION AREA."

RTS Technology recommends its remote afterloader device users to install just outside the treatment room door a sign reading "GAMMAMED BEAM ON." 



\section{MAINTENANCE REQUIREMENTS}

\subsection{General}

\subsubsection{Ceneral}

\section{NRC Requirements \& Fecommendations}

\section{$\$ 20.150 I(a)$ General.}

(a) Each licensee shall make or cause to be made. surveys that-

(t) May be necessary for the licensee to comply with the regulattons in this part; and

(2) Are reasonable under the circumstances to evaluate-

(i) The extent of radiation levels; and

(ij) Concentrations or quantities of radioactive material; and

(iii) The potential radjological hazards that coutd be present.

$\$ 35,420$ Possession of survey instrtment. (CREF)

[See 20.150](a) in section 3.3.6]

$\$ 35.59$ (a) Requirements for possession of sealed sources and brachytherapy sources.

(a) A licensee in possession of any seaied source or brachytherapy source shall follow the radiation safety and handling instructions supplied by the manufacturer, and shall maintain the instructions for the duration of source use in a legible form convenient to users.

Policy and Guidance Directive FC 86-4. Revision $1, X, A$.

A. The licensee must confinm that only personnel who are licensed by the Commission or an Agreement State to perform such services will perfom maintenance and repair on the afterloading device. Maintenance and repair includes installation, replacement. relocation or removal of the sealed source or an afterloading device that contains a sealed source. Maintenance and repair also means any adjustment involving any mecharism on the afterloading device, treatment console, or interlocks that could expose the source, reduce the shielding around the source, or affect the source drive controls. (A licensee authorized for a low dose rate afterloading device designed as a "mobile" unit may relocate the device for patient treatment if authorized to use the device in multiple rooms.)

The licensee must confirm that a record of any maintenance and repair performed on the afterloading device will be maintained for the duration that the device is in use and must isclude the date of repair, a description of the nature of the maintenance or repair, the name of the individual who performed the repair, the Agreement State or NRC license number atsthorizing the individual to perfom such repairs, and the signature of the individual who performed the repairs.

Policy and Guidance Directive FC 86-4, Revision 1, X.C.

C. The licensee may request that an ethployee tralned by the manufacturer be authorized to perform maintenance and repajr functions. Such authorization should list the employee by name and specify only those maintenance and repair functions described in a certificate or letter from the manufacturer of the device which documents the training and an outline of the training. A copy of the training certification and an outline of the training provided is to be submitted with the request.

Other Government, Standards, and Professional Organizations

AAPM 41, VII.B. (partial)

Equipment quality assurance checks should be performed at sufficient frequency to guarantee that the equipment works properly during a therapy session.

$A C R$ 2, II.B.

The physicist supervising the Q/A program is responstible for documenting that any atteration in the maintenance and repair schedule does not affect the standards promulgated in the "Physical Aspects of Quality Assurance." 


\subsection{Installation}

\subsubsection{Acceptance Testing}

\section{NRC Requirements Recommendations}

Regulatory Guide 8.33, C.3.1.9 High-DoseRafe Remote Afterloading Devices.

3.1.9. The licensee should establish a procedure for perforning acceptance testing by a qualified person (e.g., a teletherapy physicist) on each treatrnent planting or dose calculating computer program that could be used for brachytherapy dose calculations when using high-dose-rate remote afterloading devices. Acceptance testing should be performed before the first use of a treatment planning or dose calculating computer program for brachytherapy dose calculations when using high-dose-rate remote afterloading devices. The licensee should assess each treatnent planning or dose calculating computer program based on the licensee's specific needs and applications.

Regulatory Guide 8.33, C3.2.13, All Other Brachytherapy Applications.

3.2.13. The licensee should establish a procedure for perfoming acceptance testing by a qualinied person (e.g., a teletherapy physicist) on each treatment planning or dose calculating computer program that could be used for brachytherapy dose calcutations. Acceptance testing should be performed before the first use of a treatment planning or dose calculating computer program tar brachytherapy dose calculations. The licensee should assess each treatment planning or dose calculating computer prograrn based on the licensee's specific needs and applications.

Other Government, Standards, and Professlonal Organizations AAPM 4I, VI. (partial)

The acceptance tests estabtish the baseline operating performance parameters of the remote aftertoading device and facility. They can be broadly divided into ( $I$ ) the mechanical and electrical operatton of the remote afterloading device and radiation monitors, (2) the mechanical and electrical features of the facility, (3) the integrity of the applicators, (4) the integrity and proper operation of the radioac- tive source(s), (s) the proper operation of the computer that generates isodose distributions.

AAPM 4I, VI.A.

Acceptance testing of the mechanical and electrical functions of the remote afterloaders includes. but is not limited to confirming:

1. That all console functions (key switches, main power, battery power, source ON/OFF, door OPEN/CLOSE, etc.) and indicators perform properly.

2. That the source(s) retracts at the end of preset times, retracts when intertupted, retracts under loss of electrical power or air pressure if so driven, retracts if source guide tubes or applicators are connected in an improper sequence, improperly connected, constricted or blocked, and retracts when the emergency button is used. Confirm appropriate console displays or printing tape error messages by producing or sirnulating a planned "fatlure" or "error" Confirm that program data (duration of remaining treatment time, etc.) is retained if source retraction or other unplanned intersuptions occur.

3. That the battery voltage under load is adequate and that operating functions retained under battery power indeed work.

4. The accuracy of timers relative to an independent clock, for periods similar to those proposed for treatments; deternine end-time effects. End effects may not be a medically important parameter for LDR or HDR units, but may be a consideration during certain source caljbration procedures, particularly those involving charnber calibration at mults. ple distances.

5. The accuracy of any decayed source(s) activity calculated by computer. Decayed source activity tables should be avatlable to confinit source activities calculated by the remote afterloading unit.

6. That any mult-channel indexer functions properly and moves the source(s) in proper sequence into the correct channels.

7. That appropriate backup systems function properly during simulated power failutes and/or air pressure josses.

8. That the mechanical source retraction system works; it may not be possible to simu- 
late an "exposed source" condition on some units.

9. That any radiation detectors in the remote afterloader operate properly.

10. That program storage and recall function properly. Check that dwell times in stored progtams are changed to reflect source activity at the time of use (unless the machine design requires entry of dwell time patterns based on a given activity, e.g. 370-GBq (10.0-C), with automatic adjustment of the real treatment time to allow for decay).

11. That leakage radiation rates around the device are acceptable.

$A A P M 41, V, B$.

Facility testing includes, but are not limited to confirming:

1. That any door interlock systern retracts the source(s) when the door is opened, and that the unit does not restart automatically when the door is closed.

2. That the source(s) cannot be driven out of the safe with the door open.

3. That radiation waming lights in the room and over the door function properly during planned and unplanned room entry. If other radiation producing equipment is in the room, particular attention must be given to the location and proper functioning of entry way radiation stanis lights so that it is clear which unit is producing radiation.

4. That the closed circuit television and interconmunication systems function properly.

5. That the independent radiation monitor in the room performs properly, using a radioactive check source, and functions during treatrilents.

6. That any other radiation producting equipment in the same room cannot be tumed on simultaneously with the remote afterloading device.

7. That the radiation exposure rates and conditions around the facility comply with those included in the license application.

8. That emergency buttons in the room function properly.
9. That installed compressed gir lines maintain adequate pressure under load and for the planned duration of treatments.

10. That any security system, required for the storage of the remote afteroader when not in use, functions properly.

AAPM 4I, VI.C.

Source transport system and applicator testing includes, but is not limited to confirming:

1. The integrity of the source guide tubes that transport the source(s) to the applicator(s). For sources transported by cables, source guide tube length is a critical parameter and source guide tube length gauges are used to conflm the length to $1 \mathrm{~mm}$ accuracy. For pneumatic transfer of sources air tubes must be inspected for hairpin leaks, constrictions, and other obstacles to source transport. Particular care should be given to testing the remote afterloader with all combinations of scurce transport tubes and applicators to ensure that faulty connectors do not exist.

2. The mechanical jategrity of the applicators via visual inspection and/or radiographs. Conflim the presence and correct placement of any intemal shields or other critical internal components within the applicaior.

3. That any simulated (dummy) source designed to represent source position or placement and the radioactive source(s) both position propetly. geserally to $1-\mathrm{mm}$ accuracy in applicators or at static locations in test devices. Radiographs of dummy sources in test devices or applicators with their mechantcal positions indicated by pen-pricks or other extemal markers, if possible, combined with auto radiographs of the radioactive source(s) in the same device or applicators, will show any lack of coincidence between the position of the duminy sources and the position of the radioactive source(s).

For simulated sources and radioactive sotrces, one can observe, by CCTV and transparent source placement check devices, that the sources will transport as planned, to $1-\mathrm{mm}$ accitracy, to preselected locations.

4. That the radioactive sources move accurately through the applicator(s) creating the desired adiation dose patterns. Visual verift- 
cation via CCTV and/or radiographs of simulated sources at numerous planned location in test devices or in the applicators followed by autoradiography on the same film are required.

5. The radiation attenuation of applicators and deciding if attenuation corrections will be made during treatments.

\section{Manufacturers}

Manufacturess require that remote afterloader sealed source replacement be performed by personnel trained and licensed by the specific device manufacturer. These personnel are normally employed by the manufacturer, however, some technical personnel at institutions have been certified by the manufacturers to perform source changes.

Following installation of a machine by RTS Technology, the afterloader, its components, and other facility specific components (e.g., door interlocks) are reviewed to confim that they have been installed according to design speciftcations. Personsel then perform comprehensive function tests to verify the correct operation of all safety-related and ireatmentsignificant device feanures, including

- check of dummy and source drive (drive wheel, storage and connection tubes, pressure spring, security screws, emergency handcrank, etc.)

- check source head (drive belt and motor, magnets, etc.)

- test durnmy and source-head motors (verify oscillation of cable, end position of cable with step vtewer, etc.)

- test remote afterloader safety functions test for proper function of afterloader and its associated hardware when "start", "intemupt", and "emergency" buttons are pressed, check for error messages when source guide tube is without tandem, connectors not plugged in, drive distance too short or too long, etc.

- confirm that afterloader treatment unit ("icolley") functions as designed (e.g.t elevation drive up and down, brake drive, radiation lamps)

- test to confirm correct performance of computer, keyboard, monitor, printer, console, data transfer
- test to confirm correct performance of computerized treatment planning system (CTPS)

- function check of orjered applicators

- function check of facility (i.e,, treatrient vault) \$afety+related and treatment-signiflcant components (e.g., door intertocks, radiation monitor and warning lights, closed circuit television, electrical/compressed air supply and transmission lines)

RTS has developed a checklist of device checks that are suggested to be performed by licensees at source change time, including:

- verify function of all indicator lamps

- verify function of all emergency stop and intersupt buttons

- verify proper function of all device safety features

- confirm error messages agree with functional tests performed

- verify proper function of all ireatment-important device components (e.g., timers, battery).

The above checks are similar to those performed for device acceptance testing.

Nucletron and RTS Technology perfom the following service tasks at source change time on their HDR afterloaders, typically every three months:

- test emergency battery, treatment programs. master and auxiliary emergency stops, door interlocks

- test afterloader response to loss of power. interrupt, no source guide tube attached

- wjpe test afterloader indexer

- perform radiation survey.

Nucletron, in its Selectron LDR User Manual (January 1986), advises Selectron LDR users to carry out a cormplete functional test as \$oon as the machine has been installed and monthly thereafter. 


\subsubsection{Survey Instrument Calibration and Response Check}

NRC Requirements fiecommendations

\section{$\$ 35.51$ Callbration and check of survey in-} struments.

(a) A licensee shall callbrate the survey instruments used to show compliance with this part before their first use, annually, and following repair. The licensee shall:

(1) Calibrate all scales with readings up to 1000 miltirem per hour with a radiation source.

(2) Calibrate two separate readings on each scale that must be calibrated.

(3) Conspicuously note on the instniment the apparent exposure rate from a dedicated check source as determined at the time of cali. bration, and the date of calibration.

(b) When calibrating a survey instrument, the licensee shall consider a point as calibrated if the indicated exposure rate differs from the calculated exposure rate by not more than 20 percent, and shall conspicuously attach a correction chart or graph to the instrument.

(c) A licensee shall check each survey in. strument for proper operation with the dedicated check source each day of use. A 11 . censee is noc required to keep records of these checks.

(d) A licensee shall retain a record of each survey instrument calibration for three years. The record must include:

(1) A description of the calibration procedure, and

(2) The date of the calibration, a description of the source used and the certified exposure rates from the source, and the rates indicated by the instrument being calibrated, the correction factors deduced from the calibration data, and the signature of the individual who perfomed the calibration.

\section{$\$ 20.1501$ (b) General.}

(b) The licensee shall ensure that instruments and equipment used for quantitative radjation measurements (e.g., dose rate and effluent monitoring) are calibrated periodically for the radiation measured.

Regulatory Guide 10.8, Revision 2, App. B. (partiat)

2. Either the apparent source activity or the exposure rate at a given distance must be traceable by documented measurements to a standard certified within 5 percent accuracy by the National Bureau of Standards.

Other Government, Standards, and Protessional Organizations

ANSI N323, 4.2.1.

To check reproducibility, the instrument stould be exposed to a radiation field three or more times under identical conditions. The readings obtained should normally not deviate from the mean value by more than \pm 10 percent.

\section{ANSI N323, 4.5 .}

A record shall be maintained of all calibration, maintenance, repair, and modification data for each instrument. The record shall be dated and shall identify the individual performing the work.

ANSI N323, 4.7.1.

Primary caltbration [of portable radiation protection instruments] will be required at least annually.

\section{Technical Note}

ANSI N323, Radiation Protection instrument Test and Caljbration, and IPSM Report No. 46, Radiation Protection in Radfotherapy, Section 5 provide much additional detail on this topic.

\subsubsection{Brachytherapy Source Installation and Calibration}

\section{NRC Requirements \& Recommendetions}

Policy and Guidance Directive FC $36-4$, Revision 1, VIII.C.

C. The licensee must develop and implement procedures goveming calibration of the afterloading device. The procedures should be approved by the licensee's authorized physicist(s) and must be submitted for review. 
At a minimum, the calibration procedures must address the following:

1. Calibration measurements of the remote afterloading device source(s) must be performed by the licensee's guthorized physicist(s). The licensee should provide information about the individual's experience in the use of dosimetry systems necessary to perform the calibration measurements. The licensee must confirm that the individual(s) performing calibration measurements will complete all measurements and calculations in accordance with the procedures established by the licensee's authorized physicist.

2. The method used to determine the $e x$ posure rate under spechfic criteria (i.e., distances used for the measurement, whether the measuremerit is an "in-air" measurement or done using a phantom, configuration of the chamber with respect to the source guide tube and device, scatter factors used to compute the exposure rate, etc.).

3. Record maintenance requirements, including a commitment to maintain a record of calibration measurements and associated calculations for a period of three years. The records must tnclude the manufacturer's name, model number, and serial number for both the afterloading device and source; the manufacturer's name, model number and serial number of the instrument used to measure the output of the afterloading device, the date that the calibration measurement was performed, and the narne of the individual who performed the measurement. The record must also include the output of the device expressed in centigray (rads) per hour or, if appropriate, sieverts (rems) per hour and a comparison of manufacturer's ("expected") output value (corrected for decay).

The "expected" and meastred output values should be within $+/-5$ percent. If the measured value differs by more than 5 percent of the expected value, the licensee must commit to having the results reviewed by their radiation safety officer or medical physicist prior to performing further patient treatrnents.

4. A description of the dosimetry system which will be used to perform calibration measurements must be submitted with the procedures. The licensee must also confirm that the dosimetry systert (e.g., Fanner chamber, electrometer, etc.) will be calibrated by a laboratory accredited by NIST or AAPM within the previous two years and after any servicing that may have affected system calibration. The $1 \mathrm{j}$. censee should confirm that records of such calibrations will be maintained for inspection.

5. The frequency for calibration measurements must be specified. It is required that calibrations be perfomed following in. stallation of a new source(s) before patient treatment is resumed, and recommended monthly thereafter.

6. The procedures must include a de. scription of the method to be used to confim source homogeneity for each source contained in the afterloading device. This may be done by autoradiography, following source replacement but prior to using the source(s) for patient ireatment.

Pollcy and Guldance Directive FC 83-20, Revision 2, II2I.

121. The following shall be performed only by manufacturer's representatives or persons speciftcally authorized by the Commission or an Agreement State to perform such services:

A. Installation and replacement of the sealed sources contained in the afterloading brachytherapy device(s).

B. Any maintenance or repair operations on the remote afterloading brachytherapy unit(s) listed in Item 9, Subitem(s) involving work on the source safe, the source drive unit, or other mechanism that could expose the source, reduce the shielding around the source, or compromise the safety of the unit and result in increased sadiation levels.

Other Government, Standards, and Professlonal Organlzallons

AAPM 2I, N. (partial)

Two levels of traceability to NIST are defined and traceability by statistical inference is recognized as an existing practice:

Direct traceability is established when the source is caltbrated at NIST or at a suilably accredited brachytherapy calibration laboratory. 
Secondary traceability is established when the source is calibrated by comparison with a source of the same kind, the calibration of which is directly traceable to NIST.

Secondary traceability by statistical inference is established when a source is part of a group of sources, of which a suitable random sample has been calibrated by comparison with a directly traceable source.

\section{AAPM 4I, V.E. (partial)}

Policies and procedures for handling radioactive sources of remote afterioaders are in general conceptually the same as for conventional brachytherapy sources, but obviously vary depending on the amount of radioactivity in the sources and the frequency with which sources are exchanged. They generally in. clude, but are not limited to:

1. Procedures for receiving and returing sonrces (allow adequate time after source exchange to prepare and ship the decayed source; six weeks is a good time period).

2. Frequency of leak testing (usually every six months). If sources are retained for a shorter period of time, it is sufficient for the user to rely on the manufacturer's leak test, provided it is recent enough.

3. Frequency of inventory checks (usually quarterly); as remote sources are self contained it is possible to write altemate procedures in the license that substitute for a physical inventory.

4. Specifications of radiation surveys to be made with each source change in order to:

g. Ensure that all sources are either in the safe of the remote afterloader or in the shipment container.

b. Determine the exposure rate at agreed points around the safe. These rates must be within the limits set by the regulatory licensing agency.

c. Determine for "exposed sources" that the exposure rate at points outside the treatment room, identified in the license application, are within the limits set by that agency.

5. If patients receiving multiple fractions are in therapy when a source change occurs, it is particularly important to confirm that the newly established source activity is used for calculation of their treatrnent times.

6. Frequency of dose rate measurements in and around areas where sonrces in remote afterloading units or supplemental safes are stored when mot in use.

AAPM 41, V.D.

Acceptance testing of the radioactive source(s) will include:

1. A careful review of the source(s) certiflcate regarding physical and chemical form, source encapsulation, and model number, to confinm that the source(s) delivered complies with those allowed under the license. A source design drawing should be available as details of source(s) construction may be nequired for computer models of source(s) and the resulting radiation dose distribution.

2. Determination of correct number of, and the relative activities for multiple sources of the same design. A well ionization chamber may be used to determine relative activities as long as each individual source in the batch is measured in an identical manner, e.g., at the same position in the center of the well ionization chamber. Mujtiple autoradiographs of each source on one film and a comparison of relative optical densittes is an alternate method, but requires greater attention to procedural detail.

3. Leak testing of the source(s). Swabs of filter papers moistened with water or alcohol are used to wipe either the source surface or the interior of the sclected source carrier. Activity can be measured with calibrated $\mathrm{GM}$ tubes or scintillation counters that can detect $37-\mathrm{Bq}(1,0-\mathrm{nCi})$. Often indirect leak testing is required by testing the interior of applicators or source guide tubes directly in contact with the source rather than direct leak testing of the source(s). Generally, the extent of leakage from a sealed non-gaseous sousce is estimated by multiplying the measured activity obtained by a factor of 10 . Normally, sources that have less than $185 \mathrm{~Bq}(5.0-\mathrm{nCj})$ removable activity on their exterior surface are considered uncontaminated.

4. Determination of dose distribution anisotropy. Sousce construction and encapsolation generally produce dose distributions 
that are anisotropic, particularty near the ends of small linear sources (Figure 10). Often, these effects are negiected and the sources are considered point sources for dose computations. Generally, the user should determine if the dose anisotropy for a speciflc model source has been measured. Measuring dose distribution anisotropy is difficult, and few reports exist. Cerra and Rodgers measured dose anisotropy for a GammaMed IIl High activity Is source: dose anisotropy in low activity Ir seeds was reported by Ling et $\mathrm{al}_{\text {, }}$ and $\mathrm{C}$. Thomason et al., as well as for Cs seed sources. Siwek et al., reported on the dose anisotropies produced by adjacent spherical Cs sources in a Selectron. Users should deternitie, by measurement, if possibte, or by review of the literature, the dose anisotropy of specific source models. Data for dose distribution anisotropy would only be used for the specific model sources reported and not applied to other sources.

5. Absolute callbration of the sources(s). For remote afterloaders using single ir sources replaced several times yeatly. it is most important to develop a consistent, reproducible method of calibration. For long lived sources, e.g. Cs pellets, where the unit contains multi. ple sources of the same nominal activity, one needs to determine the average activity and standard deviation of the lot and confiom that they meet manufacturer-stated certificate values. Methods of absolute calibration are discussed in Section VIll of the report.

\section{AAPM 4l, WH.A. (partial)}

The user needs to confirm the stated certificate value to within its stated uncertainty. $O F$ ten, the uncertainty in the absolute accuracy of source certificale's activity will be between $\pm 5 \%$ to $\pm 10 \%$.

\section{NCRP 40, 4.1.2. (partial)}

All [brachytherapy] sources used for medical therapy shall be calibrated is such a manner that the user can determine the exposure rate or absorbeo dose rate ander defined conditions of use.

\section{Users' Recommendations and Practices}

Facility 2, for HDR dosimetry (iridium-192 source), uses techniques recommended by
Ezzell (Brachytherapy HDR and LDR, Edited by Martinez, A.A., et al,, Nucletron Corporation, 1990).

Facility 3, for HDR dosimetry (lridium-192 source), uses the in-air calibration procedure recommended by Goetsch et al. (Med. Phys. 18; $462-467,1991$ ). An accuracy of $\pm 2 \%$ relative to NIST standards is recommended. Calibration of a clinical LDR source is perfomed using a re-entrant ton chamber calibrated against a NIST traceable calibration standard for each type of LDR source.

At all factlitles interviewed, full calibration measurements are generally performed by senior level staff from the physics department.

\subsubsection{Brachytherapy Source Leakage Check and Surveys \\ NRC Requirements \& Recommendations}

$\$ 20.150$ I (a) General. (CREF)

[See 20.1501(a) in section 4.1.1\}

\section{$\$ 20.1906$ Procedures for receiving and} opening packages.

(a) Each licensee who expects to receive a package containing quantities of radioactive matertal in excess of a Type A quantity, as defined in $\$ 71.4$ and appendix $A$ to part 71 of this chapter, shall make arrangements to receive--

(1) The package when the carrier offers it for delivery; or

(2) Notification of the arrival of the package at the carrier's terminal and to take possession of the package expeditously.

(b) Each licenstee shall--

(1) Monitor the extemal surfaces of a labeled $/ 3 \mathrm{a} /$ package for radioactive contamination unless the package contains only radioactive matertal in the form of a gas or in special form as defined in 10 CFR 71.4;

NOTE 3a Labeled with a Radioactive White I, Yellow II, or Yellow III label as specified in U.S. Department of Transportalion regulations, 49 CFR 172,403 and $172.436-440$.

(2) Monitor the external surfaces of a labeled 3a package for radjation levels unless the package contains quantitles of radioactive 
material that are less than or equal to the Type A quantity, as defined in $\$ 71.4$ and appendix A to part 71 of this chapter, and

(3) Monitor all packages known to contain radioactive material for radioactive contamination and radiation levels if there is evidence of degradation of package integrity. such as packages that are crushed, wet, or darnaged.

(c) The licensee shall perform the monitor. ing reguired by paragraph (b) of this section as soon as practicable after receipt of the package, but not later than 3 hours after the package is received at the licensee's facility if it is received during the licensee's normal working hours, or not later than 3 houts from the beginning of the next working day if it is received after working hours.

(d) The licensee shall immediately notify the final delivery carrier and, by telephone and telegram, mailgram, or facsimile, the Administrator of the appropriate NRC Regional Office listed in appendix D to Secs. 20.1001-20.2401 when--

(1) Removable radiosctive surface contamination exceeds the limits of $\$ 71.87(i)$ of this chapter: or

(2) External radiation leveis exceed the limits of $\$ 71.47$ of this chapter.

(e) Each licensee shall-

(1) Establish, maintain, and retain written procedures for safely opening packages in which radioactive material is received; and

(2) Ensure that the procedures are followed and that due consideration is given to special instructions for the type of package being opened,

(f) Licensees transferring special form sources in licensee-owned or licensee-0perated vehicles to and from a work site are exempt from the contamination monitoring requirements of paragraph (b) of this section, but are not exempt from the survey requirement in paragraph (b) of this section for measuring radiation fevels that is required to ensure that the source is still properly lodged in its shield.

\section{\$ 35.59(b)-(e) Requtrements for possession of sealed sources and brachytherapy sources.}

(b) A licensee in possession of a sealed source shall:

(I) Test the source for leakage before its first use unjess the licensee has a certificate from the supplier indicating that the source was tested within six months before transfer to the licensee.

(2) Test the source for leakage at intervals not to exceed six months or at other intervals approved by the Commission or an Agreement State and described in the label or brochure that accompanies the source.

(c) To satisfy the leak test requirements of this section, the licensee must:

(1) Take a wipe sample from the sealed source or from the surfaces of the device in which the sealed source is mounted or stored on which radioactive contamination might be expected to accumulate or wash the source in a small volume of detergent solution and treat the entise volume as the sample;

(2) Take teletherapy and other device source test samples when the source is the "off" position; and

(3) Measure the sample so that the leakage test can detect the presence of $0.005 \mathrm{mi}$ crocuries of radioactive material on the sarnple.

(d) A licensee shall retain leakage test records for five years. The raconds must contain the model number, and serial number if assigned, of each source tested, the identity of each saurce radionuclide and its estimated activity, the measured activity of each test sample expressed in microcuries, a description of the method used to measure each test sample, the date of the test, and the signature of the Radjation Safety Officer.

(e) If the leakage test reveals the presence of 0.003 microcurie or more of removable contanination, the licensee shall:

(1) Immediately withdraw the sealed source from use and stere it in accordance with the requirements in parts 20 and 30 of this chapter; and 
(2) File a report within five days of the leakage test with the appropriate NRC Office listed in $\$ 30.6$ of this chapter, with a copy to Director, Office of Nuclear Material Safety and Safeguards, U. S. Nuclear Regulatory Commission, Washington, DC 20555 describing the equipment involved, the test results. and the action taken.

Policy and Gutdance Directive FC 83-20, Revision 2, IJ20.

120. Prior to initiation of a treatment program, and subsequent to each source exchange, using the remote afterloading brachytherapy devices, radiation surveys and tests shall be performed in accordance with the following:

A. A radiation survey shall be made of:

1. The frradiator source housing, with the source in the shilelded position. The maximum radiation levels at 10 centimeters from the surface of the main source safe shall not exceed 1 milliroentgen per hour.

2. All areas adjacent to the treatment roort with the source in the "irradjation" position. The survey shall clearly establish:

(a) That radiation levels in restrtcted areas are not likely to cause personnel exposure in excess of the limits specified in 10 CFR 20.101 (10 CFR 20.1201).

(b) That radiation tevels in unrestricted areas do not exceed the limits specified in 10 CFR 20.10S(b) (10 CFR 20.1301).

\section{Policy and Guidance Directive FC 86-4. Revision $1, V, G$.}

G. The licensee must confim that it will implement a survey program to demonstrate compliance with 10 CFR 20.1301 and submit a description of the program. The program should include requirements for conducting surveys following source replacement in medium and high dose rate afterloading devices used in a dedicated treatment room and when the device location changes from conditions existing during previous surveys. For low dose rate afterloading devices, the program should include requirements for conducting surveys following source replacement or loading of any additional sources. Survey programs for low dose rate afterloading devices may include surveys described in Section
V.B. At a minimum, the survey program must be sufficient to confm the following:

1. Maximum radiation levels at 10 centimeters from the nearest accessible surface surrounding the main source safe of the afterloader shall not exceed 1 milliroentgen per hour with the source in the shielded position.

2. Radiation levels in restricted areas accessible to radiation workers are not likely to cause personnel exposure in excess of the limits specified in 10 CFR 20.1201 .

3. Radtation levels in unrestricted areas will not result in a dose to any member of the public in excess of the limits specified in 10 CFR 20.1301.

4. Records of survey results will be maintained for inspection by the Commission for the duration of the license.

Regulatory Gutde 8.33, C.3.1.9, High-DoseRate Remote Afterloading Devices. (CREF).

[See Regulatory Guide 8.33, C.3.1.9 in section 4.2.1.]

Regulatory Guide 10.8, Revision 2, App. H. (partial)

[Appendix H of Regulatory Gujde 10.8 contains a model procedure.]

Regulatory Guide 10.8, Revision 2, App.L. (partial)

1. Special requirements must be followed for packages containing quantities of radioactive material in excess of the Type A quantity linits specified in paragraph 20.205(b) of 10 CFR Part 20 (e.g., ...more than 3 curies of Cs137 or Ir-192). Such packages must be monitored for extemal radjation levels and surface contamination within 3 hours after receipt if recefved during working hours or within 18 hours if received after working hours, in accordance with the requirements of paragraphs 20.205(a) through (c). The NRC Regional Office must be notified if removable contamination exceeds 0.01 microcurie (22,000 dpa/ $100 \mathrm{~cm} 2)$.

Other Government, Standards, and Professtonat Organizations AAPM 41, V.E. (CREF).

[See AAPM 41, V.E.2 in section 4.2.3.] 
AAPM 4I, VIILA. (CREF).

[See AAPM 41. VIII.A, In section 4.2.3.]

ANSI N/3.2, 5.2.1.1.

Installations using sealed sources shall be surveyed indtially by, or under the direction of. a qualified expert. Safe handling procedures should be established ptior to initial use.

\section{ANSI N44.2, 5.1,}

Radioactive sources shall be tested for source leakage prior to initial use and at intervals thereafter. However, testing after each use of sources whtch are used in contact with tissue would be appropriate to make certain that no leakage has occurted during use and would serve as a test for the source prior to its use again. Each sealed source with a half-life of move than 30 days shall be tested for source leakage or contamination at intervals not to exceed six months, unless specified otherwise by the appropriate state, federal, or other goverimental agency. Sources with a half-life of less than $\mathbf{3 0}$ days shall be tested for source leakage prior to use.

\section{ANSI N44.2, 5.3.}

Results of leak tests shall be maintained and used (1) to assess the acceptability of sources (2) to establish and note the range for baseline leakage levels (3) to satisfy regulatory requirements for leak testing sealed sources, and (4) for use in support of possible litigation. Records should include not only results of tests expressed in terms relative to the goveming standard but also identification of the test method and calibration used.

ANSI N44.2, 6.1.

Individuals performing leak tests shall be qualified by both training and experience to safely handle the quantities and physical form of radionuclides incorporated in the sources being tested.

They shall be knowledgeable about the ineasurernent and evaluation of contamination and source leakage, the types of radiation emitted by radioactive materials and means for their detection and measurement, and they shall recognize the hazardous nature of these radiations. A minimum requirement should be eligibility for relevant certification by the American Board of Radiology or the Ameri- can Board of Health Pbysics, or equivalent quallfications.

\section{NCRP 57, 3.1. (partial)}

Area surveys shall be made prior to the initial use of the radiation installation, or as soon as possible after radiation sources are brought into the area.

\section{Manufacturers}

All "Registry of Radioactive Sealed Sources and Devices - Safety Evaluation of Sealed Source" documents for brachytherapy sources used in remote afterloaders state that sources should be Jeak tested at six month in. tervals using techniques capable of detecting 0.005 microcurie of removable contamination.

\section{Technical Note}

BSI 5288.4, ANSI 44.2.4, ANSI N13.2.5.2.1.2, NCRP 40.4.6, IPSM 46.3.5.2ii have similar procedures as 10 CFR 35.59(c)(1) and (3) above for perfomance of leak tests and/or have identical leakage criterion.

NCRP 57, Chapter 3, addresses area survey methods in detail.

The requtrements of $10 \mathrm{CFR} 20$ call for a detailed survey of the surounding rooms, including those above and below the treatment room, with the source exposed. This survey is needed to verify the shielding calculations of the design and license are valid and the radiation fields are teduced to levels appropriate for the existing controls in those areas. Even though the room may have previously been used for a procedure with higher radiation levels than those expected by the new brachytherapy machine, differences in source posittons and radiation field alignment call for a new survey.

\subsection{Daily or Each Use}

\subsubsection{Source Activity Veriflcation \\ NRC Requirements * Recommendations}

\section{$\$ 35.32$ Quality management program.} (CREF).

[See 35.32(a) in section 3.2.1.] 
$\$ 35.59$ Requirements for possession of sealed sources and brachytherapy sources. (CREF).

[See $35.59(a)$ in section 4.1.1,]

Regulatory Guide 8.33, C.3.1.9, High-DoseRate Remote Afterloading Devices, (CREF).

[See Regulatory Guide 8.33, C.3.1.9 in section 4.2.1.]

Other Government, Standards, and Professlonal Organizations

AAPM 41, VIIB. (partial)

Any computer decayed source activity should be checked against a pre-calculated decay chart to confirm the unit has decayed source activities accurately. In a facility with only a few patients a year, all quality assurance tests can be done the day prior to or on any day that remote afterloading unit is scheduled for use rather than daily or weekly.

\subsubsection{Remote Afterloader and Facllity Functlonal Checks}

NRC Requirements \& Recommendatlons

Policy and Guidance Directive FC 86-4, Revision I, V.E.3-S

[cf. FC 86-4, V.E.1,2 in section 3.3.4.]

3. The radiation monitor will be checked with a dedicated check source for proper operation each day before the afterloader device is used. A record of the radiation monitor check described above will be maintained for a period of three years. The operability check will be performed and documented in accordance with Section VIII, Item B.3(a).

4. If a radiation monitor is found inoperable, the licensee will require any individual entering the treatment room to use a survey instrument to monitor for any malfunction of the source exposure mechanism that may result in an exposed or partially exposed source. The survey instrument will be checked with a dedicated check source for proper operation at the beginning of each day of use.

5. The licensee will promptly repair or replace a radiation monitor that is found to be either inoperable or evidences intermittent problems.
Policy and Gtidonce Directive FC 86-4, Revision 1, VII.B.l.

B. The licensee must confirm, that as a minimum, the following safety checks will be performed and that written, as well as verbal, instruction will be provided to individuals as. signed to complete the checks. A description of the method used to perform the following checks must be subritted for review. Procedures should be submitted where indicated:

1. At the beginning of each day of use. the following checks will be performed in accordance with the manufacturer's instructions:

(a) For dedicated treatment rooms, the permanent radiation monitor will be checked with a dedicated check source for proper operation.

(b) If a dedicated treatment room relies upon a TV monitor to maintain constant observation, the TV monitor will be checked to verify proper operation. Intercom systems installed in dedicated treatment rooms will be checked to verify proper operation.

(c) Treatment console operational function check, test of all indicator lamps, other status and operational displays, and, if appropriate, printer test.

(d) Source status indicators ("safe" or "unsafe"), including those which are integral to the afterloading device as well as any additional indicators installed at the ireatment console or room entrance, will be checked using a dedicated check source (the afterloading device may be used) to verify proper operation.

(a) Electrical interlocks installed at each entrance to a dedicated treatment room for high and medium dose rate device will be tested for proper operation (See V.D.1.(d)), Records of each test will be maintained for a period of three years and will include the date of the test, the results of the test, and the initials of the individual who performed the test-

(f) The mechanical integrity of all applicators, source guide tubes, and connectors to be used shall be detemined by visual inspection and/or radiographs. The presence and correct placement of any intermal shields and other essential internal components shall be deternined. 
(g) A record of these checks will be maintained for a period of three years and will include the date of the check, the results of the check, and the initials of the individual who performed the check.

Policy and Gutdonce Directive FC 83-20. Revision 2, 125.C. (CREF).

[See FC 83-20, 125.C in section 3.3.3.]

Other Government, Standards, and Professlonal Organlzatlons AAPM 4J, VI.B. (partid)

The frequency of quality assurance often is determined by the frequency of the use of the equipment. Generally, a unit used daily should have functional tests performed daily or weekly. Verify that the console keys and lamps work, that tape or computer printer works and has adequate paper for the duration of the treatment, that the closed circuit TV and patient intercom work, that radiation monitors, door interlocks, and watning lights work, that batteries are charged, and that the unit operates properly during a simulated or test therapy session.

\section{Manufacturers}

Nucletron, in the "Pre-Installation Manual" for microSelectron HDR, provides guidance to users on daily checks, which should include

- reproducibility of source posittoning to within $\pm 1 \mathrm{~mm}$

- verification of source position indicators

- inspection of guide tubes for kizks and other imperfections.

RTS Technology, in its "Operator's Manual" for the GammaMed HDR, recommends QA checks be carried out before the first treatment on each treatment day. These checks include:

- visual check of source movement behavior (i.e.. source should dwell for the proper time in each of the programmed treatment positions)

- radiation waming light test

- treatment room interlocks test

- HDR console intemupt and abort test.
- confirm active source position accuracy through periodtc autoradiographs.

\subsubsection{Survey Instrument Response Check}

\section{NAC Requirements \&} Recommendations

$\$ 35,51$ Calibrastion and check of survey instruments. (CREF).

[See $\$ 35.51$ (c) tn section 4.2.2.]

Other Govermment, Standards, and Professlonal Organizations

NIST 92, 6.7. (partial)

Interim checks on the quantitative performance of survey instruments should be made with small sources readily ayailable to the user of the instrument and should include several points on the range.

\subsection{0-Day, Monthly or Quarterly}

\subsubsection{Source Inventory and $\mathrm{OM}$ Checks}

\section{NAC Requirements \& Recommendallons}

\$ $35.59(\mathrm{~g})-(\mathrm{h})$ Requirements for possession of sealed sources and brachytherapy sources.

(g) A licensee in possession of a sealed source or brachytherapy soure shall conduct a quarterly physical inventory of all such sources in its possession. The licensee shall retain each inventory record for five years. The inventory records must contain the model number of each source, and serial number if one has been assigned, the identify of each source radionuclide and its nominal activity. the location of each source, and the signature of the Radiation Safety Officer.

(b) A licensee in possession of a seated source or brachytherapy source shatl measure the ambient dose rates quarterly in all areas where such sources are stored. This does not apply to teletherapy sources in teletherapy units or sealed sources in diagnostic devices.

Policy and Guidance Directive FC 864. Revision ], VIILD.

D. The licensee must describe the method(s) it plans to use for conducting in. 
ventories of the source(s) contained in afterloading device(s). To obtain compliance with 10 CFR 35.59, the licensee must confim that physical inventories will be conducted quarteriy and that records of the inventorites will be maintained in accordance with 10 CPR $35.59(\mathrm{~g})$. To meet this requirement, it is reconmended that an autotadiograph be obtained of the source, or set of sources, concained in the afterloading device.

Policy and Guidance Directive FC 86-4, Revision J, VIIIB.2.

B. The licensee must conftrm, that as a minimum, the following safety checks will be performed and that written, as well as verbal, instruction will be provided to individuals assigned to complete the checks. A description of the method used to perform the following checks must be subrijtted for review. Procedures should be stbmitted where indicated:

2. Prior to use, the following checks will be performed in accordance with the manufacturer's instructions, within the proceeding 30 days:

(a) The afterloading device will be tested to determine the accuracy of source positioning. Source positioning within the catheter guide tube should be accurate to within $+/ 21$ millimeter of the programmed position. A record of the test will be maintained and will include the date of the test, the programmed position, the actual position of the source following activation of the device, and the initials of the individual who performed the test. (This record may include the radiograph used to determine source position.) If the source position tolerance noted above $(+/-1 \mathrm{~mm})$ is exceeded, the authorized user and radiation safety officer must be notified prior to performing patient treatments. The licensee should subrait the procedure describing the test and specify the number of dwell positions used to conduct the test.

(b) Timer accuracy and linearity.

(c) For devices that use a cable and/or wire to transport the source(s), measurement of source guide tubes to confirm the length to ? mm accuracy.

(d) The backup battery for the remote afterloading device will be tested, iil accordance with the manufacturer's instructions, to verify emergency source retraction capability upon power failure. At a minimum, this shall consist of function test with the $\mathrm{AC}$ power disconnected.

(e) A record of these checks will be maintained for a perlod of three years and will include the date of the check, the results of the check, and the initials of the individual who performed the check.

Policy and Gutdance Directive $F C$ 86-4, Revision I, WII.C. (CREF).

[See FC 86-4, VIll.C.5 in section 4.2.3.]

Other Govermment, Standards, and Professional Organlzations

AAPM 4l, VI.B. (partial)

Monthly or quarterly quality assurance checks generally include confirmation of timer accuracy and linearity; confimation of source positioning; radiography of simulated (dummy) sources in conjunction with aucoradiography of the active source; checks of operation of the unit when power or compressed air is lost; checks of all emergency systems; and careful measurement of the lengths of source guide tubes and connectors to determine critical lengths have not changed and that all connectors function; and a review of compliance with regulatory requirements, proper signs posted and instructions present; and proper daily or weekly logs completed per the license.

\section{NST 92, 6.7. (partial)}

All survey instruments used in evaluating the radiation hazards in terms of exposure or absorbed dose, or for setting time limits for personnel itradiation shall be calibrated on a routtine basis not less than once per quarter.

\section{Manufacturers}

The following Nucletron micro\$eleciron HDR maintenance is perfomed quarterly:

- source replacement

- cable check

Both Nucletron and RTS Technology, for theit HDR devices using iridium-192 sources, perfom a quarterly service check of the aflerloader at source change. 
Nucletron performs various checks of facility-specific systems quarterly for HDRs.

RTS Technology recommends device users perform quarterly checks to verify facility systems and remote afterloader ancillary components function property.

\subsection{Semi-annually or Annually}

\subsubsection{Leak Testing}

Leak tests of brachytherapy sources are required semi-annually. See section 4.2.4 above.

\subsubsection{Survey Ingtrument Calibration}

Calibration of survey instruments is required antsually. See section 4.2 .2 above.

\subsubsection{Inspection}

\section{NAC Requirements a Recommendations}

Policy and Guidance Directive FC $86-4$. Revislon $J, X . B$.

B. The licensee must confimm that the following requirements are met for inspection and service of remote afterloading devices.

1. Each afterloading device will be fully inspected and serviced at intervals not to ex. ceed one year, to ensure proper functioning of the source exposure mechanism. In addition. the licensee must confim that scheduled ser. vice recommended by the manufacturer will be performed in accordance with the manufacnuret's insiructions.

2. Inspection and service will only be performed by the manufacturer or other persons specifically licensed to do so by the Commission or an Agreement State.

3. Records of inspection and service will be maintained for the curation of the license and will include the date of the inspection/service, the name of the indivjdual who performed the inspection/service, the Agreement State or NRC license number authorizing the individual to perform inspection/service, a description of the nature of the inspection/service including a list of the components inspecter and a list of components serviced or replaced, and the stegnature of the inspector.
Other Government, Standards, and Professional Organizations

\subsubsection{Quallty Management Audjt}

NRC Requirements \&

Recommendations

5 35.32 Quality Management Program. (CREF).

[See \$35.32(b)(1) in section 3.2.1.]

Regulatary Guide 8.33, C.3.1.10, High-DoseRate Remote Afterloading Devices.

3.1.10 The licensee should establish procedures to perform periodic reviews of the brachytherapy $Q M$ program for using the high-dose-rate remote afterloading device. Guidance on periodic reviews is provided in Regulatory Position 6. A QM prograrn review is required by $\$ 35.32(\mathrm{~b})$.

Regulatory Guide 8.33, C.3.2.14, All Other Brachytherapy Applications.

3.2.14 The licensee should establish procedures to perform periodic reviews of the brachytherapy QM program. Guidance on periodic reviews is provided in Regulatory Position 6. A QM program review is required by $10 \mathrm{CFR} 35.32(\mathrm{~b})$.

Regulatory Gulde 8.33, C.6, Periodic Reviews.

6. PERIODIC REVIEWS. The licensee should establish written procedures to conduct periodic reviews of each applicable program area, e.g., radiophamacenticals, teletherapy, brachytherapy, and gamma stereotactic radiosurgery. The review should include, from the previous 12 months (or since the last review), a representative sample of patient administratons, all recordable events, and all misadministrations. The number of patient cases to be sampled should be based on the principles of statistical acceptance sampling and should rep. resent each treatment modality performed in the institution, e.g., radiophamaceutical, teletherapy, brachytherapy, and gamma stereotactic radiosurgery. For example. using the acceptance sampling tables of 10 CFR 32.110 and assuming an error rate (or lot tolerance percent defective) of 2 percent. the number of patient cases to be reviewed (e.g., 115) based on 1000 patients treated would be larger than the number of patient cases to be reviewed (e.g., 85) based on 200 
patients treated. In order to eliminate any bias in the sample, the patient cases to be reviewed should be selected randomly. For each patient's case, a comparison should be made between what was administered versus what was prescribed in the written directive. If the difference between what was administered and what was prescribed exceeds the criteria for either a recordable event or a misadministration, that comparison is unacceptable. The number of "unacceptable comparisons" that is allowed for each sample size and lot tolerance percent defective is provided in the acceptance sampling tables of 10 CFR 32.110.

These periodic reviews could be conducted weekly, monthly, or quarterly if one of these periods is more compatible with the licensee's operations.

If feasible, the persons conducting the review should not review their own work. If this is not possible, two people should work together as a team to conduct the review of that work. The licensee or destgnee should regularly review the findings of the periodic reviews to ensure that the QM program is effective.

For each patient case reviewed, the licensee should determine whether the admisistered radiophamaceutical dosage or radiation dose was in accordance with the written directive or plan of treatment, as applicable. For example. were the following correct:
...For high-dose-rate remote afterloading brachylherapy: the radioisotope, treatmenl site, and total dose;

For all other brachytherapy prior to implantation: the radioisotope, number of sources. and source strengths; after implantation bul prior to completion of the procedure: the radioisotope, treatment site, and totat source strength and exposure time (or, equivaLently, total dose);

...For each patient case reviewed, the licensee should identify deviatfons from the written directive, the cause of each deviation. and the action required to prevent recurrence. The actions may include new or revised poljcies, new or revised procedures, additional training, or increased supervisory teview of work.

The licensee should reeviluate the QM program's policies and procedures after each annual review to determine whether the program is still effective or to identify actions requined to make the program more effective.

Program review results should be documented and should be available for NRC inspectors. To obtain the maximum results from the lessons learned from each review, the program review reports should be distribuled within the institution to appropriate management and departments. Corrective actions for deficient conditions should be implemented within a reasonable time after identification of the deficiency. 


\section{OPERATIONS}

\subsection{Normal Operations}

\subsubsection{Definitions}

\section{NAC Requirements \& Recommendations}

\section{$\$ 35.2$ Definitions, (partial)}

Authorized user means a physician, dentist. or podiatrist who is identifled as an authorized user on a Commlssion or Agreement State license that authorizes the medical use of byproduct material.

Radiation Safety Officer means the individual identified as the Radiation Safety Officer on a Commission license.

Visitlng authorized user means an authorized user who is not identified as an authorized user on the license of the licensee being visited.

\subsubsection{Procedures}

\section{NRC Requirements \&} Recommendations

$\$ 19.11$ Posting of notices to workers. (CREF).

[See $19.11(a)(3)$ in section 3.3.7.]

Policy and Guidance Directive FC 86.4, Revision I, VWIA.

A. The licensee must provide a copy of operating procedures which, at a minimum, include the following commitnents:

1. Copies of operating procedures will be provided to approprtate staff and one copy will be maintained at the afterloading device console. Operating procedures may be updated and revised without NRC approval provided that such revisions do not relax restrictiveness or degrade safety.

2. Operating procedures will inchude steps to ensure that the following requirements are me1:

(a) A remote afterloading device, console, and treatment or storage room will be secured when unattended. (b) Only the pattent will be in the treatment room during activation of pulsed. mediun, and high dose rate afterloading devices. If the patient is allowed visitors, either between treatment fractions with a pulsed dose mate afterloader or during low dose rate treatments, written procedures shall be established to insure the source is retracted into the shielded safe prior to permitting the entry of any visitor(s) into the treatment room. The maximum number and length of visits allowed will be charted.

(c) Nursing personnel must follow the authorized user's and radiation safecy officer's specific instructions regarding care to be provided to a patient during treatments performed using low or pulsed dose rate afterloading devices. If the treatment is to be conducted over a period of several hours and direct patient care will be required, such instructions will be provided to the nursing staff in writing. Nursing personnel will also be provided docunented instruction on how to maintain radiation exposures ALARA when providing patient care and, if personnel trained in the operation of the remote afterloader, are not continuously present during the treatment, then the nursing personnel must also be trained in the recognition of, and response to, abnormal device operation or conditions.

(d) Treatment planning computer systems utilizing removable media to store each patient's treatment parameters for direct transfer to the treatment system will have each card labeled with the corresponding patient's name and identification number. Such media may be reused (and must be relabeled) in accor. dance with the manufacturer's instructions.

(e) Inmediately after each use of the afterloading device, a survey of the device and patient will be performed to ensure that the source(s) has (have) been reained to the fully shielded position. The suryey should include connectors and applicator apparatus, the foll length of the catheter guide tube, and the extemal surface of the device to ensure that the source is fully retracted. The patient shall be 
surveyed over the body suface near the treatment site prior to removing the patient from the treatment room. For surveys associated with ireatments using a medium, high, or pulsed dose rate afterloading device, the survey instrument must be capable of measuring dose rates of 1 - 1000 millitem per hour. For treatments performed using low dose rate afterloading devices in a patient room, the survey must be perfomed prior to relocating the patjent or portable shtelding tsed during treatment, at the end of treatment or each fraction of treatment and after any intersuption of treatment.

(f) A record of the survey described in Item 2(e) above will be maintained for a period of thre years. The record must contain the date of survey, identification of the afterloading device (model and serial number), identiffcation of the patient. identification of the instrument used to conduct the survey (make, model, and serial number), a representative background dose rate, the survey resulks, and the initials of the individual performing the survey.

(g) A commitment from the licensee that if the survey specified above in Item 2(e) indicates that the source is not fully retracted to a shfelded position in the device, persomel will tmmediately implement the licensee's applicable emergency procedures.

(h) A commitment from the licensee that it shall not conduct any treatment procedure for which a decoupled or jammed source cannot be removed expeditiously from the patient and placed in a shielded container, as determined by the authorized user with consultation by the radiation safety officer or medical physicist.

(i) During all patient treatments using a medium or high dose rate afterloading device, both the authorized user and either the medical physicist or radiation safety officer must be physically present. Physical presence, for this purpose, is defined as within audible range of normal human speech. To satisfy the requirenent for ensuring adeguate control of the source during patient treatments using a pulsed dose rate remote afterloading device, the licensee must comply with the requirement described above or submit altemative procedures for NRC review. (j) During patient treatments using a low dose rate afterioading device over a period of several hours, a device operator trained in the licensee's emergency procedures must be physically present at the licensee's facility or avallable by telephone in an "on-call" status when not physically present at the facility. The medical physicist or radjation safety officer and the authorized user must be available for prompt assistance in the event that a source appears to have decoupled or becomes jammed in the catheter guide tube. The authorized user and medical physicist or radiation safety officer must be immediately notjfied of any problems encountered duning a treatment. Device operators will follow the instructions of the authorized user and medical physicist/radiation safety officer and implement the licensee's emergency procedures as necessary.

Regulatory Gudde 833, C.3.I.4, High-DaseRate Remote Afterloading Devices.

3.1.4. The licensee should establish a policy for all workers to seek guidance if they do not inderstand how to carry out the written djrective. That is, workers should ask if they have any questions about what to do or how it should be done rather than continuing a pro. cedure when there is any doubt.

Regulatory Guide 8.33, C.3.2.4, All Other

Brachytherapy Applications.

[C.3.2.4 is identical to C.3.1.4.]

NRC Bulletin 93-01 (3).

3. During all patient treatments, both the authorized user and either the medical physicist or radiation safety officer must be physically present. Physical presence, for this purpose, is defined as within audible range of nomial human speech.

Other Government, Standards, and Professional Organizations AAPM 4I, V.D. (partial)

An Operator Manual should be at the control console or nearby area and at a minimum:

1. Describes the functioning of the control console options.

2. Describes how to program a treatment and supplies a sample program. 
3. Describes how to check that the program and time adjustment factor (if applicable) are correct.

4. Desctibes emergency procedures (these shall also be posted).

5. Provides a list of names and telephone numbers of people to contact in case of an emergency (these shall also be posted.)

6. Provides a check list of quality assurance procedures to be performed and the name and number of the person to call if quality assurance is not acceptable.

7. Provides a list of error messages, if appticable.

\section{AAPM 4I, VIIC. (partial)}

Preparation and use of well planned pretreatment forms and check lists for each anatomic site commonly treated is recommended. A generic checklist could include. but would not be limited to, the following items: Have the pre-treatment, functional QA rests been done? Is the prescription (written directive) completed and signed? Has the prepared treatment plan (prescription, target volune specification, dose, dose rates, number of sources, their spatial positions, etc.) been independently reviewed, e.g+, will the planned use of the device yield the desired dose and oose distribution? Have the treatment parameters keyed by an operator into the microprocessor controlling urit been reviewed by a second individual? Are all pre-treatment forms compieted and signed prior to treatment? Do pretreatment autoradiographs, if any, confint the proposed treatment is correctly entered into the console?

Standard methods of treating specific anatomic sites should be adopeed so that standard key entry propedures are followed. Misadministrations most likely will occrr when a treatment plan requires use of non-standard parameters while someone keys in the "usual" standard parameters. We encourage users of remote afterloading units to share, in their user groups, written materials which have been prepared for the use of specific units.

\section{Technlcat Oplnton}

As in all areas of advanced technology, successful operations require clear, formal com- munications; formally approved procedures: strjct compliance to applicable procedures; and a conscientious, questioning attitude on the part of the staff.

\subsubsection{Written Directive NAC Requirements \& Recommendations}

\$35.32 Quality Management Program. (CREF).

[See $\$ 35.32(a)(1)$ in section 3.2.1.]

Regulatory Gutde 8.33, C.3.J.1, High-DaseRate Remote Afterlaading Devices.

3.1.1. The licensee should establish a policy to have an authorized user date and sign a written directive prior to the adritinistration of any brachytherapy dose from a high-dose-rate remote afterloading device. A written directive ts required by $10 \mathrm{CFR} 35.32(\mathrm{a})(1)$. Procedures for oral directives and revisions to written directives are contained in Regulatory Position 5.

Regulatory Guide 8.33, C.3.2.1, All Other Brachytherapy Applications.

3.2,1. The licensee should establish a poijcy to have an authorized user date and sign a written directive prior to the administration of any brachytherapy dose. A written directive is required by 10 CFR 35.32(a)(1). Procedures for oral directives and revisions to written directives are contained in Regulatory Position $\$$.

Other Government, Standards, and Professlonal Organizatlons

AAPM 4I, VIIC. (CREF).

[See AAPM 41, VII.C in section 5.1.2.]

ACR 2, IA (CREF).

[See ACR 2, I.A.2.(b) in section 6.2.3]

5.1.4. Patient Identifjcation

NAC Requirements \& Aecommendattons

$\$ 35.32$ Quality Management Program. (CREF).

[See $\$ 35.32(a)(2)$ in section 3.2.1.] 
Regulatory Gtide 8.33, C.3.J.2, High-DoseRate Remote Afterloading Devices.

3.1.2. Before administering a brachytherapy treatment, the licensee should establish a procedure to verify by more than one method the identity of the patient as the individual narned in the written directive. Identifying the patient by more than one method is required by $10 \mathrm{CFR}$ 35.32(a)(2). The procedure used to identify the patient should be to ask the patient's name and confirm the name and at least one of the following by comparison with the corresponding information in the patient's record: birth date, address, social security number, signature, the name on the patient's ID bracelet or hospital ID card, the name on the patient's medtcal tnsurance card, or the photograph of the patient's face.

Regulatory Guide 8.33, C.3.2.2, All Other Brachytherapy Appications.

[C.3.2.2 is identical to C.3.1.2.]

Other Government, Standards, and Professlonal Organizallons None.

\subsubsection{Calculation Veriflcation}

NAC Requirements \& Aecommendations

$\$ 35.32$ Quality Management Program. (CREF).

[See \$35.32(a)(3) in section 3.2.1.]

Regulatory Guide 8.33, C.3.J.6, High-DoseRate Remote Afterloading Devices.

3.1.6. The licensee should establish a procedure to check the dose calculations before administering the prescribed brachytherapy dose. An anthorized user or a qualified person under the supervision of an authorized user (e.g., a radiation therapy phystcist, oncology physician, dostmetrist, or radiation therapy technologist), who whenever possible did not make the original calculations, should check the dose calculations. The responsibltities and conditions of "supervision" are contained in 10 CFR 35.25. Suggested methods for checking the calculations include the following:

Computer-generated dose calculations should be checked by examining the com- puter printout to verify that correct input data for the patient were used in the calculations (e.g., source strength and positions).

The computer-generated dose calculations for input into the brachytherapy afterloading device should be checked to verify correct transfer of data from the computer (e.g. channel numbers, souroe postions, and treatment times).

Regulatory Guide 8.33, C.3.1.8, High-Dose.

Rate Remote Afterloading Devices.

3.1.8. If the authorized user determines that delaying treatment in order to perform the checks of dose calculations (see Regulatory Position 3.1.6) would jeopardize the patient's health because of the emergent nature of the patient's medical condition the checks of the calculations should be getformed within two working days of the treatment.

\section{Regulatory Guide 8.33, C.3.2.10, All Other Brachytherapy Applications.}

3.2.10. The licensee should establish a procedure to check the dose calculations before the total prescribed brachytherapy dose has been administered. An authorized user or a qualified person under the supervision of an authorized user (e.g., a radjation therapy physicist, oncology physician, dosimetrist, or radiation therapy technologist), who whenever possible did not make the original calculations, strould check the dose calculations. The responsibilities and conditions of supervision are contained in 10 CFR 35.25. Manual dose calculations shotilt be checked for:

Arithmetic errors,

Appropriate transfer of data from the written directive, plan of treatment, tables, and graphs,

Appropriate use of nomograms (when applicable),

Appropriate use of all pertinent data in the calculations.

Computer-generated dose calculations should be checked by examining the computer printout to verify that the correct data for the patient were used in the calculations (e.t., position of the applicator or sealed sources, number of sources, total source strength, or source loading sequence). Alter- 
natively. the brachytherapy dose should be manually calculated to a single key point and the results compared to the computer-generated dose calcujations. If the mamul dose calculations are performed using computer-generated outpuss (or vice versa), particular emphasis should be placed on veri. fying the correct output from one type of calculation (e.g.. computer) to be used as an input in another type of calculation (e.g.r manual).

Regulatory Guide 8.33, C.3.2.12, All Other Brachytherapy Applications.

3.2.12. If the authorized user determines that delaying treatment in order to perform the checks of dose calculations (see Regulatory Position 3.2.10) would jeopardize the patient's health because of the emergent nature of the patient's medical condition, the checks of the calculations should be performed within two working days of completion of the brachytherapy treatment.

Other Govermment, Standards, and Professional Organizations

AAPM 41, VILC. (CREF).

[See AAPM 41, VII.C in section 5.1.2.]

\section{Manufacturers}

Procedures should exist to allow quitck but independent confirmation by a second person of two aspects of the proposed treatment; the treatment parameters and the entry into the operating console of the planned treatnent parameters.

\subsubsection{Treatment Accuracy Veriflcation}

\section{NhC Aequirements \& Becommendations}

$\$ 35.32$ Quality Management Program. (CREF).

[See \$35.32(a)(3) in section 3,2.1.]

Regulatory Guide 8.33, C.3.13, High-DoseRate Remote Afterloading Devices.

3.1.3. The licensee should establish a proceduse to verify, before administering the brachytherapy dose, that the speciffic detais of the brachytherapy administration are in accordance with the written directive and plan of treatment. The prescribed radioisotope, treatment site, and total dose stould be confimed by the person administering the brachytherapy treatment to verify agreement with the written directive and plan of treatment.

\section{Regulatory Guide 8.33, C.3.J.5, High-Dose-}

Rate Remote Afterlaading Devices.

3.1.5. The licensee should establish a procedure for using radiographs or other comparable images (e.g., computerized tomography) as the basis for verifying the posttion of the nonradioactive "dummy" sources and calculating the administered brachytherapy dose before inserting the sealed sources. 6

Regulatory Guide 8.33, C.3.2.3, All Other

Brachytherapy Applications.

3.2.3. The licersee should establish a procedure to vertfy, before administering the brachytherapy cose, that the specific details of the brachytherapy administration are in accordance with the written directive and plan of treatment. In particular, the radioisotope, number of sources, and source strengths should be confirmed to verify agreement with the written directive and plan of trealment.

Regulatory Guide 8.33. C.3.2.5, All Other Brachytherapy Applications.

3.2.5. The licensee should establish a procedure to have an authorized user or a qualified person under the supervision of an authorized user (e.g., a radiation therapy physjcist, oncology physician, dosimetrist, or radiation therapy technologist) verify that the radioisotope, number of sources, source strengths, and, if applicable, loading sequence of the sources to be used are in agreement with the written directive and plan of treatment before implanting the radjoactive seajed sources.1 The licensee may use any appropriate verification method, such as checking the serial number of the sealed sources behind an appropriate shield, using a radiation detector, using a dose calibrator, using color-coded sealed sources, or using clearly marked storage locations, i.e., one location for each source strength. The responsibilities and conditions of supervision are contained in 10 CFR 35.25.

B The torm sealed sources includes wires and onsepsulated sources. 
Other Government, Standards, and Professlonal Organizations

AAPM 41, VII.C. (CREF),

[See AAPM 4I, VII.C in section $5.1,2$ above regarding checklist jtems.]

\subsubsection{Safe-Handling Precautions}

\section{NRC Requtrements \&}

Recommendations

\$ 35.59 Requirements for possession of sealed sources and brachytherapy sources, (CREF).

[See \$35.59 in section 4.1.1.]

Other Govermment, Stendards, and Professional Organizations

IAEA 75, D.3.3.

For the quantity and types of sources usually transported in hospitals, a shiclded container on wheels is regulred.

NCRP 40, 4.3.1. (partial)

Brachytherapy sources shall never be touched with the hands. There should always be as much distance as practical between sources and the operator.

\section{Manufacturers}

The three manufacturers list limitations or condtions associated with the handling, storage, use, transfer and disposal of the radioac. tive source in the "Registry of Radioactive Sealed Sources and Devices." More detailed instructions are found in the operator manuals.

All thanufacturers advise users not to use the remote afterloader units if any facility. specific safety systems such as door interlock mechanisms, are found to be defective or not function as originally designed.

\section{Users" Aecommendations and Practices}

If the outcome of any facility safety checks is unsatisfactory, senior level brachytherapy staff nembers are informed. The renote afterloader device is generally not used for any patient treatments until facility-specific safety systems have been repaired.

If any periodic test fails, the brachytherapy physicist is immediately informed and treat- ment delayed until the physicist assesses the situation.

\subsubsection{Record of Treatment \\ NFC Aequirements \& Recommendallons}

$\$ 35.32$ Quality Mandgement Program. (CREF).

[See $\$ 35.32(\mathrm{~d})$ in section 3.2.1.]

Regulatory Gutde 8.33, C.3.I.7, High-DoseRate Remote Afterloading Devices.

3.1.7. The Iicensee should establish a procedure to have an authorized user, after administering the brachytherapy treatment, date and sign or initial a written record of the calculated administered dose in the pattent's chart or in another appropriate record. A record of the administered dose is requited by 10 CFR 35.32(d)(2).

Regulatory Guide 8.33, C.3.2.11, All Other Brachytheropy Applications.

3.2.11. The licensee should establish a procedure to have an authorized user date and sign or initial a written record in the patient's chart or in another appropriate record after insertion of the brachytherapy sources but prior to completion of the procedure. The written record should include the radioisotope, trealment site, and total source strength and exposure time (or, equivalently, the total dose). A record of the administered dose (or, equivalently, the total source strength and exposure time) is required by 10 CFR 35.32 (d)(2).

\subsubsection{Surveys - Patient and Surroundings}

NRC Requirements \& Recommendations

\$20.2101 General provisions, (CREF).

[See $\$ 20.2101$ in $\$ 3.2 .2$.]

$\$ 20.2103$ Records of surveys.

(a) Each licensee shall maintain records showing the results of surveys and calibrations required by Secs. 20.150t and 20.1906(b). The licensee shall retain these records for 3 years after the record is made.

(b) The licensee shall retain each of the following reconds until the Commission termi. 
nates each pertinent license requiring the record:

(1) Records of the results of surveys to determine the dose from external sources and used, in the absence of or in combination with individual monitoring data, in the assessiment of individual dose equivalents; and

(2) Records of the results of measurements and calculations used to determine individual intakes of radioactive material and used in the assessment of intemal dose; and

(3) Records showing the results of air sampling, surveys, and bioassays required pursuant to $\$ 20.1703(a)(3)$ (i) and (ii); and

(4) Records of the results of measurements and calculations used to evaluate the release of radioactive effluents to the environment.

\section{Policy and Guidance Directive FC 86-4, Reviston I, V.B.}

B. If the licensee requests authorization to use a low dose rate afterloading device in multiple rooms rather than in a dedicated foom, the following information must be submitted:

1. The licensee must confirm that when portable shields are required to obtain compliance with to CFR 20.1301, a positive method (such as permanent position markings of electrical/ mechanical shield tntertocks) of ensuring that the shield(s) are correctly positioned for each treatment will be employed.

2. The licensee must confirm that promptly after initiating treatment, surveys of restricted and unrestricted areas contiguous with the treatment room will be conducted to demonstrate compliance with 10 CFR Part 20.

3. The licensee must confimt that records of the surveys described above will be maintainted for a period of three years and that such records will include an annotated drawing of the room used for treatment (showing the configuration of the portable shields relative to the patient, if applicable) the measured dose rate at several points in contiguous restricted and unrestricted areas, the instrument used to make the survey, and the initials of the indjvidual who made the survey.

4. The licensee must confirm that after relocating a device to a new location (room), and prior to treatment, that all safety features and interlocks are operating properly.

NOTE: Low dose rate devices may be licensed for use in multiple rooms within a single building provided that portable shields are used to obtain compliance with the dose limits of 10 CFR 20.1301 for unrestricted areas adjacent to the treatment room (patient room) if applicabie.

$\$ 35.404$ Release of patients treated with temporary implants.

(a) Intmediately after removing the last temporary implant source from a patient, the licensee will make a radiation survey of the patient with a radjation detection survey instrument to confirm that all sources have been removed. The licensee may not release from confinement for medical care a patient treated by temporary implant until all sources have been removed.

(b) A licensee shall retain a recond of patient surveys for three years. Each record must include the date of the survey, the name of the patient, the dose rate from the patient expressed in millinem per hour and measured one meter from the patient, the survey instrument used, and the initials of the individual who made the survey

Policy and Guidance Directive FC 83-20. Revision 2, 17J8.

118. In liev of 10 CFR 35.404(a), immedialely after retracting the source from the patient into its shielded position in the remote afterloading device, a radkation survey shall be made of the patient and the remote afterloading device with a portable radiation detection survey instrument to confirm that the source has been removed from the patient. Records of the survey shall be maintained in lieu of the record required in 10 CFR 35.404(b).

NRC Bulletin 93-01 (l).

Because the consequences of such a loss of control are so severe, NRC. through this Bu]letin, is alerting appropriate medical licensees and expects them to implement the following measures to minimize the possibility of such an event occurring again. Therefore, licensets using HDR afterloaders are requested to either intmediately implement the following actions in conjunction with any use of the unit and to 
respond in writing, stating thesr commitment to these actions or, else, stating why these requested actions do not apply to their facility:

1. In accordance with 10 CFR 35.404(a), following removal of the source, the licensee shall make a radiation survey of the patient with an appropriate radiation detection survey instrument, as specified in 10 CFR 35.420 , to confin that all sources have been removed. For surveys associated with HDR procedures, the licensee must use a portable radiation measurement survey instrument, capable of measuring dose rates of 1 millirem per hour to at least 1000 millirem per hour. It is important to use caljbrated survey instruments with appropriate sensitivity, since the high exposure rates associated with these sources can easily overload some survey instrument detectors, resulting in a false low reading. This survey of the patient must be done whether or not there is any indication of radiation levels provided by an area radiation monttor. The surveys shall be performed immediately after completion of the therapy procedure before removal of the patient from the treatment room, and appropriately documented in accordance with 10 CFR 35.404(b).

The required area monitor provides an immediate indication of a possible problem and thus serves a useful function as an early waming device. This area monitor will provide a visible indication of an exposed or partially exposed source, and must he observabie immediately on entry into the treatrient vault. It must be equipped with an independent source of backup power and checked with a dedicated check source for proper operation each day of use of the HDR device. However, it has neither the accuracy nor the sensitivity required to comply with the survey reguirements of 10 CFR 35.404(a).

Policy and Guidance Directive FC 86-4, Revision 1, VIIIA.2. (CREF).

$5.1 .2+]$

[See FC 86-4, VIII.A.2.(e)-(g) in section

Other Government, Standards, and Professlonal Organizallons

AAPM 4I, V.C. (partial)

Documented exit radiation surveys of patients, which may seem redundant, are still good practice, and may be required by license to confirm there are no sources in the patient, depending on the regulatory agency and license application content. An independent vistble radiation detector in the room generally is required and may serve as the exil survey device. However, it must have sufficient sensitivity to respond to the smallest individual radioactive source used in the device at the maximum distance the sotrsce could be from the detector. A hand-held Geiger-Mueller survey meter is best for exts surveys.

\section{Manufacturers}

All brachytherapy remote afterloaders are designed to indicate to the user, via a printed message or on screen display, if all radioactive sources had been successfully withdrawn in the storage safe upon completion or intermption of the treatment. In addition, manufacturers require users of their HDR devices to have an independent radiation monitor (with a visible light) located inside the treatment room or vault. This conflguration provides a double indication that all sources have been removed from the patient.

GammaMed has a built-in detector that will alam if the source is not properly stowed.

\section{Technical Opinion}

Technical knowledge of the device in use is required so that the operators understand the basis of all panel indications. In this case, an indication that states "Source Stored" may be based on a cable measuring device that can not tell if the source detaches; therefore, a survey with a radiation survey instrument is necessary to confim that no radioactive sources remain in the patient.

\subsubsection{Brachytherapy Source Control \& Inventory \\ NAC Requirements \& Recommendations}

\section{$\$ 20.1801$ Security of stored material.}

The licensee shall secure from unauthorized removal or access licensed materials that are stored in controlled or unrestricted areas.

\section{$\$ 20.1802$ Control of material not in storage.}

The ijcensee shall control and maintain constant surveillance of licensed material that 
is in a controlled or unrestricted area and that is not in storage.

Poltcy and Guidance Directive FC 86-4, Revision I, VIIIA.Z.e.\{CREF\}.

[See FC 86.4, V]lLA.2.(e) in section 5.1.2.]

Pollcy and Gutdance Directive FC 83-20, Revision 2, "II9.

119. In lies of the source inventory required in 10 CFR 35.406, the licensee shall:

A. Promptly determine that all sources have retumed to the safe, shielded position at the conclusion of each remote afterloading brachytherapy procedure.

B. Promptly make a survey of the area of use to confirm that no sources have been misplaced.

C. Make a record of the survey including the survey instrument used. dose rate expressed in mrem/hr ( $\mu$ Sieverts/hr), time, date and name of the individual making the survey.

D. Retain the record of the survey in lieu of the record required in 10 CFR 35.406(d).

Other Government, Standards, and Protesslonal Organlzations

None

\section{Manutacturers}

Nucletron's Selectron LDR remote afterloader "counts down" the radioactive sources (pellets) and non-radioactive spacer pellets as they are retumed to the device storage safe. Source inventory status is displayed by the console and is printed out.

The HDR remote afterloaders reviewed here have one radioactive source.

\section{Users' Recommendations and Practices}

Facility 3, for all procedures that use the Selectron LDR remote afterloader, has an entry on its treatment checklists to confim that all sources are in the device storage safe at the end of the trearment time.

\subsection{Infrequent Operations}

\subsubsection{MisadmInistrations and Recordable Events}

NRC Requirements \& Recommendatlons

\$ 35.2 Definitions. (partial)

Misadministration means the administration of:

...(5) A brachytherapy radiation dose:

(i) involving the wrong patient, wrong radioisotope, or wrong treatment site (excluding, for permanent implants, seeds that were implanted in the correct site bat migrated outside the treatment site);

(ii) involving a sealed source that is leaking:

(iii) when, for a temporary implant, one or more sealed sources are not removed upon completion of the procedure; or

(iv) when the calculated administered dose differs from the prescribed oose by more than 20 percent of the prescribed dose.

Recordable event means the administration of:

....(6) A brachytherapy radiation dose when the calculated administered dose differs from the prescribed dose by more than 10 percent of the prescribed dose.

$\$ 35.32$ Quality management program. (CREF).

[See \$ 35.32(c) in section 3.2.1.]

$\$ 35.33$ Nontfications, reports, and records of misadministrations.

(a) For a misadministration:

(1) The licensee shall notify by telephone the NRC Operations Center no later than the next calendar day after discovery of the misadministration.

(2) The ficensee shall submit a written report to the appropriate NRC Regional Office listed in 10 CFR 30.6 within 15 days after discovery of the misadministration. The written report must include the licenseets name; the prescribing physician's name; a brief description of the event; why the event coccurred; the 
effect on the patient; what improvements are needed to prevent recurence; actions taken to prevent recurrence; whether the licensee notified the patient, or the patient's responsible relative or guardian (this pesson will be subsequently referred to as "the patient" in this secthon), and if not, why not, and if the patient was notified, what information was provided to the patient The report must not include the patienl's name or other information that could lead to identiftcation of the patient.

(3) The licensee shall notify the referring physician and also notify the patient of the misadministration no later than 24 hours after its discovery, unless the referting physician personally informs the licensee either that he will infom the patent or that, based on medical judgment, telling the patient would be hamful. The licensee is not required to notify the patient without first consulting the referring physician. If the referring physician or patient cannot be reached within 24 hours, the licensee shall notify the patient as soon as possible thereafter. The lícensee may not delay any appropriate medical care for the patient, including any necessary nemedial care as a resuli of the misadministration, because of any delay in notification.

(4) If the patient was notified, the Iicensee shall also furntsh. within 15 days after discov. ery of the misadministration, a written report to the patient by sending either,

(i) A copy of the report that was submitted to the NRC: or

(i) A brief description of both the event and the consequences as they may affect the patient. provided a statement is included that the report submitted to the NRC can be obtained from the ticensee.

(b) Each licensee shall retain a record of each misadministration for five years. The record must contain the names of all individuais involved (including the prescribing physician, allied health personrel, the patient, and the patient's refening physician), the patient's social security number of identiftcation number if one has been assigned, a brief description of the misadministration, why it occursed, the effect on the patient, what improvements are needed to prevent recurrence, and the actions taken to prevent recurrence. (c) Aside from the notification requirement, nothing in this section affects any rights or duties of licensees and physicians in relation to each other, patients, or the patient's responsible relatives or guardians.

Other Covernment, Standards, and Professional Organizations

FDA $88-4226,4.01 . B$.

If a health care professional informs a manufacturer or inporter that the device has malfunctioned and that the device or any other device marketed by the manufacturer or importer would be likely to cause or contribute to a death or a serious injury if the malfunction were to recur, that information constitutes a reasonable suggestion that a repontable event has occursed. The manufacturer or importer may not wait until it receives the device from the health care professional or until it has conducted its own analysis of the device before it reports under 21 CFR 803.24(b)(2).

If the health care professional does nol make the aforementioned association between the device and the likelihood of causing or contribeting to a death or serious injury, or if the information is received from a person who is aot a health care professional, the firm may determine whether the information reasonably suggests that a reportable event has occurred and that the event is likely to cause or contribute to a death or serious injury.

\section{Manufacturers}

Manufacturers recommend that all equipment faults, however minor, be reported to them. They atso recommend that their jicensees not use the device until it has been evaluated by a manufacturer's representative. Nucletron has assembled a database that includes specifics of equipment faults (or incldents) for their remote afterloaders.

\subsubsection{Emergency Procedure Guldelines}

\section{NRC Requirements \& Recommandations}

Policy and Guidance Directive FC 86-4. Revision I. IX.

A. The licensee must submit for review the emergency procedures approved by the authorized user(s) and radiation safety officer 
or medical physicist. The licensee must confirm that copies of the procedures will be provided to device operators, authorized user(s) and other personnel as necessary. In addition, a copy of the procedure must be posted at the afterloading device console or in a conspictuous location at the treatment area.

B. At a minimum, the procedures should address the following:

1. Specify when the procedures are to be implemented, such as, any circumstance under which the sotirce cannot be retracted to a fully shielded postion in the afterloading device.

2. The actions specifled for emergency source removal should give primary consideration to minimizing exposure to the patient and healthcare personnel while maximizing safety of the patient.

3. Specify step-by-step actions for single or multiple equipment failures that specify the individual(s) responsible for implementing the actions. The procedures should clearly specify which steps are to be taken under different scenartos (t.e., source decoupling versus a jammed source) The procedure should specify situations when surgical intervention may be necessary and the steps which must be taken in the event that surgical intervention is required.

4. For low dose rate procedures only, a requirement that the authorized user and the medical physicist or radiation safety offices be notffied immediately of any problem requiring implementation of emergency procedures to include a commitment to post the names and on-duty and off-duty telephone aumbers of these individuals at the operating console of the device. (These individuals ane required to be present for pulsed-, high- and mediom-dose rate procedures.)

5. Requirements to restrict and post the treatment area with appropriate signs to minimize the risk of inadvertent exposure of personnel not directly involved in emergency source recovery.

6. Identify the location of emergency source recovery equjpment and specify what equipment may be necessary for the various equipraent failures described in the procedure. At a mininum, emergency equipment should include shielded storage containers, remote handling tools, and, if appropriate, supplies necessary to surgically remove applicators or sources from the patient. including sclssors and cabie cutters.

NRC Bulletin 93-0I (2).

2. A licensee shall have written emergency procedures describing actions to be taken, including surgical intervention, should the source not retum to the shielded container at the concluston of treatment. The licensee shall not begln any treatment procedure for which a decoupled or jammed source camnot be removed expeditiously from the patient and placed in a shielded condition. The licensee shail ensure that appropriate staff and equip ment are available immediately, at the location that the HDR procedure is perfonmed, to implement the written emergency procedures. Equipment shall include shielded storage containers, remote handling tools, and, if appropriate, supplies necessary to surgically remove applicators or sources from the patient, to include scissors and cable cutters. The emergency source removal procedure should minimize exposure to health care personnel while maximizing safety of the patient.

\section{Other Government, Stendards, and Professional Organizations}

\section{AAPM 4I, V.C. (partial)}

Posted emergency procedures should ad. dress the appropriate sequence of actions if the source(s) fails to retract and explain the mext sequence of actions if the first corrective action sequence fails to retract the source(s), e.g. describe what actions to take if the source(s) fails to retract when the "emergency off" is pushed: describe what sequence of actions to follow if the mechanical retraction system fails; describe who to call nexl if no one responds at the first emergency number called. etc.

Finally, well described procedures should exist for source(s) retrieval if the source totally detaches from its dtive mechanism and falls to the floor, or remains in an applicator in the patient Particular care must be given to emergency procedures for HDR sources because the exposure rates are so high. Expostrre rates $1-\mathrm{m}$ from an unshielded $370-\mathrm{GBq}$ (10.0-Ci) 192lr source are about 4.6-R/A. 
AAPM 4l, VF.

In preparing emergency procedures it is important to have separate procedures estabItshed for electrical (power loss) energencies. fire (in the treatment facility or in the remote afterloading device) emergencies and radjation emergencies. For the latter, typical "emergencies" include (1) source(s) failing to seat in the applicator, aborting the treatment; (2) potential interruption of the therapy because the sources dislodge from the applicator, the applicator dislodges from the patient, or a source guide tube becomes loose or ruptures: (3) ciock or timer failure during therapy; (4) at the end of therapy, the source faits to retract. and (5) the sources or source capsule break away and spill the radioactive material in the room.

\section{ANSI N13.2. 5.2.1.2. (partal)}

A qualified expert should assist in developing emergency plans to minimize personnel exposure and damage to the installation in the event a source is broken and radionative naterial is released within the working area.

\section{IAEA 9. VIII.8OJ.}

For any sources or practices authorized by the competent authority that could lead to accidental or emergency exposures of workers or metnbers of the public, an intervention plan shall be established and approved by the competent authority. The plan shall deal with foreseeable situations and shall include provisions for demonstrating the efficiency of the planned countermeasures.

IAEA 75, D-7.

... In dealing successfully with an emergency situation, the most important factor is careful and detailed planning well in advance.

Portable radiation monitors should be available for use in searching for a lost source and assessing the extent of contamination if a source is broken. To reduce the likelihood of a source being lost, sonse hospitals also have radiation monitors permanently installed in certain areas, such as the entrance to the incinerator, the entrance to the latudry, and hospilal exits.

A pack of equipment and supplies required for decontamination, such as gowns, gloves, detergent, and brushes, should be assembled and held in readiness. ... These supplies should be held in reserve for emergency use only.

In each institution, one person, sometimes called the Radiation Safety Officer, should be appointed to assume full responsibility for carFying out procedures in the event of an emergency, and all potentialty hazardous situations should be reported to him without delay.

IPSM 46, 3.11.4. (portial)

+..The management of serious malfunctions may be considered as having three stages:

(i) training of staff in the procedures to be adopted;

(ii) the carrying out of these procedures when necessary in a speedy and efficient manner;

(iii) subsequent investigation of the occurrence so that, where appropriate, measures may be implemented to prevent any re-occurcrence.

IPSM 46, 3.5.2,iii. (partial)

The procedure to be followed in an emergency must be drawn up and a written copy kept at the control desk and the room entrance (if the two are not adjacent) at all times. ...In particular, a suitable shielded container and remote handling equipment must be kept available.

NCRP 40, 6.4.1.

All persons suspected of having been contaminated shall be surveyed. If a survey cannot be done tmmediately, such persons should be confined to a restricted area so as to reduce the possibility of spreading contamination throughout the building.

\section{Manufacturers}

Nucletron, in the "Pre-Installation Manual" for jts microSelectron HDR afterloader, requires its device users to confim that they have procedures in place to

- instruct device operators on specific actions (including their sequence and by whom) that must be followed for abmormal or emergency conditions; and

- ensure that cognizant safety persomnel at the medical facility are contacted and in- 
formed of the abnormal or emergency condjtion.

Omnitron, in the "Instruction Manual * Omnitron High Dose Rate Remote Afterloader," provides procedures to its users on the actions required in the event of a failure of the source wire to retract. These step-by-step procedures are required to be posted by the afterloader console.

RTS Technology has an entire section in its GammaMed 12i "Operator's Manual" that addresses emergency situations which may occur during the operation of the remote afterloader. RTS gives instructions on specific ac- tions that should be followed in an emergency situation. RTS provides an emergency procedures sign which is required to be posted near the operator's console.

\section{Users' Recommendations and Practlces}

All interviewed medical facilities have posted instructions near the afterloader console. These instructions are to be followed in the event of abnorinal or emergency conditions that arise during the operation of the remote afterloader. Emergency numbers are also listed on the instruction poster. 


\section{TRAINING AND EXPERIENCE}

\subsection{Training Administration}

\subsubsection{Training Records \\ NAC Requirements \& Recommendations}

\$35.21 Radiation Safety Officer. (CREF).

[See \$ 35.21(b)(2)(x) in 3.tion 3.2.4.]

\section{\$35.410(b) Safecy Instruction.}

(b) A licensee shall retain for three years a record of individuals receiving instruction required by paragraph (a) of this section, a description of the instruction, the date of instruction, and the name of the individual who gave the instruction.

Policy and Guidance Directive FC 86-4. Revision I, N.E.

E. The licensee must confirm that records of initial and refresher training provided for both device operators and ancillary personnel will be inaintained for a period of three years. Such records must include the names of the instructors, the names of attendees, and an outline of the topics discussed.

Other Government, Standards, and Protesstonal Organizations

NCRP 71, 2.3. (partial)

A system for maintainting training information can be used to evaluate the adequacy of the training program. Records of trainee performance should be retained and be available to the student. These records should be used to determine the continuing training needs of the workers.

NCRP 105, 5.4. (partial)

Records must be maintained to ensure compliance with regulations and license conditors, to provide internal review capabilities, and to reduce liability. Such records include reports on contamination and radiation surveys, results of personnel monitoring, instrument and equipinent calibrations, and documentation of training programs for employets.

\subsubsection{Tralning Programs \\ NAC Requlrements \& Fecommendations \\ Regulatory Guide 10.8. Revision 2, App. A. (partial)}

[Appendix A of Regulatory Guide 10.8 contains a model program.]

\subsection{TralnIng Requirements}

\subsubsection{Safety Instruction \\ NRC Requirements \& \\ Recommendallons}

\$ 79.12 Instructions to workers.

All individuals working in or frequenting any portion of a restricted area shall be kept informed of the storage, transfer, or use of radioactive materials or of radiation in such portions of the restricted area; shall be instructed in the health protection problems associated with the exposure to such radioactive materials or radiation, in precautions or procedures to minimize exposure, and in the purposes and function of protective devices employed: shall be instructed in and instructed to observe, to the extend within the worker's control, the applicable provisions of Commission regulations and licenses for the protection of personnel from exposures to radiation or radioactive materials occurring in such areas; shall be instructed in their responsibility to report promptly to the licensee any condition which may lead to or cause a violation of Commission regulations or licenses or unnecessary exposure to radiation or radioactive material; shall be instructed in appropriate response to wamings made in the event of any unusual event or occurrence or malfunction that may involve exposure to radiation or radioactive material; and shall be advised as to the radiation exposure reports which workers may request pursuant to $\$ 19.13$. The extent of these instructions shall be commensitrate with potential radiological health protection problems in the restricted area. 


\section{\$35.410(a) Safecy Instruction.}

(a) The licensee shall provide radiation safety instruction to all personnel caring for the patlent undergoing implant therapy. To satisfy thts requirement, the instruction must describe:

(1) Size and appearance of the brachytherapy sources:

(2) Safe handling and shielding instructons in case of a dislodged source;

(3) Procedires for patient control;

(4) Procedures for visitor control: and

(5) Procedures for notification of the Radiation Safety Officer if the patient dies or has a medical emergency.

Other Government, Standards, and Professionaf Organizations AAPM 4I, V.G. (partial)

As past of the purchase price. the vendor should include a training course to be attended by those who use and operate the equipment, usually physicists, engineers (if applicable), dosimetrists, technologists, and/or chief technologist and health physicists and attending physicians if they are operators.

The course should thoroughly review:

1. Avajlable applicators and their proper use.

2. The functioning and operation of the unit under normal conditions.

3. The furction and eperation of the unit under emergency conditions.

4. All safety features.

5. Radiation protection procedures.

6. Suggested quality assumance proce. dures.

7. All aspects of the dose calculation (eatment planuing) system, if applicable.

IPSM 46, 3.J0.

Although much of the instruction/training of staff in the safe use of brachytherapy sources is based on in-service "apprenticeship" teaching there is a need to provide initial "induction course" instruction to all such persons. As well as explaining the local procedures for radiation protection, including individual monttoring arrangements and the use of waming signs, the oppontunity is provided to explain the dose-reducing benefits to be obtained from the use of distance. batriers, and speed when handling sources and to emphasize the need to adhere closely to written procedures, including the keeping of records, as set down in the local nules and systems of work.

\section{NCRP 105, 5.5. (partial)}

Changes that occur in instrumentation. montloring methods, recommendations and regulations make it imperative that all individuals involved in the use of jonizing radiation sources receive initial and continuing training and education. ...It is the responsibility of management as well as of radiation workers to maintain a professional level of training and expertise.

NIST 92, 3.2. (partial)

Radiatlon protection personnel must have training and experience in the field commensurate with the complexity of work. They must know the types of hazands involved with the various kinds of nuclides handled.

\section{Manufacturers}

Remote afterloader manufacturess provide safety instructions to their users on how to manage emergency situations such as source fails to retract, dislodged source, and mechanical malfunction of the device or ancillary components.

\subsubsection{Facllfty Maintenance Personnel}

NRC Requirements \& Recommendations

Policy and Guidance Directive FC 86-4. Revision J, X.A. (CREF).

[See FC 86-4, X.A in section 4.1.1.]

Other Government, Standards, and Professlonal Organizations

ANSI N44,2, 6.1. (CREF).

[See ANSI N44.2, 6.1 in section 4.2.4.] 
NCRP 71, 4.4. (partial)

Contractor personnel must be provided with training commensurate with the potential hazards. Their training should be similar to that for regular fult-time employees working in the same conditions.

\subsubsection{Facllity Staft/Authorized Users}

\section{NAC Requirements Recommendations}

\$3.940 Training for use of brachytherapy sources.

Except as provided in 35.970 , the licensee shall requitre the authorized user of brachytherapy source listed in $\$ 35.400$ for therapy to be a physician who:

(a) Is certified in:

(1) Radiology or therapeutic radiology by the American Board of Radtology;

(2) Radiation oncology by the American Osteopathic Board of Radiology;

(3) Radiology, with specialization in radiotherapy, as a British "Fellow of the Faculty of Radiology" or "Fellow of the Royal College of Radiology": or

(4) Therapeutic radiology by the Canadian Royal College of Physicians and Surgeons; or

(b) Is in the active practice of therapeutic radiology. has had classroom and laboratory training in radioisotope bandling techniques applicable to the therapeutic use of brachytherapy sources, supervised work experience, and supervised clínical experience as follows:

(1) 200 hours of classroom and laboratory training that includes:

(i) Radiation physics and instrumentation;

(ii) Radiabon protection;

(iti) Mathematics pertaining to the use and measurement of radioactivity: and

(iv) Radiation biology;

(2) 500 hours of supervised work experience under the supervision of an authorized user at a medical institution that includes: (i) Ordening, receiving, and bnpacking radioactive materials safely and performing the related radiation surveys:

(ii) Checking survey meters for proper operation:

(iii) Preparing, implanting, and removing sealed sources:

(iv) Maintaining ruming inventories of material on hand;

(v) Using administrative controls to prevent the misadministration of by-product material; and

(vi) Using emergency procedures to control byproduct materiai; and

(3) Three years of supervised clinical experence that includes one year in a formal training program approved by the Residency Review Comumittee for Radlology of the Accreditation Council for Graduate Medical Education or the Committee on Postdoctoral Training of the American Osteopathic Association, and an additional two years of clinjcal experience in therapeutic radiology under the superviston of an authorized user at a medical institution that includes:

(i) Examining individuals and reviewing their case histories to deternine their suitability for brachytherapy treatment, and any limitations or contraindications:

(ii) Selecting the proper brachytherapy sources and dose and method of administration;

(iii) Calculating the dose; and

(iv) Post-administration follow-up and revicw of case histories in collaboration with the authorized user.

\section{\$35.25 Supervision.}

(a) A licensec that penmits the receipt, possession, use, or transfer of byproduct material by an individeral under the supervision of an authorized user as allowed by $\$ 35.11(b)$ of this part shall:

(1) Instruct the supervised individual in the principles of radiation safety appropriate to that individual' use of byproduct material and in the licensee's written quality management program; 
(2) Require the supervised individuat to follow the instuctions of the supervising authorized user, follow the written radiation safety and quality management procedures established by the licensee, and comply with the regulations of this chapter and the license conditions with respect to the use of byproduct matertal; and

(3) Periodically review the supervised individual's use of byproduct material and the records kept to reflect this use.

(b) A licensee that supervises an individual is responsible for the acts and omissions of the supervised judividual.

\section{$\$ 35.970$ Training for experienced authorized users.}

Physicians, dentists, or podjatrists identified as authorized users for medical, dental, or podiatric use of by-product material on a Cornmission or Agreement State license issued before April 1, 1987 who perform only those methods of use for which they were authorized on that date need not comply with the training requirements of subpart $J$.

\section{$\$ 35.971$ Physician training in a three month program.}

A physician who, before July 1, 1984, began a three month nuclear medicine tratning program approved by the Accreditation Council for Graduate Medical Education and has successfully completed the program need not comply with the requirements of 35.910 or 35.920 .

\section{$\$ 35.972$ Recenthess of waiting.}

The tratning and experience spectified in this subpart must have been obtained within the five years preceding the date of application or the individual must have had related continuing education and experience since the required training and experience was completed.

Pollcy and Guidance Directive FC 86-4. Revision I. IV.A-D.

A. An outline of injtial training that the licensee gives to authorized physician users and device operators, including a description of the didactic portion of the training and the minimum (should be no less that 8 hours) hours of "hands on" device operation training that will be provided, must be submitted.
Training should be specific to the device model, and include the following:

1. Radiation protection and instrumentation, including the proper use of personnel dosimeters, survey instruments, and radiation monitors.

2. The licensee's operating and emergency procedures.

3. Design, use and function of the devtce. including safety systems.

4. On-the-job training in actual operation of the device under the direct supervision of an experienced device user. This aspect of the tratning should include "dry rons" (using dummy sources) of routine patient set-up and treatment, as well as implementation of the ljcensee's emergency procedures.

5. Method of detemining each trainee's competency to use the device for each type of proposed tuse.

B. The name, affiliation, and qualifications of the instructor(s) conducting the training discussed above must be submitted. A description of the trainer's experience in use of the spectific device(s) for which training will be provided to licensee personnel must be included.

C. An outline of the topics to be covered during periodic retraining of device operators must be submitted and the licensee must confim that retraining will be conducted at intervals not to exceed 12 months. The licensee must also confirm that retraining will include practice in implementing (using dummy sources) the licenseets emergency procedures (dry run).

D. The licensee must submit a description of the orientation training that will be provided to ancillary staff (including nurses, technologists, security staff, custodians, ete.) who provide patient care during treatment or frequent areas where remote afterloading devices are stored or used. This training must meet the requirements of 10 CFR 19.12 and $10 \mathrm{CFR}$ 35.410. The licensee must confim that the aforementioned staff will be provided refresher training, as appropriate, at intervals not to exceed 12 months. An outline of the training to be provided for ancillary personnel must be stbmitted for review. 
Trajning provided for ancillary nursing personnel caring for patients undergoing treatment with a low dose rate remote afterloading device in a patient room should be consistent with 10 CFR $35.410(a)(1),(2)$, (3) and (5). In addition, the licensee should confirm that nursing personnel will be provided training in the proper use of a survey instrument if pattent care requfres that nursing personnel work in close proximity to the patient. Alternatively, the license must confim that an individual trained in the use of a survey instrument and the procedures specified in 10 CFR 35.410 will be present during pertods when patlent care is performed.

Note: Training provided to nursing personnel caring for patients undergoing treatment with a low dose rate remote afterloading device should be consistent with, and should include, the applicable procedures submitted under Section VIII.

Policy and Guidance Directive FC 86-4, Revision I, VIIIA. (CREF).

[See FC 86-4, V]II.A.2.(c) in section 5.1.2.]

NRC Bulletin 93-0I (4).

4. The licensee shall ensure that personnel are trained in both the routine use of the HDR afterloading device and emergency procedures necessary to return the source to a safe condition. Training shall be provided immediately to new personnel and periodic retraining, not to exceed 12 month intervals, shall be provided for all personnel. The licensee shall retain records of this training for a period of 3 years.

Other Government, Standards, and Protesslonal Organizations

ACR 2, I.A.

Personnel staffing will be in accordance with a set of minimum staffing standards to be developed by editors of the "blue book." Radiation Oncology in Integrated Cancer Management by the Intersociety Council for Radiation Oncology, or by an appropriate commtssion of the American College of Radiology.

A. Qualifications

1. Radiation Oncologists (a.) American Board of Radiology Certification

(b.) American Board of Osteopathic Radiology

(c.) Royal College of Physicians and Surgeons of Canada

2. Radiation Therapy Technologists

(a.) State License or American Registry of Radiologic Techrology Certification (ARRT) in radiation Therapy Technology.

(b.) Follows the written order of the Radiation Oncologist for all treatment procedures.

3. Medical Radjation Physicists

(a.) American Board of Radiology certifl. cation in Therapeutic or Radiological Pnysics, or an equivalent body as recognized by the American College of Radiology or by the appropriate state law.

\subsubsection{Radiation Safety Offlcer}

\section{NRC Requirements \& \\ Recommendations}

$\$ 35.900$ Radiation Safety Officer.

Except as provided in 35.901 , the licensee shall require an individual fulfilling the responsibilities of the Radiation Safety Officer as provided in 35.32 to be an individual who:

(a) Is certified by:

(1) American Board of Health Ptysics in Comprehensive Health Ptysics;

(2) American Board of Radiology;

(3) American Board of Nuclear Medicine;

(4) Amejican Board of Science in Nuclear Medicine; or

(5) Board of Pharmaceutical Specialties in Nuclear Phanmacy; or

(b) Has had classroom and laboratory training and experience as follows:

(1) 200 hours of classroom and laboratory training that includes:

(i) Radiation physics and instrumentation;

(ii) Radiation protection;

(iti) Mathemattes pertaining to the use and measurement of radioactivity; 
(iv) Radiation biology; and

(v) Radiophannaceutical chemistry; and

(2) One year of full time experience as a radiation safety technojogist at a medical institution under the supervision of the individual identiffed as the Radiation Safety Officer on a Commission or Agreement State license that authorizes the medical use of by-product materiali or

(c) $\mathrm{Be}$ an authorized user identified on the licensee's license.
\$35.90I Training for experienced Radiation Safety Officer.

An individual identified as a Radiation Safety Offices on a Cormmission or Agreement State License before October 1, 1986 need not comply with the training requirements of 35.900 .

Other Government, Standards, and Professional Organizatlons NCRP 105, 5.3. (CREF).

[See NCRP 105, 5.3 in section 3.2.4.] 


\section{Appendix A Bibliography}





\section{Appendix A}

\section{BIBLIOGRAPHY}

The address or phone number of the document publisher is provided before a document is listed.

US Nuclear Regulatory Commlssion (NFC)

Superintendent of Documents

U.S. Government Printing Office

P.O. Box 371954

Pittsburgh, PA 15250-7954

(202)783-3238

Titic 10, Code of Federal Regulations, (CFR) Parts 0 through 50, "Energy." (Stock Number 869019-00029-1)

Policy and Guidance Directive FC 83-20. Revision 2, "Standard License Conditions"

Policy and Guidance Directive FC 86-4, Revision 1, "Information required for licensing remote afterloading devices"

Regulatory Guide 8.7, Revision 1, "Instsuctions for Recording and Reporting Occupational Exposure Data"

Regulatory Guide 8.18, "Information retevarit to ensuring that occupational radiation exposures at medical institutions will be as low as reasonably achievable"

Regulatory Guide 8.33, "Quality Management Program"

Regulatory Gutde 10.8. "Guide for the Preparation of Applications for Medical Use Programs"

Available through NRC Regional Offices

NRC Bulletin 93-01: "Release of Patients After Brachytherapy Treatment with Remote Afterloading Devices" (April 20, 1993)

Food and Drug Administration (FDA).

Superintenden of Documents

U.S. Government Printing Office

P.O. Box 371954

Pjttsburgh, PA 15250-7954

(202)783-3238

Title 21, Code of Federal Regulations, (CFR) Food and Drugs

National Technical Information Service

Springfield. VA 22161

FDA 77-8004, "The Biological Effects of lonizing Radiation: An Overview (1976)."

FDA 83-8218, "A Basic Quality Assurance Program for Small Diagnostic Radiology Facilities."

FDA 83-8219, "Checklist for Establishing a Diagnostic Radiology Quality Assurance Program FDA."

FDA 84-4191, "Medical Device GMP Gujdance for FDA Investigators."

FDA 87-4199, "Medical Device Establishment Registration: Information and Instructions."

FDA 89-4165, "Regulatory Requirements for Medical Devices: A Workshop Manual."

FDA 88-4226, "Medical Device Reporting Questions and Answers." 


\section{Bibliography}

FDA 90-46, "Compliance Program Guidance Manual: Inspection of Medical Device Manufacturers (1990)."

FDA 90-4158, "Premarket Notification: 510(k) - Regulatory Requirements for Medical Devices."

FDA 90-4235, "Device Recalls: A Study of Quality Problems."

FDA 90-4236. "Preproduction Qualliy Assurance Planning: Recommendations for Medical Device Manufacturers,"

FDA 91-4179, "Medical Device Good Manufacturing Practices Manual, Fifth Edition"

"Compliance Program Guidance Manual: Enforcement of the Medical Device Reporting (MDR) Regulation (1988)."

Compliance Program Guidance Manual 7382,830 "Inspection of Medical Device Manufacturers (September 30, 1992)"

Compliance Program Guidance Manual 7382.010 "Medical and Radiological Device Monttoring and Quality Confonnance - Medical Device Problem Reporting (September 30, 1991)."

"Application of the Medical Device GMPs to Computerized Devices and Manufacturing Processes Medical Device GMP Guldance for FDA Investigators (1990)."

"Safe Medical Devices Act of 1990."

"Medical Device Facility User Reporting, INTERIM GUIDANCE, November, 1991."

"Reviewer Guidance for Computer Controlled Medical Devices Undergoing 5109(k) Review (1991)."

\section{Amertcan Assoclation of Physiclsts in Medicine (AAPM)}

American International Distrtbuting Corp.

64 Depot Road

Colchester, VT 05446

(802)878-0315

AAPM Report No. 6, "Scintillation Camera Acceptance Testing \& Perfomance Evaluation," Nuclear Medicine Committee, Audrey V. Wegst. Chairperson.

AAPM Report No. 13. "Physical Aspects of Quality Assurance in Radiation Therapy," Radiation Therapy Committee Task Group \$24, with contrtbution from Task Group \#22 (out of stock)

AAPM Report No. 21. "Specification of Brachytherapy Source Strength," Radtation Therapy Cornmittee. Task Group \#32, Ravinder Nath, Chairman.

AAPM Report No. 22, "Rotation Scintillation Camera Acceptance Testing and Quality Control," Nuclear Medicine Comntittee, Spect Task Group, Jeffry A. Siegei, Chaintan,

AAPM Report No. 41, "Remote Afterioading Technology," Radiation Therapy Committee, Task Group \#41, Glenn P. Glasgow, Chairman.

AAPM Symposium Proceedings, Number 3, "Proceedings of a Symposium on Quality Assurance of Radiotherapy Equipment."

AAPM Sympasium Proceedings, Number 4, "Radiotherapy Safety."

\section{Amerlcan College of Medical Physics (ACMP)}

American College of Medical Physics

1891 Preston White Drive

Reston, VA 22091

(703)648-8966

Report No. 2, "Radiation Control and Quality Assurance in Radiation Oncology." 


\author{
Medical Physics Publishing \\ 27B \\ 1300 University Avenue \\ Madison, WI $\$ 2706$ \\ (608)262-4021
}

"Quality Assurance in Radiotherapy Physics: Proceedings of an ACMP \$ymposium. May 1991"

Amerlcan College of Nuclear Phystcians (ACNP)

American College of Nuclear Physicians

1101 Connecticut Avenue, NW, Suite 700

Washington, DC 20036 4303

(202)857-1135

Publication Number 92-3, "Nuclear Medicine Practice Audit Program," Quality Assurance ano

Practice Centification Committee

American College of Radiology (ACR)

Amertcan College of Radiology

Publications Departinent

1891 Preston White Drive

Reston, VA 22091

(703)648-8900 or (800)-ACR-LINE

Criteria for Radiation Oncology in Multidisciplinary Cancer Management, 1981.

"Quality Assurance Progran in Radiation Oncology (1989)," Gerald E. Hanks, Chairman,

Committee on Quality Assurance

Practlce Accreditation Program in Radiation Oncology (1989).

Practice Survey Guide (1989).

"ACR Standards for Monitoring and Evaluation in Departments of Diagnostic Radiology and Nuclear Medicine, (1990)"

"ACR Standards for Radiation Oncology, (1990)"

"Physical Aspects of Quality Assurance (1990)," Gerald E. Hanks, Chaiman, Committee on Quallty Assurance in Radiation oncology.

American College of Radiology
1101 Market Street, 14th Floor (Suite 1400)
Philadelphia, PA 19107
(215)\$74-3164

Theodore J. Brickner, Chaiman, "Carcinoma of the Cervix," Pattems of Care Study Newsletter 1990-90, \#1

American National Standards Instltute (ANSI)

American National Standards Institule

1430 Broadway

New York, NY 10018

or

Global Engineering Documents

3130 South Harbor Blvd., Suite 330

Santa Ana, CA 92704

$(800) 854-7179$ or (714)979-8135 
N13.2-1969, "Guide for Administrative Practices in Radiation Monitoring."

N44.1-1973, "Integrity and Test Specifications for Selected Brachytherapy Sources."

N44,2-1973, "Standard for Leak-Testing Radioactive Brachytherapy Sources."

N449-1974, "Guidelines for Maintaining Cobalt-60 and Cesizm-137 Teletherapy Equipment."

N542-1977 [See "NBS 126" under NIST below]

The Institute of Electrical and Electronics Engineers, Inc.

345 East 47th Street

New York, NY 10017

or

Global Engineering Documents

3130 South Harbor Blvd., Suite 330

Santa Ana, CA 92704

(800)854-7179 or (714)979-8135

N13.4-1971, "Standard for the Specification of Portable X or Gamama Radiation Survey Instruments."

N323-1978, "Radiation Protection Instrumentation Teșt and Calfbration."

N449.1-1978, "Procedures for Periodic Inspection of Cobalt-60 and Cesium-137 Teletherapy Equipment."

Brltish Standards Instltute (BSI)

British Standards House

2 Park Street

London W.1A 2 BS

England

or

Global Engineering Documents

3130 South Harbor Blvd., Suite 330

Santa Ana, CA 92704

( 800$) 854-7179$ or (714)979-8135

B.S. 4094: Part 1: "Data on Shielding from Ionizing Radiation, Shielding from gamma radiation."

B.S. 4094: Part 2: "Data on Shielding from Ionizing Radiation, Shielding from X-radiation."

B.S. $\$ 288$ "Sealed Radioactive Sources."

B.S. 5724: Part 1: "Medical electrical equipment, General requirements for safety." and Amendment no. 1

B.S. 5724: Part 2: Sect. 2.1: "Medical electrical equipment, Particular requirements for safety, Specification for medical electron accelerators in the range $1 \mathrm{MeV}$ to $50 \mathrm{MeV}$."

B.S. 5724: Part 2: Sect. 2.9: "Medical electrical equipment, Particular requirements for safety, Specification for dosimeters used in radiotherapy with electrically connected radiation detectors."

B.S. 5724: Part 2: Sect. 2.11: "Medical electrical equipment, Particular requirements for safety, Specification for gamma beam therapy equipment."

B.S. 5724: Part 2: Sect. 2.11: Supplement 1: "Medical electrical equipment, Particular requirements for safety, Specification for gamma beam therapy equipment, Revised and additional text." 
B.S. 5724: Part 2: Sect. 2.17: "Medical electrical equipment, Particular requirements for safety, Specification for remote-controlled automatically-driven gamma-ray afterloading equipment." and Amendoment no. 1.

College of American Pathologlsts (CAP)

325 Waukegan Road

Northfield, IL 60093

(708) $446-8800$ or $(800) 323-4040$

Laboratery Accreditation Manual (1991).

Hospltal Physicists' Association (HPA)/institute of Physical Sclences in Medlcine (IPSM)

Institute of Physical Sctences in Medicine

47 Belgrave Square

London, SW i X 8QX

England

IPSM Report No. 37: "Safe Design \& Construction of Electromedical Equipinent."

IPSM Report No. 38: "Quaijity Control of Nuclear Medicine Instrumentation."

IPSM Report No. 41: "Notes on Building Materials and References on Shielơing Data for Use Below 300 kVp."

IPSM Report No. 45: "Dosimetry \& Clinical Uses of Aftetloading Systems."

IPSM Report No. 46: "Radiation Protection in Radiotherapy."

International Atomic Energy Association (IAEA)

IAEA

Wagramerstasse 5, P.O. Box 100

A-1400 Vienna

Austrita

or

National Agency for Intemational Publications, Inc.

317 East 34th St.

New York, NY 10016

Safety Series No. 9: "Basic Safety Standards for Radiation Protection."

Tech. Report Series No. 75: "Physical Aspects of Radioisotope Brachytherapy."

Tech. Report Series No. 110: "Manual of Dosimetry in Radiotherapy."

Tech. Report Series No. 133: "Handbook on Calibration of Radiation Protection Monitoring Instruments,"

Tech. Report Series No. 150: "Measurement of Short-Range Radiations."

Tech. Report Series No. 277: "Absorbed Dose Deternination in Photon and Electron Bearns."

International Commlssion on Radlological Protection (ICRP)

Pergamon Press

Headington Hill Hall

Oxford OX3 OBW

England

"Risks Associated with Ionizing Radiations," Annals of the ICRP, Vol. 22, No. 1, 1991

"Protection of the Patient in Radiation Therapy," Amals of the ICRP, Vol. 15, No. 2, 1985 
Bibliography

"The Handling, Storage, Use and Disposal of Unsealed Radionuclides in Hospitais and Medical Research Establisturients," Anntals of the ICRP, Vol. 1, No. 2, 1977

International Electrotechnical Commlssion (IEC)

Burau Central de la Conmission Electrotechnique Intemational

3, rue de Varembé

Geneva

Switzerland

or

Glooal Engineering Documents

3130 South Habor Blvd., Suitte 330

Santa Ana, CA 92704

(800)854-7179 or $(714) 979-8135$

IEC 601.2.9: [Same as B.S. 5724: Part 2: Sect. 2.9] "Medical electrical equipment, Particular requitrements for the safety of dossimeters used in radiotherapy with electrically connected radiation detectors."

EC 601.2.17: [Same as B.S. 5724: Part 2: Sect. 2.17] "Medical electrical equitpment, Particular requirements for the safety of remote-controlled automatically-driven gamma+ray afterloading equipment."

IEC 601.2.11: [Same as B.S. 5724: Part 2: Sect. 2.11] "Medical electrical equipment, Particular requirements for the safety of gamma beam therapy equipment"

IEC 601.2.11.A1: [Sarne as B.S. 5724: Part 2: Sect. 2.11: Supplenent 1] "Medical electrical equipment, Particular requirements for the safety of gamma beam therapy equipment. Amendment $1^{*}$

Joint Commisston on Accreditation of Healthcare Organizations (JCAHO) 1 Renaissance Blyd.

Oak Brook Terrace, Il 60181

(708)916-5600

AMH-91, Accreditation Manual for Hospitals (1991).

National Councli on Radiation Protection \& Measurements (NCRP)

NCRP Publications

7910 Woodmont Ave., Suite 800

Bethesda, MD 20814

(301)657-2652

NCRP Report No. 30, "Safe Handling of Radioactive Materials."

NCRP Repot No. 40, "Protection Against Radiation from Brachytherapy Sources."

NCRP Report No. 41, "Specifications of Gamma-Ray Brachytherapy Sources."

NCRP Report No. 49, "Struchural Shielding Design and Evaluation for Medical use of X-rays and Gamma-Rays of Energies Up to $10 \mathrm{MeV}$."

NCRP Report No. 57. "Instrumentation and Monitoring Methods for Radiation Protection."

NCRP Report No. 58, "A Handbook of Radioactivity Measurements Procedures, 2nd ed.."

NCRP Report No. 69, "Dosimetry of X-Ray and Gamma-Ray Beams for Radiation Therapy in the Energy Range $10 \mathrm{keV}$ to $\$ 0 \mathrm{MeV}$."

NCRP Report No. 71, "Operational Radiation Safety-Training." 
NCRP Report No. 102, "Medical X-ray, Electron Beam and Gamma-Ray Protection for Energies Up to $50 \mathrm{MeV}$ (Equipment Design, Perfomance, and Use),"

NCRP Report No, 105, "Radiation Protection for Medical and Alled Health Personnel."

NCRP Report No. 107, "Implementation of the Principle of As Low As Reasonably Achievable (ALARA) for Medical and Dental Personnet."

NCRP Report No. 111, "Developing Radiation Emergency Plans for Academic, Medical, or Industirlal Factilities"

NCRP Report No. 116, "Limitations of Exposure to Ionizing Radiation."

National Institute of Standards and Technology (NIST)

Superintendent of Documents

US Goveriment Printing Office

Washington, DC 20402

NBS Handbook 126, "Sealed Radiation Sources, Classification," US Department of Commerce. National Bureau of Standards,

Handbook 92, "Safe Handling of Radiaactive Materials," US Department of Commerce, National Bureau of Standards, March 9, 1964.

Society of Nuclear Medicine (SNM)

136 Madison Ave.

Eighth Floor

New York, NY 10016-6760

(212)889-0717

order from:

Bookmaster

P.O. Box 2039

Mansfield, OH 44905

(800)247-6553

Quatty Assurance Resource Manual for Nuclear Medicine (1990). 


\section{Appendix B Cross Reference Guide}





\section{Appendix B}

\section{CROSS REFERENCE GUIDE}

The Tables on the following pages summarizes the references used in the body of this report. In Table B-1, each row in the table corresponds to the section of this report whose number and title appear in the first two columns. Subseguent columns in the row identify the references used in that section. References are listed in the column of the originating organization. The reference entry lists the document number and the section within the document. For example the entry

\begin{tabular}{|c|c|c|c|c|c|c|c|}
\hline Report & seation and $t$ & topio & NAC & FDA & AAPM & $A C A$ & ANSI \\
\hline 3a1. & Facmly Quality & & 10 CFA 35.92 & & $41, \sqrt{1}$ & & \\
\hline
\end{tabular}

means that section 3.2.1 of this report is titted Facility Qwality Management Programs and that the references included in this section are: Part 35.32 from Titte 10 of the Code of Federal Regulations issued by the Nuclear Regulatory Commission; and Section VII of Report Number 41 from the American Association of Physicists în Medicine.

Questions regarding the meaning of particular document abbreviations used in this table can be resolved by reference to Appendix $A$ under the applicable organization.

In Table B-2, extemal references are listed in alpha numeric order and the page on which they appear in the body of this report is listed opposite them. 


\begin{tabular}{|c|c|c|c|c|c|c|c|c|c|c|}
\hline \multicolumn{2}{|c|}{ Report section and topic } & NAC & FDA & AAPM & ACH & ANSI & IAEA & IPSM & NCRP & NIST \\
\hline 3.1. & Fadiliy License hpptication & 10 CFR 35.11 & & & & & & & & \\
\hline 3.2.1. & $\begin{array}{l}\text { Fadity Qualing ManzgenenI } \\
\text { Programs }\end{array}$ & 10 CFR 35.32 & & भI, भा & & & & & & \\
\hline 3.2 .2$. & ALARA Program & 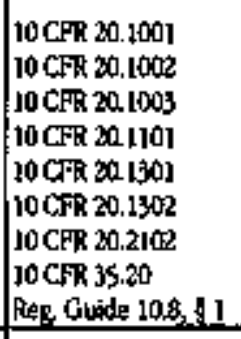 & & & & & & & $105,4,4$ & $\begin{array}{l}92,1.5 \\
92,3.2\end{array}$ \\
\hline 3.2.3. & Radialion Salely Commitlee & $\begin{array}{l}10 \text { CFR } 35.22 \\
\text { 30CRR } 35.23\end{array}$ & & & & & & & $105,5.3$ & \\
\hline 3.2.4. & Asadialion Safery Oficer & $\begin{array}{l}10 \text { CFR } 306 \\
30 \text { CFR } 35.13 \\
10 \text { CRR } 35.14 \\
10 \text { CrR } 35.21 \\
10 \text { CR } 35.23 \text { (CREF) }\end{array}$ & & & & & & & $105,5.3$ & \\
\hline 3.2.5. & Personnel Alonitoring & 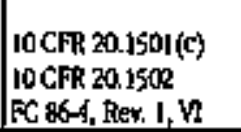 & & A1, V.C & & $\begin{array}{l}N 13.2,45 \\
N 13.2,5.2 .13\end{array}$ & & $46,5,2$ & 105,56 & \\
\hline \$.3.1. & Facialy Design & $\begin{array}{l}10 \mathrm{CFR} 35.13(\mathrm{e}) \\
\mathrm{EC} \text { 864, Rev, I, } \mathrm{VA}_{\mathrm{A}}\end{array}$ & & $\begin{array}{l}\text { 11,IIl.B } \\
\text { i1, Ill.C. }\end{array}$ & & & & & & \\
\hline 3.3.2. & Facility Shielding & 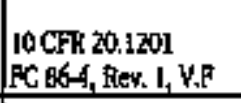 & & $\begin{array}{l}\text { al, III,B } \\
\text { \{1,III,C }\end{array}$ & & & & & & $92,4.1$ \\
\hline 3.33. & $\begin{array}{l}\text { Facilly Invetlods and Salety } \\
\text { Devines }\end{array}$ & $\begin{array}{l}\text { FC B3, 20, Rev, 2, } 125 \\
\text { FC BGA, Rev, J, YD }\end{array}$ & & \$1, tu, C & & & & $46,3.52 . \mathrm{i}$ & $57,22,1$ & \\
\hline 3.34. & PermanenI Radlation Monitors & FC BSG, Rev. L, VB & & $\begin{array}{l}\text { 41, UL, B } \\
\text { i1, Ut.C (CREF) }\end{array}$ & & & & & & \\
\hline
\end{tabular}




\begin{tabular}{|c|c|c|c|c|c|c|c|c|c|c|}
\hline \multicolumn{2}{|c|}{ Heport section and lople } & NAC & FDA & AAPM & ACR & ANSI & IAEA & IPSM & NCRP & NIST \\
\hline 3.3 & Fraicat Observation Equipmenn| & FCSOA- Rer. 1, VC & & 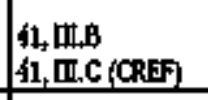 & & & & & & \\
\hline $3,3$. & Survey bastinments - Fecibly & $\begin{array}{l}\text { 10CCR 35,420 } \\
\text { PC } 860 \text {, Rer. } 1, \text {, }\end{array}$ & & $\{1, y, c$ & & & & \$6, 5.1.1. & $105,7,3$ & \\
\hline 33. & Latseling and Porsting & 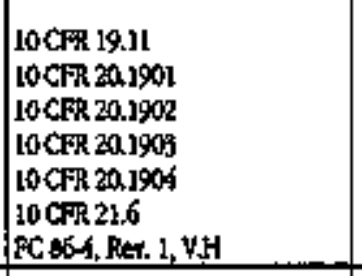 & & & & & 9. 4511 & & 楥, 8.1 & \\
\hline 4.1. & Geqeeral & 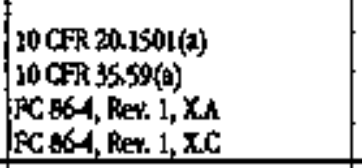 & & 41, vilB & $2,1.6 \mathrm{~B}$ & & & & & \\
\hline 4.2. & Furaiontal Ghecks & 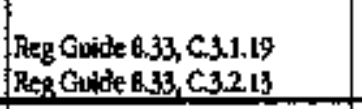 & & G1, VLAC & & & & & & \\
\hline 4.2 & $\begin{array}{l}\text { Survey Insinument Calbration } \\
\text { and Response Chect }\end{array}$ & 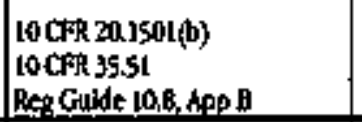 & & & & 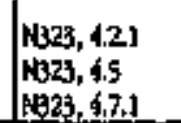 & & 46,5 & & \\
\hline 4.2 & 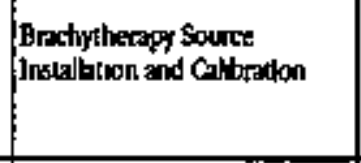 & 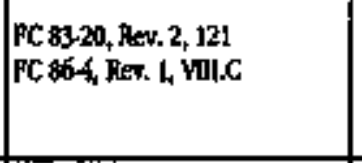 & & 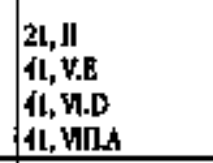 & & & & & $10,4.1 .2$ & \\
\hline 6.2. & 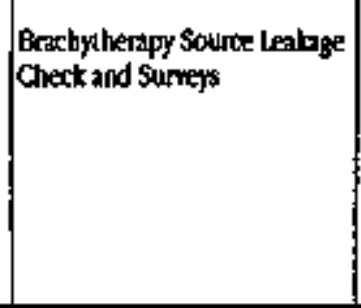 & 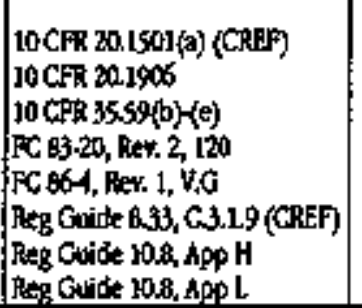 & & $\begin{array}{l}11, V E \text { (CREF) } \\
\{1, W N L \text { (CREP })\end{array}$ & & 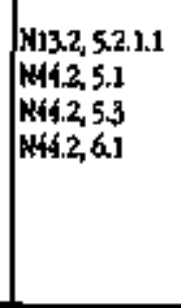 & & & $57,3.1$ & \\
\hline
\end{tabular}




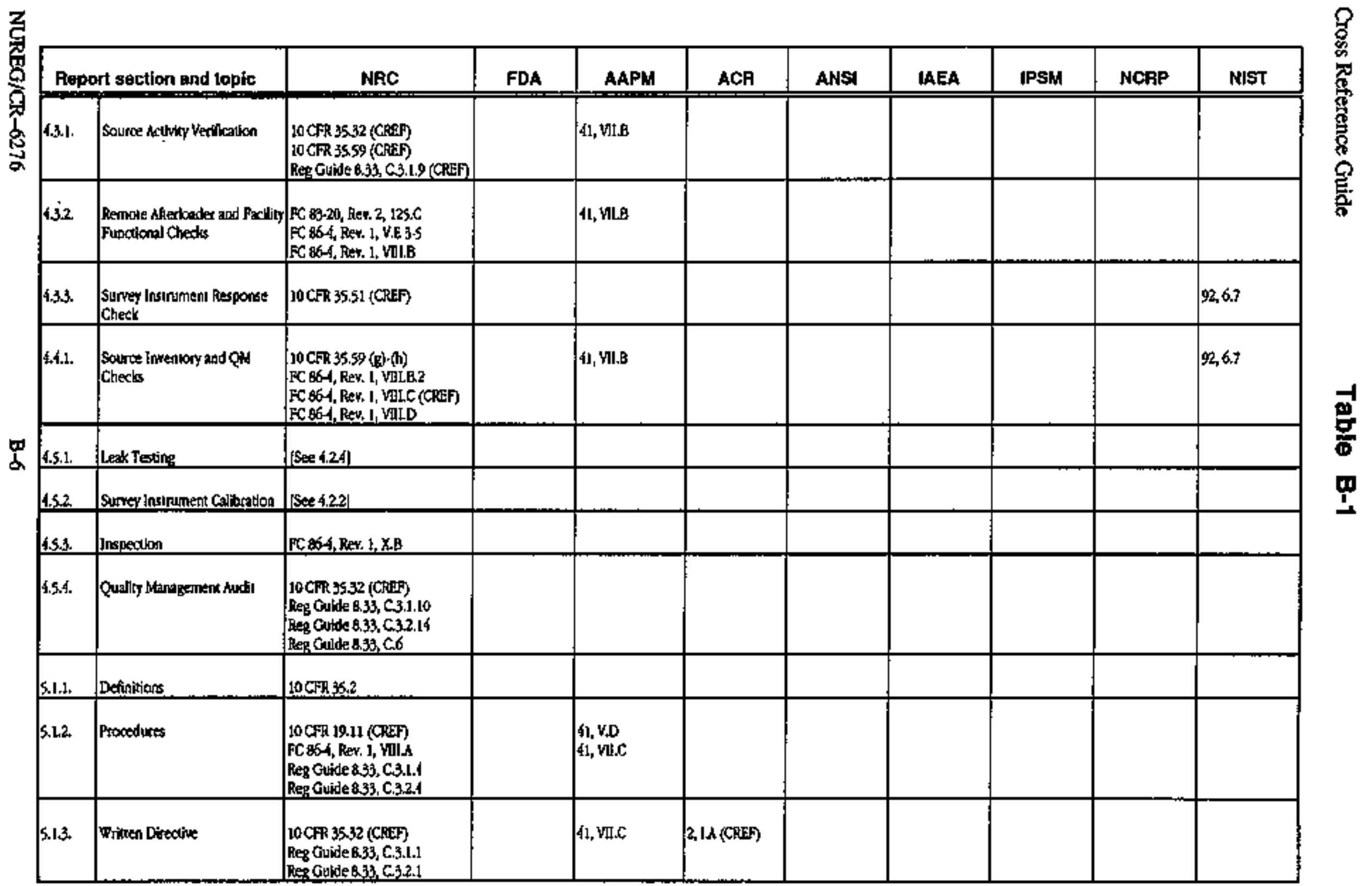




\begin{tabular}{|c|c|c|c|c|c|c|c|c|c|c|}
\hline \multicolumn{2}{|c|}{ Report section and topic } & NRC & FDA & AAPM & ACA & ANSI & LAEA & IPSM & NCRP & NIST \\
\hline 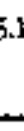 & Paient Identiberion & 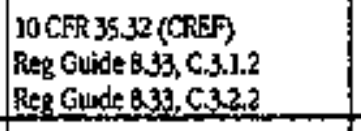 & & & & & & & & \\
\hline S.1 1 & Cakuthiog Yenfication & 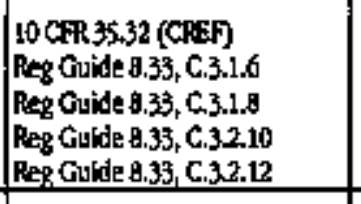 & & (12, VICC (CREA) & & & & & & \\
\hline 5.1. & 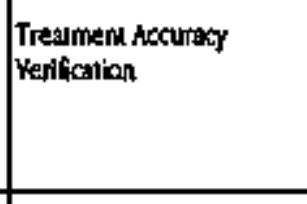 & 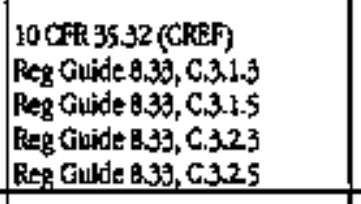 & & 11, YI.C (CRTS) & & & & & & \\
\hline S.1. & Sale-Handilen Precsuncions & 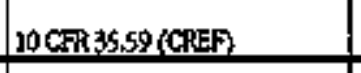 & & & & & $x, 0,3$ & & 招, 1,3.1.1 & \\
\hline 5.1 & Reocord of Trealment & 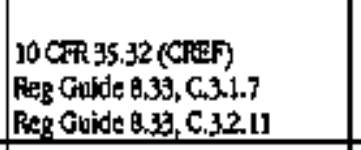 & & & & & & & & \\
\hline & Sungys & 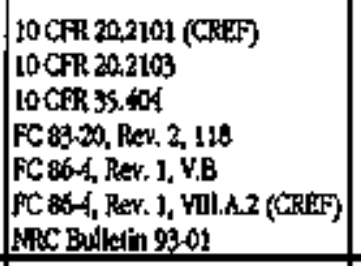 & & in, Y,C & & & & & & \\
\hline & 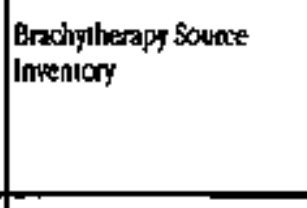 & 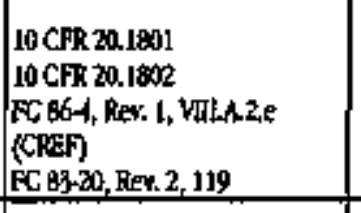 & & & & & & & & \\
\hline & 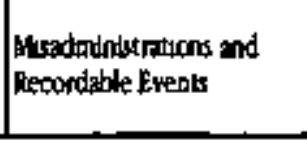 & 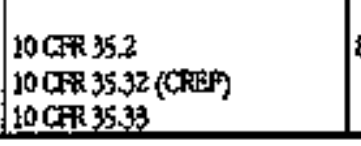 & $36-4225,4,018$ & & & & & & & \\
\hline
\end{tabular}




\begin{tabular}{|c|c|c|c|c|c|c|c|c|c|c|}
\hline \multicolumn{2}{|c|}{ Report section and topic } & NAC & FDA & AAPM & ACF & ANSI & IAEA & IPSM & NCAP & NIST \\
\hline 5.2 .2$. & $\begin{array}{l}\text { Emergency Procedere } \\
\text { Guldelines }\end{array}$ & FC 86-1, Rer. 1, XX & & $\begin{array}{l}\text { iL, Y.C } \\
\text { iL, Y.F }\end{array}$ & & H13.2,S2.1.2 & $\begin{array}{l}\text { 9. भाI.801 } \\
x, 0.7\end{array}$ & $\begin{array}{l}46,3.11 .4 \\
46,3.5,2.1 \mathrm{ii}\end{array}$ & $40,6,4.1$ & \\
\hline 6.1.1. & Trining Reconds & $\begin{array}{l}\text { 10CFR 35.21 (CREP) } \\
\text { 10CFR 35.410(b) } \\
\text { FC, \$6A, ReY L, W.E }\end{array}$ & & & & & & & $\begin{array}{l}71,2.3 \\
105.5 .1\end{array}$ & \\
\hline 6.1 .2$. & Treining Progrms & Reg Guide 10.8. Rer. 2. $\mathrm{pp} \Lambda$ & & & & & & & & \\
\hline 623. & Salety Listruction & $\begin{array}{l}\text { 10CFR 15.12 } \\
10 \text { CFR 35.410(a) }\end{array}$ & & $41, \forall 0$ & & & & 46.3 .10 & $105,5,5$ & $92,3.2$ \\
\hline $6,22$. & 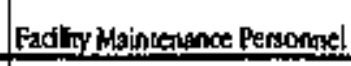 & IE $854,1,1, X_{4}$ & & & & $\mathbb{N} 41,2,6,1$ & & & 71.61 & \\
\hline 6.23. & Facility Staf /hurthorized Usex & 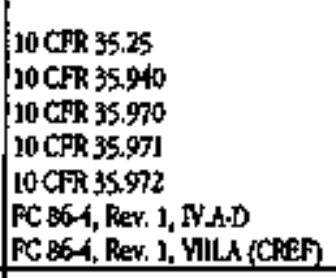 & & & $2,1 k$ & & & & & \\
\hline 6.2 .4$. & Padkation Salen Ofificer & $\begin{array}{l}10 \text { CFR } 35.900 \\
10 \text { CFR } 35.901\end{array}$ & & & & & & & $105,5.3$ & \\
\hline
\end{tabular}




\section{NRC References}

\section{Reference \\ Code of Federal Regulations, Title 10}

19.11 Posting of notices to workers...munn

19.11 Posting of notices to workers. (CREF) ,..........43

19.12 Instructions to workers. .................................57

20.1001 Pupose.

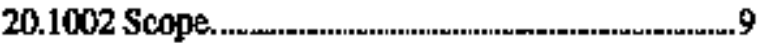

20.1003 Definitions. (partial).......................................9

20.1101 Ratiation protection programs..........................9

20.1201 Occupational dose limits for adults. ............ 17

20.1301 Dose timits for ind vidual members of the public.

20.1302 Contipliance with dose limits for individ-

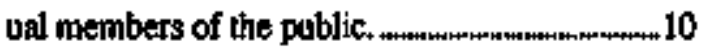

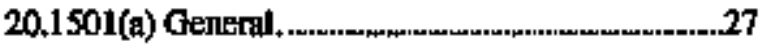

20.1501(a) General. (CREF)....................................34

20.1501(b) General......................................................

20.1501(c) General.

20.1502 Conditions requiring individual monitoring of external and internal oceupational dose.

20.1801 Security of stored material................................\$0

20.1802 Control of matetial pot in storage. . .

20.1901 Caution signs.

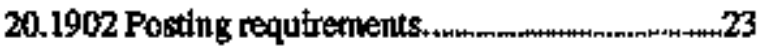

20.1903 Exceptions to posting requirements..............24

20.1904 Labeling containers................................. 24

20.1906 Procedures for receiving and opening packages, 34

20.2101 Gented provistons. 10

20,2101 Oeneral provisions. (CREF) .. .48

20,2102 Records of radiation protection programs. 10

20.2103 Records of surveys.

21.6 Posting Requiremenis + (partial)............................

30.6 Communications. (partial)

35.2 Definitions. (partial) ..................................n.rnn.....43

35.2 Definitions. (partial) ............................... 51

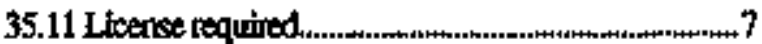

35.13(c) License amendments.......................................14

35.13(c) License amepdments......................................16

35.14 Notifications, ,.................................................14

35.20 ALARA progrem.
Reference

Page

35.21 Radiation Safety Officer..................................... 13

35.21 Rediation Safety Officer. (CREF)................... 57

35.22 Ratiation Safety Committet.

35.23 Statements of anthority and responsibili-

ties. 13

35.23 Statemeats of authority and cesponsibtitities.

(CREF) 14

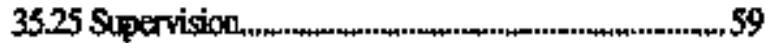

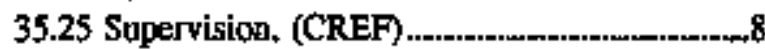

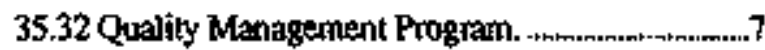

35.32 Quality Management Program. (CREF)...........41

35.32 Quality Managemena Program. (CREF).......... 45

35.32 Quality Management Progran, (CREF)............45

35.32 Qualily Managemenl Progran. (CREF),.......... 46

35.32 Quality Management Progrars. (CREF)...........47

35.32 Qpalily Management Program. (CREF)...........48

35.32 Quality Management Program. (CREF)............ 37

35.32 Quality Management Program, (CREF),..........\$1

35.33 Notificalions, reports, and records of mis*

mininistrations $-51$

35.51 Calibration and check of survey instruments. (CREF). 39

35.51 Calibration and check of survey instruments. 31

35.59(2) Requirements for possession of sealed sources and brachylherapy sources. .27

$35 . \$ 9(b)$-(t) Requirements for possersion of sealed sources and brachytherapy sources..........35

35.59(g)-(h) Requirements for possession of sealed sources and brachytherapy sources.............39

35.59 Requirements for possession of sealed sources and brachy therapy sources. (CREF)..... 38

35.59 Requirements for possession of seated sources and brachytherapy sources. (CREF)......48

35.404 Release of patients treated with temporary ímplants $-49$

35,410(a) Safey Insmetion

35.410(b) Safety Instruction. ....................................\$7

35.420 Possession of survey instrument..........................22 35.420 Possession of survey instrument. (CREF) $\ldots$ 27 35,900 Radiation Sifety Oftioer. 61 
Cross Reference Guide

Reference

35.901 Training for experienced Radiation Safety

Officer.

35.940 Training for use of brachylterapy sotrces...59

35.970 Training for experienced authorized users......60

35.97t Physician training in a three month

program. .60

35.972 Recentress of training. .60

\section{NRC Bulletins}

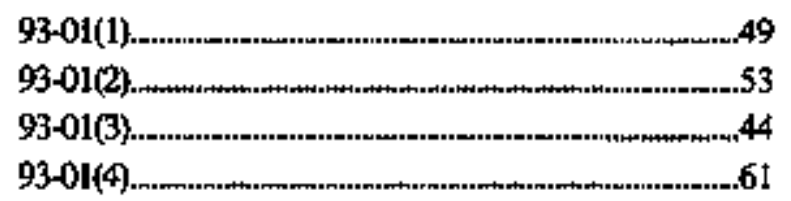

\section{Policy and Guldance Directives}

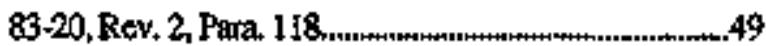

83-20, Rev. 2, Park 119........................................

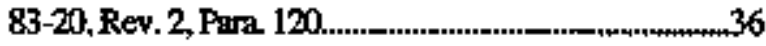

83-20, Rev. 2, Pard 121...........................................

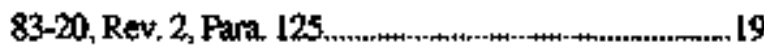

83-20, Rev. 2, Para, 125.C. (CREF)

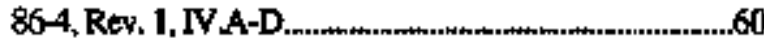

86-4, Rev. 1, TY.E. 57

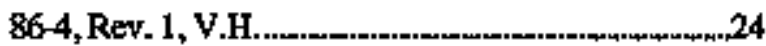

86-4, Rev. 1, V.A.

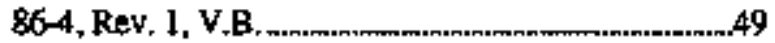

86-4, Rev, 1, V.C.

864 , Rev, I, V.D. 19

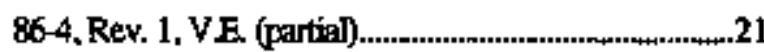

86-4, Rev. 1, V.E.3-5 38

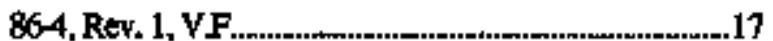

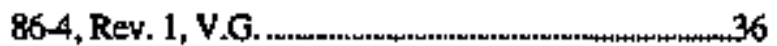

86-4, Rey. 1, VI. .................................................

864, Rev. 1, VII (partial)

86-4, Rev, I, VII, A

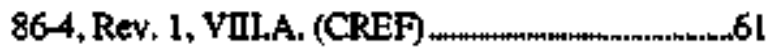

864, Rev. 1, VIII.A.2. (CREF)........................ 50

86-4, Rev. 1, VIIIA2.A. (CREF)._.......................

864, Rev, 1, VIII.B. 1,...,

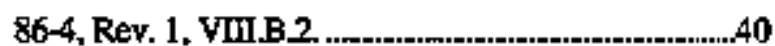

Reference Page

864, Rev. 1, VIII.C....................................... 31

86-4, Rev. 1, VIIC. (CREF) .....................................40

86-4, Rev. 1, VIII.D................................................

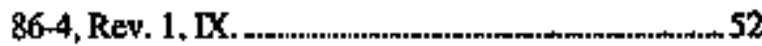

86-4, Rev. 1, X.A. 27

864, Rev. 1, X.A. (CREF).....................................58

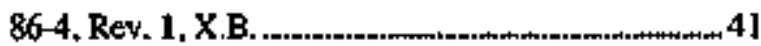

86-4, Rev. 1, X.C. . 27

\section{Regulatory Guides}

8.33, C.3.1.1.

$833, \mathrm{C} 3.12$................................... 46

833, C.3.1.3.

833, C.3.1.4.

833, C.3.1.5. 47

$833, \mathrm{C} 3.1 .6 \ldots$

$833, \mathrm{C} 3.1 .7$.

8.33, C.3.1.8. 46

8.33, C.3.1.9. . 28

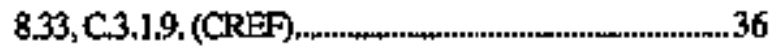

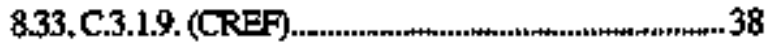

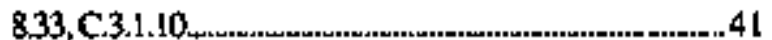

$8.33, C .3,2.1 \ldots$

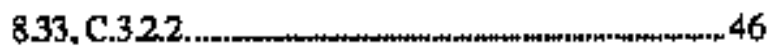

833, C.3.23

833, C.32,4

$8.33, C .3 .25 \ldots$

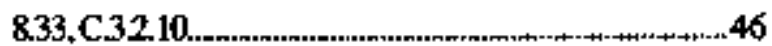

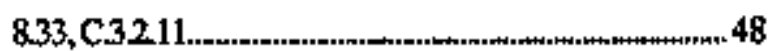

8.33.C.32.12

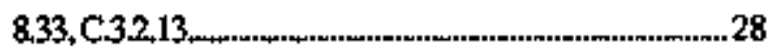

$8.33, C .3 .214 \ldots \ldots$

8.33, C.6. 61

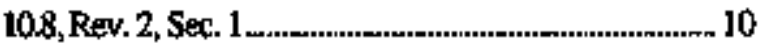

10.8, Rev, 2, App. A. (partig) ...................... 57

10.8, Rev. 2, App. B. (partial) ............................ 31

10.8, Rev. 2, App. H. (partial) ..................................

10.8, Rev. 2, App. L. (partikl) 


\section{Other References}

Reference

AAPM 21, II. (partial) ...................................32

AAPM 41, III.B. (partial)

AAPM 41, III.B. (partial)

AAPM 41, III.B. (partial)

AAPM 41, Ill.B. (partial)

AAPM 41, IfI,C. (partial)

AAPM 41, IILC. (partial)

AAPM 41, III,C. (partia)

AAPM 4L, II.C. (partial)

AAPM 41, II.C. (CREF),

AAPM 41, IIIC. (CREF)

AAPM41, V.C. (partial) ................................................15

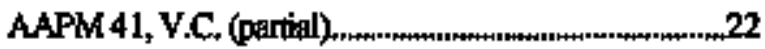

AAPM 41, V.C. (partial)................................................

AAPM 41, V.C. (partial).........................................53

AAPM 4I, V.D. (pertial)...._..............................44

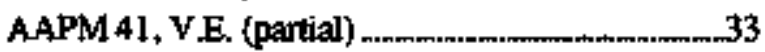

AAPM 41, VE, (CREF) (.............................................

AAPM 4L, V.F.

AAPM 4I, V.G. (partial) ........................................... 58

AAPM41, VL.(pertis) .............................................28

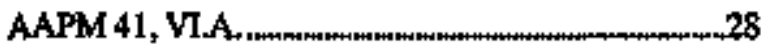

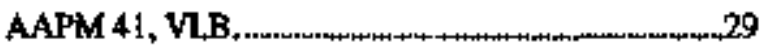

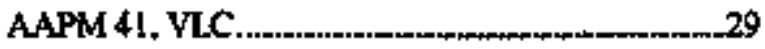

AAPM 41, VI.D.........._._._._._._._. 33

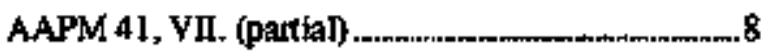

AAPM 41, VII. . (partial)............................................27

AAPM 4I, VILB, (partigl) ............................................38

AAPM 41, VII.B. (partial).............................................. 39

AAPM 41, VII.B. (partial)...........................................40

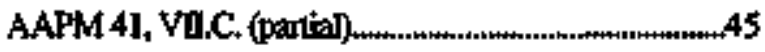

AAPM 41, VII.C. (CREF) (C...............................

AAPM 41, VIIC. (CREF) ........................... 47

AAPM 41, VIIC. (CREF) (C.............................4 48

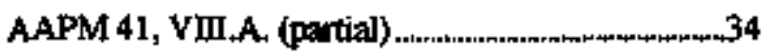

AAPM 41, YIII.A, (CREF),......................................37

$A C R$ 2, IA .

ACR 2, I.A. (CREF) ................................

ACR 2, II.B.

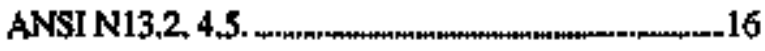

ANSI N13.2. 5.2.1.1............___..............37

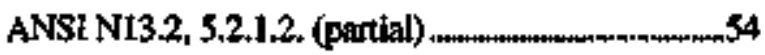

Reference Page

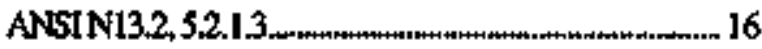

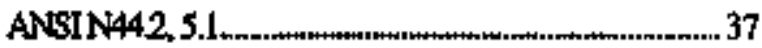

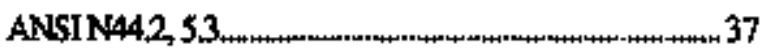

ANSIN442, 6.1........................................... 37

ANSI N44.2. 6.1. (CREF)...........................58

ANSI N323, 4.2.1...... _.......................................

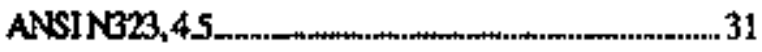

ANSI N323, 4.7.1..._._. _............................................ 31

FDA 88-4226,401.B._........................................

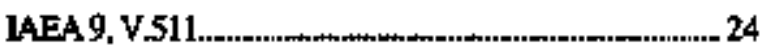

IAEA 9. VIII $801 \ldots \ldots \ldots \ldots$

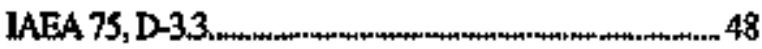

IAEA 75, D-7 .

IPSM 46, 3.5.2.i. (partial) $\ldots \ldots \ldots \ldots \ldots$

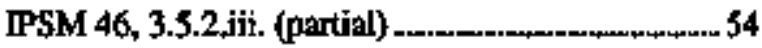

IPSM 46,3.10__._......................................58

IPSM 46, 3.11.4. (partial) ..........................................54

PPSM 46, 5.1.1. (partiall).................................................22

IPSM 46, 5.2 (partial) _.___._._._._._._........... 16

NCRP 40, 4.1.2. (partial)

NCRP 40, 4.3.1. (partial) _._.______.__............ 48

NCRP 40, 6.1.

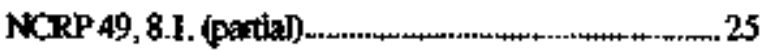

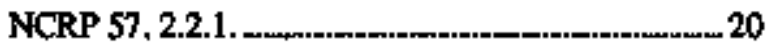

NCRP 57.3.1. (patial) _...........................................37

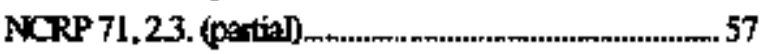

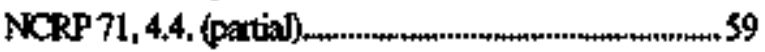

NCRP 105, 4.4. (patial).......................... 11

NCRP 105, 5.3. (partial) ................................... 13

NCRP 105, 5.3. (partial) ......_...___................. 15

NCRP 105, 5.3. (CREF) ................................................ 62

NCRP 105, 5.4. (partial) _._._........................ 57

NCRP 105. 5.5. (partial) 58

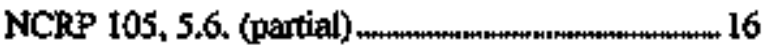

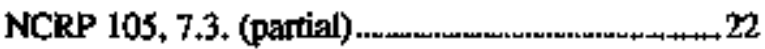

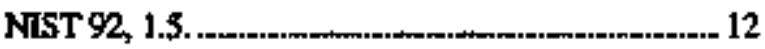

NIST 92, 3.2. (partial) (..._._._._._..................... 12

NIST 92, 3.2. (partial) ...................................... 58

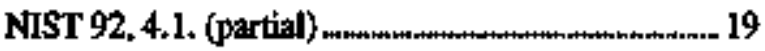

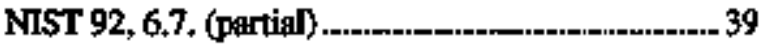

NIST 92, 6.7. (partial) .................... 40 


\begin{tabular}{|c|c|}
\hline 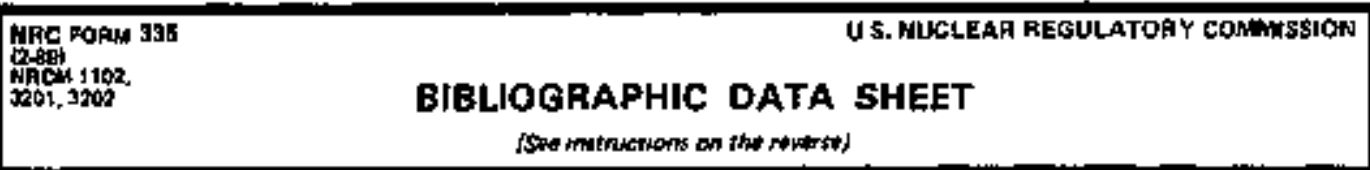 & 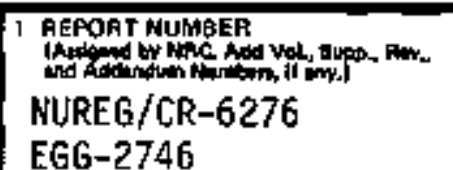 \\
\hline \multirow{4}{*}{$\begin{array}{l}\text { A Compilation of Current Regulations, Standards, } \\
\text { and Guidelines in Remote Afterloading Brachytherapy }\end{array}$} & \\
\hline & \begin{tabular}{|l}
3 \\
\end{tabular} DATE REPORT PUBLISHED \\
\hline & \begin{tabular}{c|c} 
MowTH & YEAA \\
February & 1995
\end{tabular} \\
\hline & $\begin{array}{l}4 \text { FINOA GRANT NUTABEA } \\
\text { L1939 }\end{array}$ \\
\hline \multirow{2}{*}{$\begin{array}{l}\text { J. AUTHOH[S] } \\
\text { James P. Tortorelli } \\
\text { George P. Simion } \\
\text { Stephen } \mathrm{D} \text {. Kozlowski }\end{array}$} & $\begin{array}{l}\text { 6. TYPE OF REPOAT } \\
\text { Technical }\end{array}$ \\
\hline & 7. PEAKOD COVEFED AnEthesur Dxtent \\
\hline \multicolumn{2}{|c|}{ 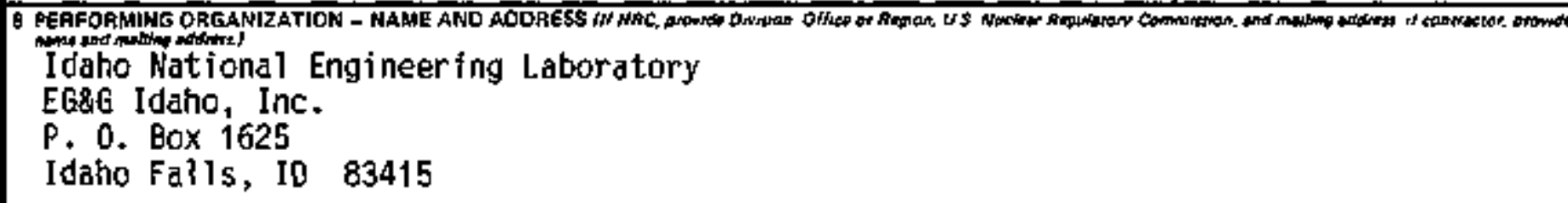 } \\
\hline
\end{tabular}

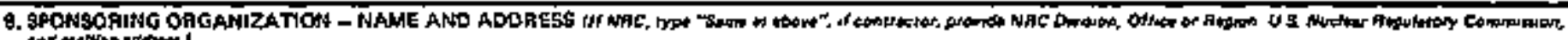
un mevang wowt

Division of Industrial and Medical Muclear Safety

Office of Nuclear Material Safety and Safeguards

U. S. Nuciear Regulatory Comission

Washington, D. C. 20555-0001

10. SUPPLEMENTAAY NOTES

11. AESTRACT 1200 mond or haw

over a dozen government and professional organizations in the United States and Europe have issued regulations and guidance concerning quality management in the practice of remote afterloading brachytherapy. Information from the publications of these organizations was collected and collated for this report. This report provides the brachytherapy licensee access to a broad field of quality management information in a singie, topically organized document.

quality management

quality assurance

radiation medicine

remote afterioading

brachytherapy

\begin{tabular}{|c|}
\hline $\begin{array}{l}\text { Unlimited } \\
\text { UVAILABLTYSTATRE:USE }\end{array}$ \\
\hline 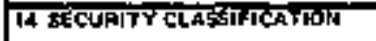 \\
\hline $\begin{array}{l}\text { Trart Paw } \\
\text { Uncli assified }\end{array}$ \\
\hline "Unclass i f ied \\
\hline 15. MUITEA OF DAGES \\
\hline 16 PAICE \\
\hline
\end{tabular}

